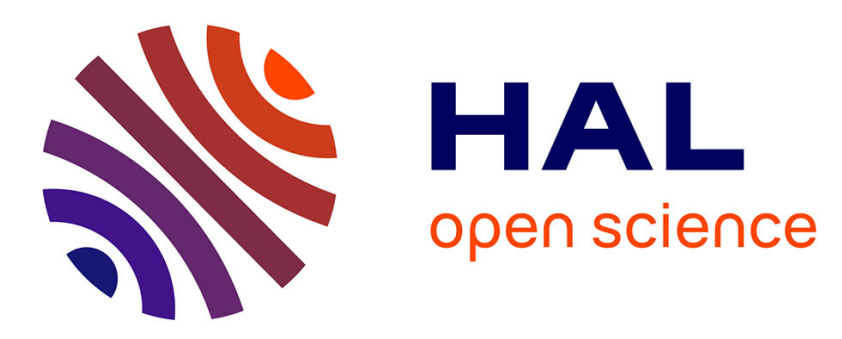

\title{
Designing Host Materials for the Emissive Layer of Single-Layer Phosphorescent Organic Light-Emitting Diodes: Toward Simplified Organic Devices
}

\author{
Cyril Poriel, Joëlle Rault-Berthelot
}

\section{- To cite this version:}

Cyril Poriel, Joëlle Rault-Berthelot. Designing Host Materials for the Emissive Layer of Single-Layer Phosphorescent Organic Light-Emitting Diodes: Toward Simplified Organic Devices. Advanced Functional Materials, 2021, 31 (24), pp.2010547. 10.1002/adfm.202010547 . hal-03217035

\author{
HAL Id: hal-03217035 \\ https://hal.science/hal-03217035
}

Submitted on 19 Oct 2021

HAL is a multi-disciplinary open access archive for the deposit and dissemination of scientific research documents, whether they are published or not. The documents may come from teaching and research institutions in France or abroad, or from public or private research centers.
L'archive ouverte pluridisciplinaire HAL, est destinée au dépôt et à la diffusion de documents scientifiques de niveau recherche, publiés ou non, émanant des établissements d'enseignement et de recherche français ou étrangers, des laboratoires publics ou privés. 
Designing Host Materials for the Emissive Layer of Single-Layer Phosphorescent Organic LightEmitting Diodes: Towards simplified Organic Devices

Cyril Poriel* and Joëlle Rault-Berthelot*

Univ Rennes, CNRS, ISCR-UMR CNRS 6226, F-35000 Rennes, France

Email: cyril.poriel@univ-rennes1.fr, joelle.rault-berthelot@univ-rennes1.fr

Keywords: Single-layer phosphorescent organic light-emitting diode, host material, ambipolar charge transport, organic electronics, electroluminescence, frontier molecular orbitals, molecular design, triplet energy

Table Of Content

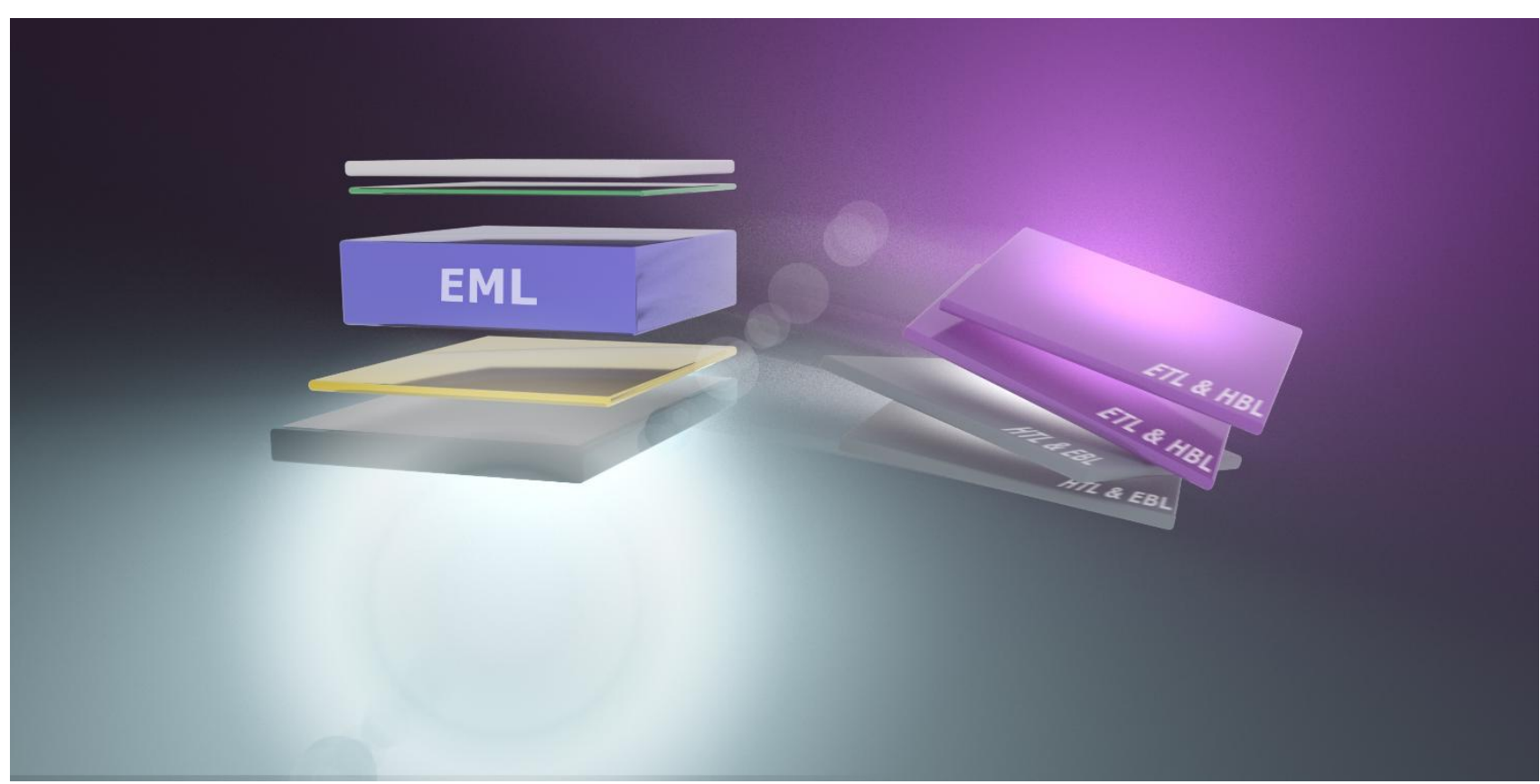


$\begin{array}{ll}\text { Abstract } & 6\end{array}$

$\begin{array}{ll}\text { Introduction } & 6\end{array}$

\section{Part I.}

1. Single-Layer PhOLEDs using a single host material 9

a. Blue SL-PhOLEDs 9

b. Green SL-PhOLEDs 17

$\begin{array}{ll}\text { c. Red SL-PhOLEDs } & 24\end{array}$

d. Yellow/Orange/White SL-PhOLEDs 27

2. Modification of the EML of a SL-PhOLED 30

a. Non-doped or Self-host Strategy 30

b Mixed-hosts Strategy 33

Part II: Single Component PhOLEDs 38

$\begin{array}{ll}\text { Conclusion } & 43\end{array}$

$\begin{array}{ll}\text { Acknowledgements } & 49\end{array}$

$\begin{array}{ll}\text { References } & 49\end{array}$ 


\section{Abbreviations}

BCP: Bathocuproine, 2,9-Dimethyl-4,7-diphenyl-1,10-phenanthroline

Bebq $_{2}$ : Bis(10-hydroxybenzo[h]quinolinato)beryllium, host for red phosphor

BPhen: 4,7-diphenyl-1,10-phenanthroline, host for green phosphor

$\mathrm{Bu}_{4} \mathrm{NPF}_{6}$ : Tetrabutylammonium hexafluorophosphate

BzBPCz: 9-[3'-(1-phenyl-1H-benzimidazol-2-yl)-biphenyl-4-yl]-9H-carbazole, host for green phosphor

BzFCz: 9-[9,9-diethyl-7-(3-(1-phenyl-1H-benz[d]imidazol-2-yl)-phenyl-9H-fluoren-2-yl]-9H-carbazole, host for green phosphor

BzTPCz: 9-[4'-(3-(1-phenyl-1H-benz[d]imidazol-2-yl)-phenyl-biphen-4-yl]-9H-carbazole, host for green phosphor

CBM4: 1,1-bis(4-(3',3"'-dimethoxy)triphenylamino)cyclohexane, host for red or orange phosphor

CBP: 4,4'-N,N'-dicarbazole-biphenyl, host for green or yellow phosphor

cd: candela

CE: Current Efficiency (cd/A)

CHex: Cyclohexane

CIE (x, y): Chromaticity Coordinate

CPHP: 4,5'- $N, N^{\prime}$-dicarbazolyl-(2-phenylpyrimidine), host for green phosphor

CPPY: 4,5'- $N, N^{\prime}$-dicarbazolyl-(2-phenylpyridine), host for green phosphor

CSC: 4,5-diaza-2',7'-bis(carbazol-9-yl)-9,9'-spirobifluorene, host for green phosphor

Cz-BP-DPI: 9-(4'-(1-(4-(tert-butyl)phenyl)-4,5-diphenyl-1H-imidazol-2-yl)-[1,1'-biphenyl]-4-yl)-9H-carbazole, host for blue, green or red phosphor

CzPAMe: $N, N$-bis-[3,5-di(9H-carbazol-9-yl)phenyl]methylamine, host for blue phosphor

CzPAPm: $N, N$-bis-[3,5-di(9H-carbazol-9-yl)phenyl]pyrimidin-2-amine, host for blue phosphor

CzPPO: Tetrakis-[3,3',5,5'-(9H-carbazol-9-yl)]triphenylphosphine oxide, host for blue phosphor

D2ACN: 2',7'-bis(diphenylamino)-9,9'-spirobi[fluorene]-2,7-dicarbonitrile, host for red phosphor

2,7-DiCbz-SBF-4'-POPh $:$ 2',7'-di(9H-carbazol-9-yl)-9,9'-spirobi[fluoren]-4-yl)diphenylphosphine oxide, host for green phosphor DQC: 9-(5',5"-diphenyl[1,1':3',1":3",1"':3"',1"'”-quinquephenyl]-5"-diyl)-9H-carbazole, host for blue phosphor

DSTPA: 4,4'-bis(dibenzothiophene-S,S-dioxide-2-yl)triphenylamine, host for red phosphor

EBBPC: 9,9'-[4'-(2-ethyl-1H-benzimidazol-1-yl) [1,1'-biphenyl]-3,5-diyl] bis- $H$-Carbazole, host for blue , green or red phosphor

EBL: Electron-Blocking Layer

$\mathrm{E}_{\mathrm{g}}$ : Energy gap between LUMO \& HOMO $(\mathrm{eV})$

$\mathrm{E}_{\mathrm{g}}{ }^{\text {opt}}: \mathrm{E}_{\mathrm{g}}$ obtained from the onset wavelength of absorption (eV)

(elec): from electrochemical investigation

EML: EMitting Layer

EQE: External Quantum Efficiency (\%)

$\mathrm{E}_{\mathrm{T}}$ : Triplet energy $(\mathrm{eV})$

ETL: Electron-Transporting Layer

EtOH: Ethanol, $\mathrm{CH}_{3} \mathrm{CH}_{2} \mathrm{OH}$

FIrpic: Bis[2-(4,6-difluorophenyl)pyridinato- $\left.\mathrm{C}^{2}, \mathrm{~N}\right]$ (picolinato)iridium(III), blue phosphor

FIr6: Bis(2,4-difluorophenylpyridinato)-tetrakis(1-pyrazolyl)borate iridium(III), blue phosphor

HBL: Hole-Blocking Layer

HTL: Hole-Transporting Layer

HOMO: Highest Occupied Molecular Orbital

IC1: Bis(5-bis[(4-methylphenyl)amino]-2-phenyl-1,2,3-benzotriazolato-N,C2') Iridium(III)(acetyl-acetonate), red phosphor

IQE: Internal Quantum Efficiency (\%)

$\operatorname{Ir}(\mathrm{bt})_{2}(\mathrm{acac})$ : Bis(2-benzo[b]thiophen-2-ylpyridine)(acetylacetonate)iridium(III), orange phosphor

$\operatorname{Ir}(\mathbf{b t p})_{2}(\mathbf{a c a c})$ : Bis(2-phenylbenzothiazolato)iridium(III)(acetylacetonate), red phosphor

$\operatorname{Ir}(\mathbf{m d q})_{2}$ (acac): Bis(2-methyldibenzo-[f,h]quinoxaline)iridium(III)(acetylacetonate), red phosphor 
$\operatorname{Ir}(\text { mppy) })_{3}$ Tris[2-(4-tolyl)pyridinato- $\left.\mathrm{C}^{2}, N\right]$ iridium(III), green phosphor

$\operatorname{Ir}(\mathbf{M p q})_{2}(\mathbf{a c a c})$ : Bis(4-methyl-2-phenylquinoline)iridium(III)(acetylacetonate), red phosphor

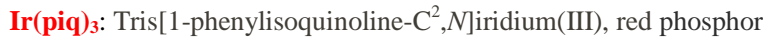

$\operatorname{Ir}(\text { ppy) })_{3}$ : Tris [2-phenylpyridinato- $\left.\mathrm{C}^{2}, N\right]$ iridium(III), green phosphor

$\operatorname{Ir}(\mathbf{p q})_{2}$ (acac), $\operatorname{Ir}(\mathbf{p i q})_{2}$ (acac), $\operatorname{Ir}(2 \text {-phq) })_{2}$ (acac): Bis(2-phenylquinoline)iridium(III)(acetylacetonate), red phosphor

$\operatorname{Ir}(\mathbf{P Q})_{2}(\mathbf{d p m})$ : Bis(2-phenylquinoline)iridium(III)(dipivaloylmethane), red phosphor

$\operatorname{Ir}(\text { ppy) })_{2}$ (acac): Bis[2-(2-pyridinyl- $N$ )phenyl-C](acetylacetonato)iridium(III), green phosphor

$\operatorname{Ir}(\mathbf{P B i})_{2}$ (acac): Bis(2,N-diphenylbenzimidazolito)iridium(III) acetylacetonate, green phosphor

$\operatorname{Ir}(\mathrm{TPm})_{2}$ (acac): Bis $\left(o\right.$-tolylpyrimidinato- $\left.N, C^{2 \prime}\right) \operatorname{Ir}(\mathrm{III})$ acetylacetonate, green phosphor

ITO: Indium Tin Oxide

L: Luminance $\left(\mathrm{cd} / \mathrm{m}^{2}\right)$

Liq: Lithium quinolate, electron-Injecting Layer

$\operatorname{lm}$ : lumen

[5]LOMP2: 5"-methyl-1,1':3',1":3",1"':3"',1'"'-quinquephenyl, host for green phosphor

[5]LOMP4: 5',5"'-dimethyl-1,1':3',1":3",1"':3"',1"''-quinquephenyl, host for green phosphor

[5]LOMP5: 5',5",5"'-trimethyl-1,1':3',1":3",1"':3"',1'"'-quinquephenyl, host for green phosphor

[5]LOMP6: 3,3"', 5',5",5"'-pentamethyl-1,1':3',1":3",1"':3"',1"''-quinquephenyl, host for green phosphor

[5]LOMP7: 3,3"',5,5',5",5"',5'"'-heptamethyl-1,1':3',1":3",1'":3"',1"'"-quinquephenyl, host for green phosphor

mCP: 1,3-bis(N-carbazoyl)benzene

LUMO: Lowest Unoccupied Molecular Orbital

5Me-[5]CMP: $1^{5}, 2^{5}, 3^{5}, 4^{5}, 5^{5}$-pentamethyl-1,2,3,4,5(1,3)-pentabenzenacyclopentaphane, host for green phosphor

Me-TBBI: Tris(2-methyl-3'-(1-phenyl-1H-benzimidazol-2-yl)biphenyl-4-yl)amine, host for green phosphor

2-MeTHF: 2-methyltetrahydofuran, $\mathrm{CH}_{3} \mathrm{C}_{4} \mathrm{H}_{7} \mathrm{O}$

ML-PhOLED: Multi-Layer Phosphorescent Organic Light-Emitting Diode

m-MTDATA: mt-DATA: 4,4',4"-tris(3-methyl)phenylphenylamino)triphenylamine, hole-injecting Layer, host for red phosphor

NPB: N,N'-di(1-naphthyl)-N,N'-diphenylbenzidine, host for red phosphor

$\boldsymbol{\alpha}$-NPB: N,N'-diphenyl-N,N'-bis(1,1'-biphenyl)-4,4'-diamine, host for red phosphor

(NPh $\left.{ }_{2}\right)$ BzImSBF: 2',7'-di-tert-butyl- $N, N$-diphenyl-7-(4-(1-phenyl-1H-benzo[d]imidazol-2-yl)phenyl)-9,9'-spirobi[fluorene]-2-amine, host for yellow phosphor

o-CzOXD: 2,5-bis(2-(9H-carbazol-9-yl)phenyl)-1,3,4-oxadiazole), host for green, red or orange phosphor

OLED: Organic Light-Emitting Diode

OXD-7: 1,3-bis[(4-tert-butylphenyl)-1,3,4-oxidiazolyl]phenylene, ETL or host

PE: Power Efficiency $(\mathrm{lm} / \mathrm{W})$

PEDOT:PSS: Poly(3,4-ethylenedioxythiophene): Poly(styrenesulfonate)

PhOLED: Phosphorescent Organic Light-Emitting Diode

PO-01: Bis(4-phenylthieno[3,2-c]pyridinato- $N, \mathrm{C} 2$ ') acetylacetonate iridium(III), orange phosphor

POAPF: 2,7-bis(diphenylphosphoryl)-9-[4-(N,N-diphenyl-amino)phenyl]-9-phenylfluorene, host for blue phosphor

POCz3: Tri(N-phenylcarbazole)phosphine oxide, host for blue phosphor

PHC: Pure Hydrocarbon

4-POPh 2 -SBF: 4-diphenylphosphine oxide-9,9'-spirobifluorene, host for green phosphor

PTC: 9,9'-(5'-phenyl[1,1':3',1'’-terphenyl]-3,5-diyl)bis-9H-carbazole

PtOEP: Platinum (II) octaethylporphine, red phosphor

26PyzCz: 2,6-bis(9-phenyl-9H-carbazol-3-yl)pyrazine, host for orange phosphor

RT: Room Temperature

SBF(POPh $)_{2}$ : 9,9'-spirobi[fluorene]-2,7-diylbis(diphenylphosphine oxide)), host for blue phosphor

SimCP2: Bis[3,5-di(9H-carbazol-9-yl)phenyl]diphenylsilane, host for blue phosphor 
SL-PhOLED: Single-Layer Phosphorescent Organic Light-Emitting Diode

SPA-F: Spirophenylacridine-fluorene, host for blue phosphor

SPA-2-FPOPh 2 : Spirophenylacridine-2-(diphenylphosphine oxide)-fluorene, host for blue, green or red phosphors

SPA-2,7-F(POPh $)_{2}$ : Spirophenylacridine-2,7-(diphenylphosphine oxide)-fluorene, host for blue, green or red phosphors

SPA-3,6-F( $\left(\mathrm{POPh}_{2}\right)_{2}$ : Spirophenylacridine-3,6-(diphenylphosphine oxide)-fluorene, host for blue, green or red phosphors

SP-EML: Solution Processed-EML

Spiro-2-CBP: 2,7-bis( $N$-carbazolyl)-9,9'-spirobifluorene, host for green phosphor

SPPO13: 2,7-bis(diphenylphosphoryl)-9,9'-spirobifluorene, host for blue phosphor

SPPO21: 2,7-bis(diphenylphosphoryl)spiro[fluorene-7,11'-benzofluorene), host for red phosphor

TAPC: 1,1-bis[(di-4-tolylamino)phenyl]cyclohexane, host for blue phosphor

TBBI: Tris(3'-(1-phenyl-1H-benzimidazol-2-yl)biphenyl-4-yl)amine, host for blue, green or red phosphor

TBCPF : 9,9-bis-(4-(3,6-di-tert-butylcarbazol-9-yl)phenyl]fluorene, host for green phosphor

TCTA: 4,4',4"-tris(carbazole-9-yl)triphenylamine, host for green phosphor

TE-EML: Thermally Evaporated-EML

THF: Tetrahydofuran

TPAFSO: Triphenylamine-dibenzothiophene-S,S-dioxide, host for red phosphor

TPBI: 1,3,5-tris(N-phenylbenzimidazole-2-yl)benzene, host for blue, green or red phosphor

TPCPZ: 2,4,6-tris(3-((9-phenyl)carbazol-3-yl)-phenyl)triazine, host for green phosphor

TOF technique: Time of Flight technique

UPS: UV Photoemission Spectroscopy

$\mu_{\mathrm{e}}$ : electron mobility $\left(\mathrm{cm}^{2} \mathrm{~V}^{-1} \mathrm{~s}^{-1}\right)$

$\mu_{\mathrm{h}}$ : hole mobility $\left(\mathrm{cm}^{2} \mathrm{~V}^{-1} \mathrm{~s}^{-1}\right)$

$\mathrm{V}_{\text {on }}$ : threshold voltage $(\mathrm{V})$ measured at $1 \mathrm{~cd} / \mathrm{m}^{2}$

WF: Work Function (eV) 


\begin{abstract}
Thanks to tremendous efforts of the last twenty years, Phosphorescent Organic Light-Emitting Diodes (PhOLEDs) represent nowadays a prevalent technology. In this technology, all the highefficiency PhOLEDs are multi-layer devices (ML-PhOLEDs) constituted, in addition to the Emissive Layer (EML), of a stack of functional organic layers. These layers have a crucial role in the device performance as they improve the injection, transport and recombination of charges within the EML. Single-Layer PhOLEDs (SL-PhOLEDs) represent ideal OLEDs, only constituted of the electrodes and the EML. However, reaching high-performance SL-PhOLED is far from an easy task as removing the functional layers of an OLED stack dramatically decreases the performance. To reach a high PhOLED efficiency without the different functional layers, the efficient injection, transport and recombination of charges should be insured by the EML and more particularly by the host material. In the present exhaustive review, we analyse the different molecular design strategies, which have been used to construct high-efficiency hosts for SL-PhOLED. The impact of the electronic properties (triplet energy, HOMO/LUMO energy, mobility...) on the device characteristics (threshold voltage, electroluminescent spectrum, external quantum efficiency...) are discussed. This allows to draw a structure/properties/device performance relationship map of interest for the future design of functional materials for SL-PhOLEDs.
\end{abstract}

\title{
Introduction
}

In the emerging technologies of organic electronics, ${ }^{[1]}$ Phosphorescent Organic Light-Emitting Diodes (PhOLEDs) ${ }^{[2-4]}$ are among the most mature devices. In such a type of devices, discovered in $1998,{ }^{[2]}$ the emitting layer (EML) is constituted of an heavy-metal complex emitter dispersed within a host material in order to harvest both singlet and triplet excitons. This technique allows the PhOLED to reach an internal quantum efficiency (IQE) of $100 \%$, whereas IQE of a fluorescent OLED is of only $25 \%$ (only singlet excitons are used in the light emission process). In a PhOLED, the role played by the host matrix is highly important as it should notably host the excitons formation, favour the confinement of excitons and prevent energy back transfers (from the emitter to the host, Figure 1, bottom). Designing highly efficient host materials for PhOLEDs has been an intense research field worldwide and one of the most important driving force in the field. ${ }^{[4]}$ This intense research has led to the advent of PhOLEDs with high efficiency reported for all colours, even for the blue, which is undoubtedly the most challenging. ${ }^{[4-10]}$

This review finds its origin in an important fact of the literature: to date, all the high-efficiency PhOLEDs (with External Quantum Efficiency EQE $>25 \%)^{[11-21]}$ are multi-layer devices. In addition to the EML, there is, in ML-PhOLEDs, a stack of organic layers. These layers have a crucial role in the device performance as they improve the injection, transport and recombination of charges within the EML. Thus, the stack of a PhOLED is usually constituted of a hole transporting layer (HTL), an electron transporting layer (ETL), a hole blocking layer (HBL) and an electron blocking layer (EBL) and these layers can even be doubled. Exciton blocking layer, possessing a high triplet energy $\left(\mathrm{E}_{\mathrm{T}}\right)$, is also frequently added in a PhOLED stack in order to well confine the triplet excitons.

Simplifying the multi-layers structure is then important to reduce the amount of commodities, the manufacture complexity, the production and recycling costs for real life applications. The simplest device is the Single-Layer PhOLED (SL-PhOLED), only made of the electrodes and the EML (host material and phosphor). Such a type of devices is highly appealing as the stack is limited to its most simple expression. As it has also been shown that SL-PhOLEDs can display better stability than MLPhOLEDs, ${ }^{[2]}$ such devices appear appealing for this technology. However, removing the functional organic blocking/transporting layers of an OLED stack often leads to a dramatic decrease of the device performance. For example, the injection of charges is usually significantly affected, leading to higher threshold voltages $\left(\mathrm{V}_{\text {on }}\right)$. 
However, in the first single-layer devices developed, exploiting single-carrier transporting materials inevitably resulted in the unbalanced charge transport and recombination, yielding unsatisfied efficiencies. Additionally, because of the unbalanced charge condition, the recombination zone was always located close to the metal electrodes. The accompanying quenching effect by the electrodes further decreases the device efficiency. In such devices, enhancing the minority injection and carefully adjusting the charge balance were essential to improve the device performance. Bipolar molecules have been one approach to solve this problem due to their capability to transport both hole and electron.

To keep a high PhOLED performance without the different functional organic layers, the efficient injection, transport and recombination of charges within the device, should be insured by the EML and more particularly by the host matrix. If hundreds of host materials have been designed for MLPhOLEDs, only a very few of them have been efficiently used in SL-PhOLEDs. For the last twelve years, many research groups worldwide have tried to design high efficiency host materials for SLPhOLED. However, gathering all the require properties in a single ideal host for SL-PhOLED has been a very difficult task. The host material should indeed fulfil several precise criteria:

a triplet state energy $E_{\mathrm{T}}$ higher than that of the phosphor used $\left(\mathrm{E}_{\mathrm{T}}>2 \mathrm{eV}\right.$ for a red phosphor, $\mathrm{E}_{\mathrm{T}}>2.5 \mathrm{eV}$ for a green phosphor and $\mathrm{E}_{\mathrm{T}}>2.7 \mathrm{eV}$ for a blue phosphor). This property is essential to insure efficient energy transfers ( $\mathrm{T} 1$ from the host to $\mathrm{T} 1$ of the guest) and to confine the triplet excitons within the phosphorescent guest,

(ii) $\mathrm{HOMO} / \mathrm{LUMO}$ levels adapted to the electrodes Fermi levels to allow an efficient charges injection,

(iii) high and well balanced mobility of electron $\left(\mu_{\mathrm{e}}\right)$ and mobility of hole $\left(\mu_{\mathrm{h}}\right)$ to compensate for the absence of ETL and HTL layers. ${ }^{[23]}$ This characteristic is particularly important for SL-PhOLED and is called the ambipolarity, thermal and morphological stabilities to extend the lifetime of the device.

From a structural point of view, the general techniques used in the design of host materials for SLPhOLEDs consist to judiciously associate in a single molecule an electron-rich unit and an electrondeficient unit. This can allow fitting HOMO/LUMO energy levels with the Fermi level of the devices electrodes and can improve the hole and electron mobilities. But, reaching a perfect ambipolarity is a very difficult task and the charge transport is often unbalanced. We will see in this review that the ambipolarity is a key step though towards high performance SL-PhOLEDs.

However, when designing host materials by these chemical engineering techniques, one should particularly take care of the $\mathrm{E}_{\mathrm{T}}$, which is strongly affected by the molecular arrangement of the fragments. Thus, the best compromise between all these properties ( $E_{T}, H O M O / L U M O$ energy levels, and charge transport) should always be considered.

We present herein the different molecular design strategies, which have been developed in the literature to build high $\mathrm{E}_{\mathrm{T}}$ ambipolar host materials for SL-PhOLEDs. As stated above, hundreds of host materials have been designed for ML-PhOLEDs but only a very few of them have been used in SL-PhOLEDs mainly due to charge carriers mobility issues. Nowadays, high performance SLPhOLEDs have been reached and this type of devices may contribute to reduce the complexity of the OLED technology. This can be an important step. In this review, we present the state of art of SLPhOLEDs performance emitting in all the colours (blue, green, red, yellow-orange and white). We focus on the design and the resulting efficiency of organic semi-conductors used as host material in these SL-PhOLEDs. Thanks to a structure-properties relationship study, we connect the different electronic properties (HOMO/LUMO energy levels, $\mathrm{E}_{\mathrm{T}}$, quantum yield, mobilities of the charge carriers...) to the PhOLED characteristics (external quantum efficiency, threshold voltage...). This 
allows to draw a structure/properties/device performance relationship map of interest for future materials design.

As far as we know, there is to date only one review dealing with single-layer devices and this review is fully dedicated to blue fluorescent materials. ${ }^{[2]}$ The present review is therefore the first dedicated to Single-Layer Phosphorescent OLEDs (several reviews have been published on ML-PhOLEDs in the last ten years). ${ }^{[10,23,25,26]}$

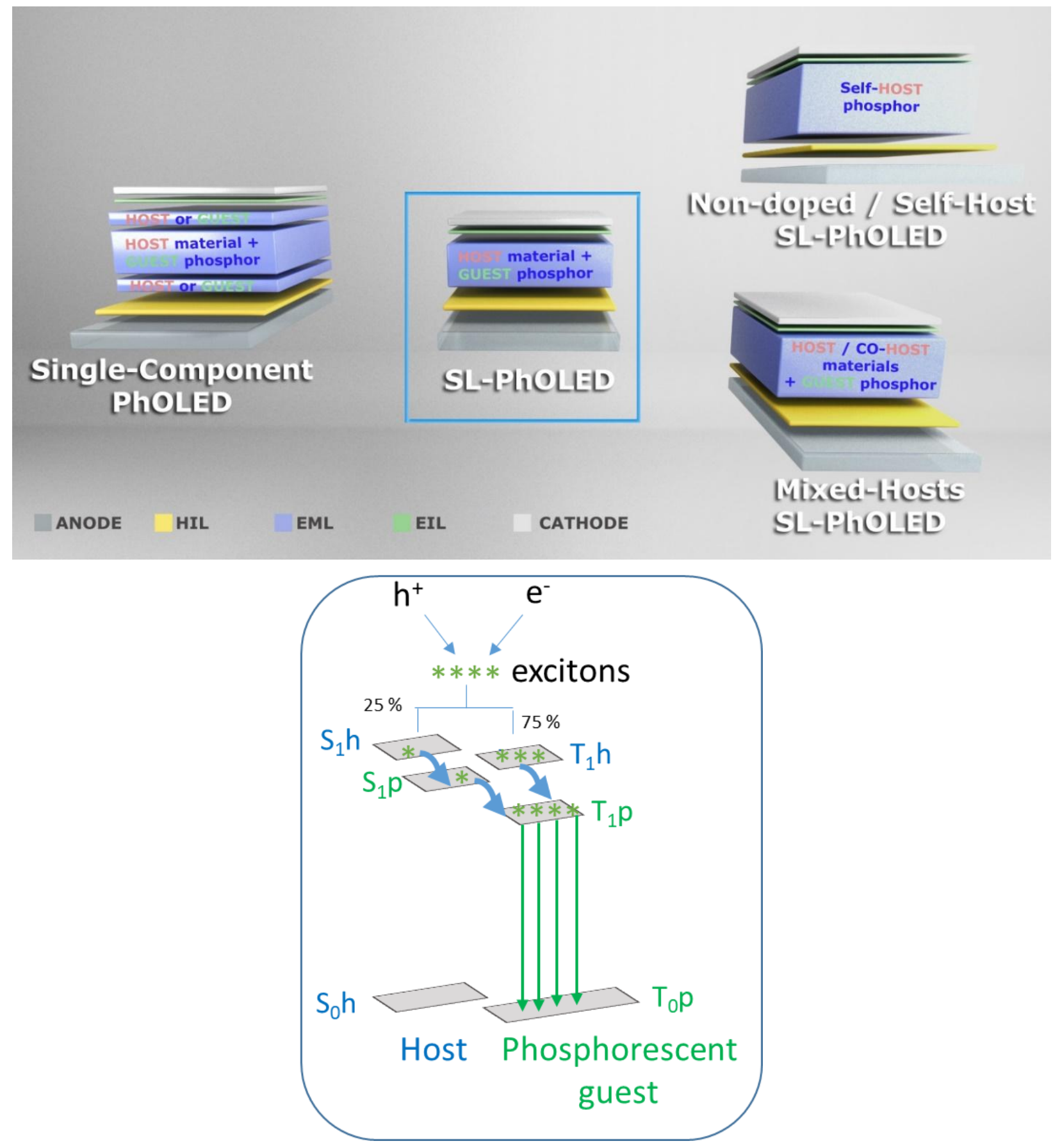

Figure 1. Top. Schematic representation of the architecture of different structures of SL-PhOLEDs, Bottom. Schematic PhOLED working principles.

Before starting, it is important to define what is a SL-PhOLED or at least those, which have been considered in the present review. Indeed, the 'Single-Layer device' appellation is widely used in the literature but can define different device structures. 
Herein, will be first reviewed the SL-PhOLEDs possessing the following architecture: Anode/EML (Host+Guest)/Cathode (see SL-PhOLED architecture in Figure 1, top middle). As neat electrodes (both anode and cathode) are rarely used in OLED technology, ${ }^{[24,27]}$ a thin hole and/or electron injection layers almost always cover the anode and the cathode respectively. In fact, most of the time, the anode is Indium Tin Oxide (ITO) either in its neat form or covered either by a thin film of poly(3,4-ethylenedioxythiophene):Poly(styrenesulfonate) (PEDOT:PSS) this allows to induce a better organization of the interface and a decrease of the anode work function (WF) ${ }^{[28]}$ ) or by $\mathrm{MoO}_{3}$ or 4,4',4"-tris(3-methyl)phenylphenylamino)triphenylamine (mt-DATA). On the other hand, the cathodes are mainly Aluminum (neat or covered either by $\mathrm{Ca}, \mathrm{Cs}, \mathrm{CsF}, \mathrm{Cs}_{2} \mathrm{CO}_{3}, \mathrm{LiF}$ or $\mathrm{Liq}$ ) or Mg:Ag. However, in SL-PhOLEDs, the nature of the EML (host material + guest phosphor) is the most important layer and is the purpose of this work.

However, the literature also reports other PhOLEDs architecture called 'single-layer'. Some are built on the same device architecture and only differ by the composition of the EML. Two types will be described: The 'mixed-hosts SL-PhOLED' and the 'self-host' or 'non-doped' SL-PhOLED. The 'mixed-hosts SL-PhOLED' uses a combination of several molecules (Host + Co-host) to host a phosphor in the EML (Figure 1, top right). The 'self-host' or 'non-doped' PhOLED does not use any host material and the emitter is specifically designed to be used neat (Figure 1, top right). These types of SL-PhOLEDs will be described in Part 1-II.

The last part will be dedicated to another generation of simplified PhOLEDs called the 'SingleComponent PhOLEDs' (Figure 1, top left). The 'Single-Component PhOLEDs' use one or more additional non-doped host layers or pure phosphorescent layers (called regions) as charge transporter/blocker on one or each side of the EML. The advantages of this type of devices is linked to the fact that the same material is used as host or guest in the EML and as charge transporter/blocker. However, the 'Single-Component PhOLED' is not literally a single-layer device but is an important class of simplified devices.

In this review reporting the performances of more than 160 devices, will be hence investigated organic materials (at the exception of polymeric hosts), which have been used over the years as a host in SL-PhOLEDs. All the colours of SL-PhOLEDs will be investigated with an emphasis placed on the molecular design of the host materials and the relationship between molecular structure, electronic properties (HOMO/LUMO energy levels, absorption, emission and charge transport properties) and devices performance. This review gives design guidelines, which will help researchers in the future to design highly efficient host materials for the new generation of simplified OLEDs.

\section{Part I.}

\section{Single-Layer PhOLEDs using a single host material a. Blue SL-PhOLEDs}

Reaching efficient and stable blue emission in OLED technology has been a very active research field for more than 20 years and for the three generations of OLEDs, fluorescent, phosphorescent and Thermally Activated Delayed Fluorescent (TADF) OLEDs. ${ }^{[5,9,24]}[29,30]$ Developing high performance host materials for blue SL-PhOLEDs represent the most difficult challenge to address. This is due to the high $\mathrm{E}_{\mathrm{T}}$ (above $2.6 \mathrm{eV}$ ) and the large HOMO/LUMO gap of blue phosphors. The most popular blue phosphor used in the field of PhOLEDs is the bis[2-(4,6difluorophenyl)pyridinato- $\left.\mathrm{C}^{2}, \mathrm{~N}\right]$ (picolinato)iridium(III) commonly abbreviated FIrpic. ${ }^{[31]}$ However, FIrpic displays an $\mathrm{E}_{\mathrm{T}}$ of $2.67 \mathrm{eV}$ (measured in 2-MeTHF at RT, ${ }^{[32]}$ other values exist depending of the experimental conditions, see $\left.{ }^{[32]}\right)$ and is considered as a sky blue or greenish blue emitter $\left(\lambda_{\max }=\right.$ 465 and $497 \mathrm{~nm}$ in 2-MeTHF). Its HOMO/LUMO energy levels obtained from electrochemical studies in $\mathrm{CH}_{2} \mathrm{Cl}_{2}+\mathrm{Bu}_{4} \mathrm{NPF}_{6}$ 0.2 $\mathrm{M}$ are of $-5.55 /-2.52 \mathrm{eV} .^{[32]}$ In addition, when incorporated in an 
OLED, this phosphor suffers from an instability, which has hindered the development of blue emitting PhOLEDs. ${ }^{[33,34]}$

Bis(2,4-difluorophenylpyridinato)-tetrakis(1-pyrazolyl)borate iridium(III), FIr6, ${ }^{[35]}$ displays a higher $\mathrm{E}_{\mathrm{T}}\left(2.72 \mathrm{eV}\right.$ measured in 2-MeTHF at $\mathrm{RT}^{[32]}$ other values exist depending of the experimental conditions, see $\left.{ }^{[32]}\right)$ and an extended HOMO (-5.66 eV)/LUMO (-2.32 eV) gap (3.34 eV vs $3.03 \mathrm{eV}$ for FIrpic). Compared to FIrpic, its phosphorescence is blue shifted ( $\left(\lambda_{\max }=456\right.$ and $486 \mathrm{~nm}$ in 2 MeTHF ${ }^{[32]}$ ). However, as far as we know, FIr6 has only been used once in SL-PhOLEDs (in 2020). ${ }^{[32]}$ This is undoubtedly due to the difficulty to host such a type of blue phosphors, which are nevertheless required for the future of this technology. To sum up, FIr6 and FIrpic are the only guests used to date in the field of blue SL-PhOLEDs (Figure 2).

To the best of our knowledge, the first blue SL-PhOLED has been reported in 2008 by the group of Qiu. ${ }^{[36]}$ They designed a fluorene/carbazole hybrid host material namely 9,9-bis-(4-(3,6-di-tert-butylcarbazol-9-yl)phenyl]fluorene (TBCPF, Figure 2) incorporating on the fluorene bridge, two N-phenyl-carbazolyl fragments. TBCPF displays a high $\mathrm{E}_{\mathrm{T}}$ of $2.88 \mathrm{eV}$ and a HOMO/LUMO energy level measured at -5.5/-2.1 eV (selected physical and electronic properties of all host materials described in this review are gathered at the end of this review in Table 8). Incorporated as host for FIrpic in the following device structure, ITO/PEDOT:PSS/EML(TBCPF:FIrpic $10 \% \mathrm{wt}$ )(thickness not provided $) / \mathrm{Cs}_{2} \mathrm{CO}_{3}(2 \mathrm{~nm}) / \mathrm{Al}$, the authors reported a current efficiency $(\mathrm{CE})$ of $3.5 \mathrm{~cd} / \mathrm{A}$ and a maximum luminance (L) of ca $8080 \mathrm{~cd} / \mathrm{m}^{2}$. Nevertheless, the CIE of the electroluminescent (EL) spectrum of the device D1 $(0.215,0.433)$ are not perfectly those of FIrpic $(0.16,0.32$; see other devices data based on FIrpic in Table 1), translating parasite emissions. Despite the performances of these devices were very low, these first data of SL-PhOLEDs using a solution-processed (SP) smallmolecule host have open the way to the design of efficient host materials for this application.

It is particularly important to note that adding in the EML another molecule (1,3-bis[(4-tert-butylphenyl)-1,3,4-oxidiazolyl]phenylene-OXD-7) as an electron-transporting co-host, significantly improves the performance of the device to $\mathrm{CE}=12.7 \mathrm{~cd} / \mathrm{A}$ at $190 \mathrm{~A} / \mathrm{m}^{2}$ and $\mathrm{L}=19900 \mathrm{~cd} / \mathrm{m}^{2}$ (at $20 \mathrm{~V}$ ), D98D101. ${ }^{[36]}$ This approach is called 'mixed-hosts' and will be described below (Part I.2.b). As TBCPF is mainly a hole transporter, and beyond the PhOLED performance, this shows the importance of having a balanced charge transport in the EML of a SL-PhOLED. In the following years of this research field, this has been a central feature in the materials design. 


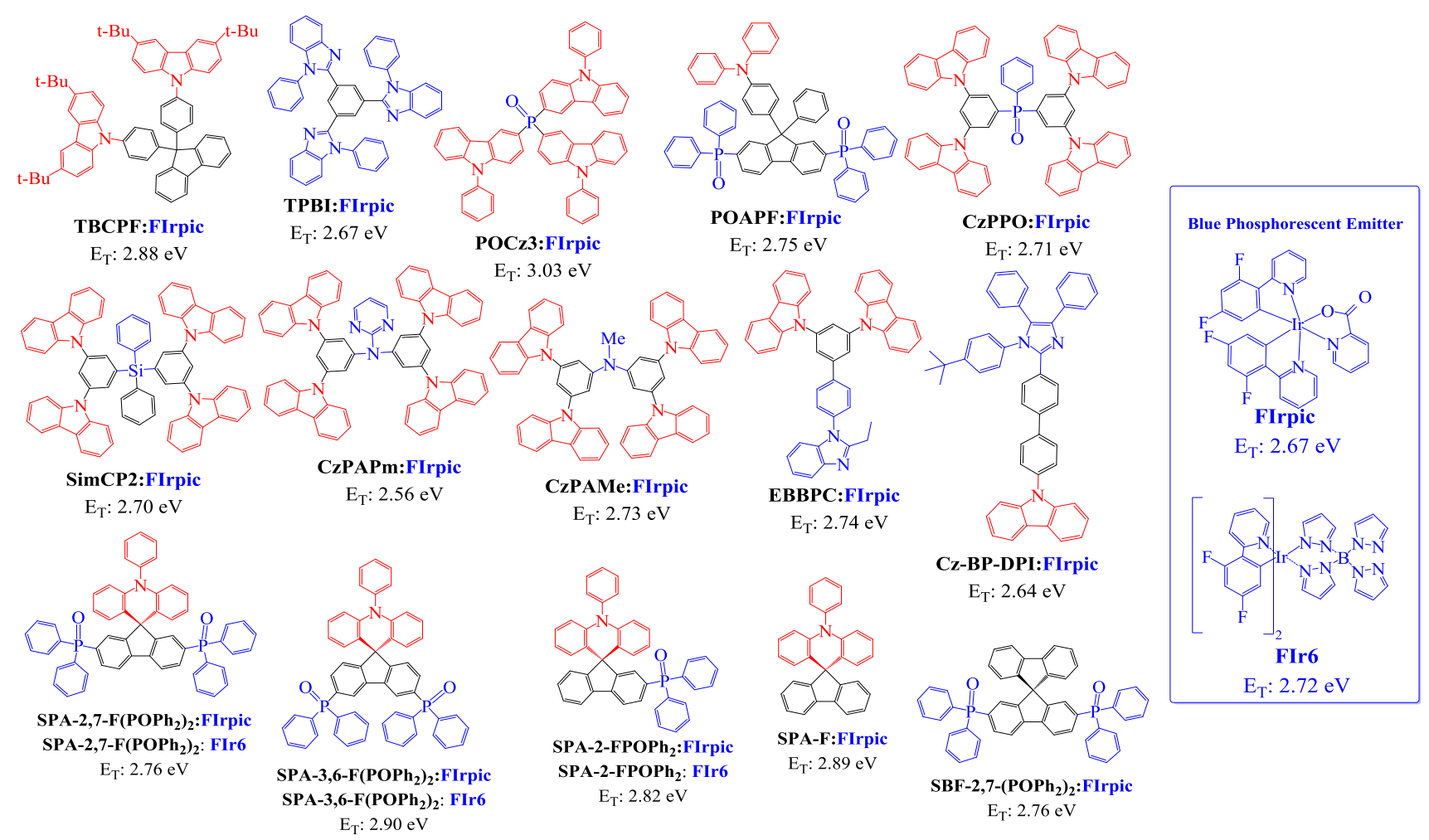

Figure 2. Molecular structure of host materials and blue phosphors used in blue SL-PhOLEDs. $E_{\mathrm{T}}$ in black (blue) is that of the host (phosphorescent emitter). In the host materials, black, blue and red fragments respectively point the $\pi$-linker, the acceptor and the donor units.

In 2009, Liu and co-workers have designed a host material, 1,3,5-tris(N-phenylbenzimidazole-2yl)benzene called TPBI, which has been successfully used for red, green and blue phosphors. ${ }^{[2]}$ Such a type of host is called 'universal' and is particularly difficult to design. Indeed, if a host with a high $\mathrm{E}_{\mathrm{T}}$ (above $2.6 \mathrm{eV}$ ) can be, in principle, used with Red, Green and Blue (RGB) phosphors, fitting the HOMO/LUMO energy levels is a difficult task. Some examples of high efficiency universal hosts have recently been reported for ML-PhOLEDs ${ }^{[37]}$ but such hosts remain very rarely reported in literature for SL-PhOLEDs. Thus, TPBI is constructed on the association of three benzimidazole units linked to a central phenyl ring, possessing therefore a C3 symmetry. This molecule is a wide gap material with good electron-transporting property, which has been widely used in OLED stacks as HBL or ETL. It should be noted that there are many different data sets for this molecule, which have been published for the last twenty years. It appears therefore complicated to properly compare the data with other compounds. For a proper comparison with a new compound, we recommend to also record the data (for example, the HOMO/LUMO energy levels by electrochemistry) of known compounds in identical conditions. TPBI presents a LUMO spreading over a large range, between $2.1^{[38]}$ and $-2.8^{[39]} \mathrm{eV}$, a HOMO between $-6.3^{[39,40]}$ and $-6.02^{[38]} \mathrm{eV}$ and the $\mathrm{E}_{\mathrm{T}}$ lies at $2.67 \mathrm{eV} .^{[38]}$ Measured by SCLC, the electron mobility $\left(\mu_{\mathrm{e}}\right)$ is reported at $6.53 \times 10^{-5} \mathrm{~cm}^{2} \mathrm{~V}^{-1} \mathrm{~s}^{-1}$ by Cao and coworkers. $^{[41]}$

TPBI was used as host for FIrpic in device D2 (ITO/TPBI:FIrpic $18 \% / \mathrm{LiF} / \mathrm{Al}$ ) in which the EML was deposited by thermal evaporation. The device emits since $7.6 \mathrm{~V}$ and reaches a $\mathrm{CE}$ of $6.8 \mathrm{~cd} / \mathrm{A}$ (Power Efficiency PE $=1.9 \mathrm{~lm} / \mathrm{W}$ ) indicating low performances. ${ }^{\text {[22] }}$ Two features can be concluded. First, this work shows the premises of the molecular design of high $\mathrm{E}_{\mathrm{T}}$ host materials for SLPhOLEDs, which will be used in the future. Indeed, in TPBI, the three benzimidazole fragments are in meta position of the central phenyl ring and hence only very weakly connected one to the other. As will be seen below, this is a key point to keep a high $\mathrm{E}_{\mathrm{T}}$ value. ${ }^{[42-44]}$ Second, the low $\mathrm{E}_{\mathrm{T}}$ of TPBI $(2.67 \mathrm{eV})$ explains the poor performance reported for this FIrpic-based SL-PhOLED, since the T1- 
T1 energy transfer is not efficient. With green phosphor, the performance of TPBI as host will be better (see Part I.1.b, D33-42), confirming the present conclusions.

In 2011, Wong and co-workers ${ }^{[45]}$ designed a new bipolar host: tri(N-phenylcarbazole)phosphine oxide (POCz3), constructed on the association of three electron-rich fragments, ie carbazole units to an electron-poor fragment, ie phosphine oxide. The $\pi$-conjugation disruption between the electronrich and electron-poor fragments is insured by the phosphorus atom and allowed to keep a very high $\mathrm{E}_{\mathrm{T}}$ of $3.03 \mathrm{eV}$ (measured at $77 \mathrm{~K}$ in $\mathrm{EtOH}$ ). The $\mathrm{HOMO}$, obtained from UV photoemission spectroscopy (UPS), is reported at $-5.5 \mathrm{eV}$, whereas the LUMO, obtained from $\mathrm{E}_{\mathrm{g}}{ }^{\text {opt }}$-HOMO, is very high, lying at $-1.8 \mathrm{~V}$. Electron carrier mobilities $\left(\mu_{\mathrm{e}}\right)$ were first measured using the time-of-flight (TOF) technique. $\mu_{\mathrm{e}}$ values are in the range of $1.4 \times 10^{-6}$ to $6.4 \times 10^{-6} \mathrm{~cm}^{2} \mathrm{~V}^{-1} \mathrm{~s}^{-1}$ for fields varying from $4 \times 10^{5}$ to $6.8 \times 10^{5} \mathrm{~V} / \mathrm{cm}$. TOF transient for holes exhibited weak photocurrent signals, which did not allow hole mobility $\left(\mu_{\mathrm{h}}\right)$ determination. The study of the charge-carrier transport properties of POCz3 studying hole- and electron-only single-carrier devices revealed a bipolar transport, with however a larger current density of electrons than of holes (at the same voltage). This indicates a superior capability of POCz3 to carry electrons than holes. The sky blue FIrpic-based PhOLED D3 incorporating POCz3 as host (EML was thermally evaporated) displayed an interesting EQE of $7.1 \%$, showing that the design strategy, incorporating electron rich and electron poor units within a single host, was promising. As will be described below, the performances of the devices using POCz3 as host for FIrpic have been improved by the introduction of a neat POCz3 film between PEDOT:PSS and EML (see Part II, single component devices, D139-141).

In 2013, the group of Xie reported a bipolar host, POAPF, for SL-PhOLED. ${ }^{[46]}$ This host was constructed on the assembly of one electron-rich unit, namely diphenylamine and an electron-poor unit, namely 2,7-(diphenylphosphine oxide)-fluorene. In POAPF, the diphenylamine is attached on a phenyl ring located on the bridge of the fluorene (C9 carbon atom), being hence electronically separated from the acceptor part. Thanks to a combination of high $\mathrm{E}_{\mathrm{T}}(2.75 \mathrm{eV})$, high HOMO $(-5.26$ $\mathrm{eV})$ and low (-2.4 eV) LUMO energy level and ambipolar charge transport $\left(\mu_{\mathrm{h}}\right.$ and $\mu_{\mathrm{e}} \mathrm{ca} 10^{-6} \mathrm{~cm}^{2} \mathrm{~V}^{-1}$ $\mathrm{s}^{-1}$ ), this host was particularly well adapted to SL-PhOLEDs due to its bipolar character. Its efficiency has been first highlighted in a ML-PhOLED in 2009 with EQE reported above $20 \%$. ${ }^{[4]}$ The high efficiency of this host was also reported in SL-PhOLEDs with an EQE of $10.8 \%$ (D4). In this work, the authors have studied the effect of the EML thickness on the performance of SLPhOLEDs (D4-D8). ${ }^{[4]}$ It was shown that the EQE of FIrpic-based SL-PhOLEDs varied between 8.8 and $10.8 \%$ as a function of the thickness of the EML $(60-100 \mathrm{~nm})$. Increasing the thickness from 60, 70 to $80 \mathrm{~nm}$ leads to an increase of EQE from 8.8, 10.6 to $10.8 \%$, then EQE decreases to 9.65 and $9.51 \%$ when the EML thickness increased to 90 and $100 \mathrm{~nm}$. This work has not only highlighted the importance of the EML thickness in SL-PhOLEDs but was the first example of blue SL-PhOLEDs overpassing an EQE of $10 \%$.

In 2014, the group of Liu also used the bipolar properties of POAPF in a SL-PhOLED and managed to reach a very high EQE of $20.3 \%$ (D9). ${ }^{[48]}$ This performance is still nowadays the highest reported for FIrpic based devices. Thus, with the same host material POAPF, one can note significant different performances between these two studies, ${ }^{[46,48]}$ which can be assigned to the device itself (different cathode, $\mathrm{Mg}: \mathrm{Ag}$ vs $\mathrm{Al}$, and different layer thicknesses). Compared to the devices presented by the group of $\mathrm{Xie}^{[46]}$ and especially that with the $100 \mathrm{~nm}$ EML thickness, the performance obtained by the group of Liu is largely higher (EQE: 9.51 (D7) vs 20.3 (D9) \%). In these devices, the architecture is similar but the cathode is different. The higher performance reached by Liu group may also find its origin in the devices preparation. Indeed, the different performance can also be explained either by (i) the FIrpic purification and doping level (10\% vs $8 \%$ ), or by (ii) a different treatment during the anode preparation, or by (iii) a different quality (Clevios P AI4083 or Clevios CH8000) and thickness of PEDOT:PSS layer (50 nm vs $35 \mathrm{~nm}$ ) or by the combination of these three 
parameters. All these observations shows the importance of the device engineering in this technology to reach very high device efficiencies and points the difficulty to compare their performances.

Table 1. EL performances of blue SL-PhOLEDs (D1 to D23)

\begin{tabular}{|c|c|c|c|c|c|c|c|}
\hline \multicolumn{8}{|c|}{ Blue SL-PhOLEDs } \\
\hline EML & Device structure & $\begin{array}{l}\mathbf{V}_{\text {on }} \\
(\mathbf{V})\end{array}$ & $\begin{array}{l}\mathbf{E Q E}_{\max } \\
(\%)\end{array}$ & $\begin{array}{l}\mathrm{CE}_{\max } \\
(\mathbf{c d} / \mathbf{A}\end{array}$ & $\begin{array}{l}\mathbf{P E}_{\max } \\
(\mathbf{l m} / \mathbf{W})\end{array}$ & $\begin{array}{l}1931 \text { CIE } \\
(x, y)\end{array}$ & $\begin{array}{l}\text { Device number, } \\
\text { References }\end{array}$ \\
\hline TBCPF:FIrpic $10 \%$ & ITO/PEDOT:PSS/SP-EML(-nm)/ $\mathrm{Cs}_{2} \mathrm{CO}_{3}(2 \mathrm{~nm}) / \mathrm{Al}(100 \mathrm{~nm})$ & 9.7 & - & 3.5 & - & $0.215,0.433$ & $\mathrm{D} 1,2008^{[36]}$ \\
\hline TPBI:FIrpic $18 \%$ & ITO/TE-EML(100nm)/LiF(1nm)/Al(100nm) & 7.6 & - & 6.8 & 1.9 & $0.20,0.49$ & $\mathrm{D} 2,2009^{[22]}$ \\
\hline POCz3:FIrpic $10 \%$ & ITO/PEDOT:PSS/TE-EML(80nm)/LiF/Al & - & 7.1 & - & - & - & $\mathrm{D} 3,2011^{[45]}$ \\
\hline POAPF:FIrpic $10 \%$ & ITO/PEDOT:PSS/TE-EML(80nm)/LiF/Mg:Ag & 5.37 & 10.8 & - & 15.2 & $0.161,0.387$ & $\mathrm{D} 4,2013^{[47]}$ \\
\hline POAPF:FIrpic $10 \%$ & ITO/PEDOT:PSS/TE-EML(70nm)/LiF/Mg:Ag & 4.91 & 10.6 & - & 13.5 & $0.155,0.345$ & D5, $2013^{[47]}$ \\
\hline POAPF:FIrpic $10 \%$ & ITO/PEDOT:PSS/TE-EML(90nm)/LiF/Mg:Ag & 5.86 & 9.65 & - & 12.3 & $0.17,0.406$ & D6, $2013^{[47]}$ \\
\hline POAPF:FIrpic $10 \%$ & ITO/PEDOT:PSS/TE-EML(100nm)/LiF/Mg:Ag & 6.07 & 9.51 & - & 13.7 & $0.178,0.428$ & $\mathrm{D} 7,2013^{[47]}$ \\
\hline POAPF:FIrpic $10 \%$ & ITO/PEDOT:PSS/TE-EML(60nm)/LiF/Mg:Ag & - & 8.8 & - & 12.2 & $0.153,0.322$ & $\mathrm{D} 8,2013^{[47]}$ \\
\hline POAPF:FIrpic $8 \%$ & ITO/PEDOT:PSS/TE-EML(100 nm)/LiF/Al & 3.0 & 20.3 & 42.2 & 26.5 & $0.15,0.35$ & $\mathrm{D} 9,2014^{[48]}$ \\
\hline CzPPPO:FIrpic $5 \%$ & $\begin{array}{l}\text { ITO/PEDOT:PSS(65nm)/SP-EML(70nm)/CsF(2nm)/Al } \\
(100 \mathrm{~nm})\end{array}$ & 4.5 & - & 9.32 & 4.97 & $0.15,0.35$ & D10, 2014 ${ }^{[49]}$ \\
\hline SimCP2:FIrpic $5 \%$ & $\begin{array}{l}\text { ITO/PEDOT:PSS(65nm)/SP-EML(70nm)/CsF(2nm)/Al } \\
(100 \mathrm{~nm})\end{array}$ & 7.2 & - & 3.43 & 1.42 & $0.15,0.35$ & D11,2014 ${ }^{[49]}$ \\
\hline CzPAPm:FIrpic $5 \%$ & $\begin{array}{l}\text { ITO/PEDOT:PSS(65nm)/SP-EML(70nm)/CsF(2nm)/Al } \\
(100 \mathrm{~nm})\end{array}$ & 8.7 & - & 2.82 & 0.93 & $0.15,0.36$ & D12, 2014 ${ }^{[49]}$ \\
\hline CzPAMe:FIrpic $5 \%$ & $\begin{array}{l}\text { ITO/PEDOT:PSS(65nm)/SP-EML(70nm)/CsF(2nm)/Al } \\
(100 \mathrm{~nm})\end{array}$ & 7.2 & - & 1.34 & 0.56 & $0.14,0.30$ & D13, 2014 ${ }^{[49]}$ \\
\hline EBBPC:FIrpic $20 \%$ & $\begin{array}{l}\text { ITO/PEDOT:PSS(40nm)/TE-EML }(90 \mathrm{~nm}) / \mathrm{LiF}(0.5 \mathrm{~nm}) / \mathrm{Mg}: \mathrm{Ag} \\
(15: 1 \text { in mass })(120 \mathrm{~nm})\end{array}$ & 5.3 & 9.8 & 21.6 & 10.4 & $0.15,0.39$ & $\mathrm{D} 14,2017^{7^{50]}}$ \\
\hline Cz-BP-DPI:FIrpic ? \% & ITO/PEDOT:PSS(40nm)/SP-EML (80nm)/CsF(1.5nm)/AI(100nm) & 8.4 & 0.045 & 0.083 & - & $0.26,0.42$ & $\mathrm{D} 15,2017^{[51]}$ \\
\hline $\mathbf{S P A}_{\%} \mathbf{\text { PA, }}-\mathbf{F}\left(\mathbf{P O P h}_{2}\right)_{2}$ :FIrpic 10 & $\begin{array}{l}\text { ITO/PEDOT:PSS }(40 \mathrm{~nm}) / \mathrm{TE}-\mathrm{EML}(100 \mathrm{~nm}) / \mathrm{LiF}(1.2 \mathrm{~nm}) / \mathrm{Al} \\
(100 \mathrm{~nm})\end{array}$ & $\begin{array}{c}2.5 \\
(2.5)\end{array}$ & $\begin{array}{l}17.6 \\
(18)\end{array}$ & $\begin{array}{l}37.8 \\
(39)\end{array}$ & $\begin{array}{c}37.8 \\
(38.4)\end{array}$ & $\begin{array}{c}0.15,0.37 \\
(0.15,0.37)\end{array}$ & $\begin{array}{c}\mathrm{D} 16,2020^{[52]} \\
\text { (best device, } 2020 \\
{[32] \text { ) }}\end{array}$ \\
\hline $\left.\begin{array}{l}\text { SPA-3,6-F(POPh } \\
\%\end{array}\right)_{2}:$ FIrpic 10 & $\begin{array}{l}\text { ITO/PEDOT:PSS }(40 \mathrm{~nm}) / \mathrm{TE}-\mathrm{EML}(100 \mathrm{~nm}) / \mathrm{LiF}(1.2 \mathrm{~nm}) / \mathrm{Al} \\
(100 \mathrm{~nm})\end{array}$ & 3.5 & 6.5 & 12.3 & 4.2 & $0.16,0.38$ & $\mathrm{D} 17,2020^{[32]}$ \\
\hline SPA-2-FPOPh 2 :FIrpic $10 \%$ & $\begin{array}{l}\text { ITO/PEDOT:PSS(40nm)/TE-EML(100nm)/LiF(1.2nm)/Al } \\
(100 \mathrm{~nm})\end{array}$ & 2.8 & 8.6 & 17.3 & 10.5 & $0.15,0.37$ & $\mathrm{D} 18,2020^{[32]}$ \\
\hline SBF-2,7-(POPh $\left.)_{2}\right)_{2}$ FIrpic $10 \%$ & $\begin{array}{l}\text { ITO/PEDOT:PSS(40nm)/TE-EML(100nm)/LiF(1.2nm)/Al } \\
(100 \mathrm{~nm})\end{array}$ & 4.1 & 0.6 & 0.7 & 0.2 & $0.15,0.37$ & $\mathrm{D} 19,2020^{[32]}$ \\
\hline SPA-F:FIrpic $10 \%$ & $\begin{array}{l}\text { ITO/PEDOT:PSS }(40 \mathrm{~nm}) / \mathrm{TE}-\mathrm{EML}(100 \mathrm{~nm}) / \mathrm{LiF}(1.2 \mathrm{~nm}) / \mathrm{Al} \\
(100 \mathrm{~nm})\end{array}$ & \multicolumn{5}{|c|}{ Performance not recordable } & $\mathrm{D} 20,2020^{[32]}$ \\
\hline SPA-2,7-F(POPh $)_{2}$ :FIr6 $10 \%$ & $\begin{array}{l}\text { ITO/PEDOT:PSS(40nm)/TE-EML(100nm)/LiF(1.2nm)/Al } \\
(100 \mathrm{~nm})\end{array}$ & 2.8 & 6.5 & 10.4 & 4.5 & $0.16,0.33$ & $\mathrm{D} 21,2020^{[32]}$ \\
\hline SPA-3,6-F(POPh $\left.{ }_{2}\right)_{2}$ :FIr6 $10 \%$ & $\begin{array}{l}\text { ITO/PEDOT:PSS(40nm)/TE-EML(100nm)/LiF(1.2nm)/Al } \\
(100 \mathrm{~nm})\end{array}$ & 4.6 & 6.5 & 14.7 & 6.8 & $0.16,0.32$ & D22, $2020^{[32]}$ \\
\hline SPA-2-FPOPh 2 :FIr6 $10 \%$ & $\begin{array}{l}\text { ITO/PEDOT:PSS(40nm)/TE-EML(100nm)/LiF(1.2nm)/Al } \\
(100 \mathrm{~nm})\end{array}$ & 2.9 & 9.1 & 16.2 & 7.7 & $0.15,0.30$ & $\mathrm{D} 23,2020^{[32]}$ \\
\hline
\end{tabular}

SP-EML for solution processed EML and TE-EML for thermally evaporated EML

In 2014, the group of Chen, designed four hosts constructed on the association of two meta-biscarbazolyl-phenyl groups as donor units connected to four different molecular fragments possessing either electron accepting characteristics (POPh in $\mathbf{C z P P O}, \mathrm{SiPh}_{2}$ in $\mathbf{S i m C P 2}$ and N-pyrimidine in CzPAPm) or electron donating characteristics (N-Me in CzPAMe). ${ }^{[4]}$ The four hosts possess similar wide energy gaps around $3.5 \mathrm{eV}$. In addition, except CzPAPm, which possess a low $\mathrm{E}_{\mathrm{T}}$ of $2.56 \mathrm{eV}$, the three other hosts possess a high $\mathrm{E}_{\mathrm{T}}$ close to $2.7 \mathrm{eV}$, higher than that of FIrpic. SLPhOLEDs were solution-processed with a $5 \%$ FIrpic concentration in the four hosts with the following structure: ITO/PEDOT:PSS(65nm)/EML(70nm)/CsF(2nm)/Al(100nm). The SL-PhOLED D10 using CzPPO as host emits blue light since 4.5 V and reaches CE / PE of $9.32 \mathrm{~cd} / \mathrm{A} / 4.97 \mathrm{~lm} / \mathrm{W}$ presenting higher efficiency than the two other devices, D11 with SimCP2 $(3.43 \mathrm{~cd} / \mathrm{A} / 1.42 \mathrm{~lm} / \mathrm{W})$ and D13 with CzPAMe (1.34 cd/A / $0.56 \mathrm{~lm} / \mathrm{W})$. Surprisingly, the device D12 using CzPAPm as host, despite an $\mathrm{E}_{\mathrm{T}}$ lower than that of FIrpic, reaches a higher value $(2.82 \mathrm{~cd} / \mathrm{A} / 0.93 \mathrm{~lm} / \mathrm{W})$ than that using CzPAMe, with however a higher $\mathrm{V}_{\text {on }}(8.7 \mathrm{~V}$ vs $7.2 \mathrm{~V})$.

In 2017, Zhao, Xie and co-workers have reported a high $\mathrm{E}_{\mathrm{T}}$ host material, EBBPC, constructed on the judicious association of benzimidazole and carbazole units. ${ }^{[50]}$ Due to the combination of a high $\mathrm{E}_{\mathrm{T}}$ of $2.74 \mathrm{eV}, \mathrm{HOMO} / \mathrm{LUMO}$ of $-5.71 /-2.36 \mathrm{eV}$ respectively, and well balance mobilities of charges $\left(\mu_{\mathrm{e}}=2 \times 10^{-5} \mathrm{~cm}^{2} \mathrm{~V}^{-1} \mathrm{~s}^{-1}, \mu_{\mathrm{h}}=10^{-5} \mathrm{~cm}^{2} \mathrm{~V}^{-1} \mathrm{~s}^{-1}\right)$ the performance of the blue device D14 reached a high EQE of $9.8 \%$ (Table 1). ${ }^{[50]}$ By comparison with ML-PhOLEDs, the authors show that the efficiency 
roll-off of SL-PhOLEDs is lower than that of ML-PhOLEDs, which can be one of the advantages of SL-PhOLEDs in the future. As the roll-off is very important in the OLED technology, such a study will deserve to be more deeply investigated in the future. EBBPC host has also been successfully used with red and green phosphors (see Part I.1b, D51 and I. 1c, D67).

The same year, the group of You designed a new bipolar host, Cz-BP-DPI, based on the donor Nbiphenyl-carbazole unit linked to a terphenylimidazole (DPI) acceptor unit. ${ }^{[51]}$ Despite its $\mathrm{E}_{\mathrm{T}}$ was estimated at $2.64 \mathrm{eV}$, close to that of FIrpic, Cz-BP-DPI was used as host for FIrpic in a solutionprocessed device (ITO/PEDOT:PSS $(40 \mathrm{~nm}) / \mathbf{E M L}(80 \mathrm{~nm}) / \mathrm{CsF}(1.5 \mathrm{~nm} / \mathrm{Al}(100 \mathrm{~nm})$. The device D15 emits at a high $\mathrm{V}_{\text {on }}$ of $8.4 \mathrm{~V}$ and the CIE obtained from the EL spectrum $(0.26,0.42)$ are not fully consistent with the emission of FIrpic. The PhOLED efficiency was therefore poor $\left(\mathrm{EQE}_{\max }: 0.045\right.$ $\%, \mathrm{CE}_{\max }: 0.083 \mathrm{~cd} / \mathrm{A}$ ) translating backward energy transfer due to similar $\mathrm{E}_{\mathrm{T}}$ values of $\mathbf{C z}$-BP-DPI and FIrpic.

More recently, in 2020 our group has designed a host material, spirophenylacridine-2,7(diphenylphosphine oxide)-fluorene (SPA-2,7-F $\left.\left.(\mathbf{P O P h})_{2}\right)_{2}\right)$ displaying all the necessary properties for high performance blue SL-PhOLED ${ }^{[52]}$ Due to its high $\mathrm{E}_{\mathrm{T}}(2.76 \mathrm{eV})$, this molecule was adapted to host blue but also red and green phosphors (see Part Ib, D53 \& Ic, D69). The design of SPA-2,7$\mathbf{F}\left(\mathbf{P O P h}_{2}\right)_{2}$ is inspired by that of POAPF presented above. SPA-2,7-F $(\mathbf{P O P h})_{2}$ is constructed on the association of an electron-rich unit, namely phenylacridine ${ }^{[53,54]}$ and an electron-poor unit, namely 2,7-(diphenylphosphine oxide)-fluorene. ${ }^{[55]}$ The two molecular fragments are connected via a spiro bridge in order to achieve an efficient $\pi$-conjugation disruption, maintaining a high $\mathrm{E}_{\mathrm{T}}$ of $2.76 \mathrm{eV}\left(\mathrm{E}_{\mathrm{T}}\right.$ of POAPF is $2.75 \mathrm{eV}$ ). The spiro-bridge also allows to provide very good thermal properties, which is a mandatory point for industrial application. Compared to POAPF, in which the donor was a pending diphenylamine, herein the donor is a rigid spiro-linked phenylacridine. ${ }^{[53,54]}$ The acceptor part is identical in SPA-2,7-F $\left(\mathbf{P O P h}_{2}\right)_{2}$ and POAPF. In order to rationalize the impact of the incorporation of the electron-rich and electron-poor units within $\mathbf{S P A - 2 , 7 - F}(\mathbf{P O P h})_{2}$, its properties have been compared to those of model compounds incorporating either the electron-rich part (spirophenylacridine-fluorene SPA-F) or the electron-poor part (9,9'-spirobi[fluorene]-2,7diylbis(diphenylphosphine oxide)), $\left.\mathbf{S B F}(\mathbf{P O P h})_{2}\right) .{ }^{[56]}$ This type of strategy appears particularly efficient to draw a precise structure/properties relationship map and is of interest to well understand the efficiency of a molecule within a device and to further design efficient functional materials. We encourage researchers involved in the field to carry such a type of comparative studies.

The electrochemical properties of SPA-2,7-F(POPh $)_{2}, \mathbf{S P A - F}$ and $\mathbf{S B F}(\mathbf{P O P h})_{2}$ nicely illustrate the molecular association investigated in this work (Figure 3, top). ${ }^{[52]} \mathbf{S P A}-\mathbf{2 , 7 - F}\left(\mathbf{P O P h} \mathbf{P}_{2}\right)_{2}$ displays the behaviour of $\mathbf{S B F}(\mathbf{P O P h})_{2}$ in reduction and that of SPA-F in oxidation. Indeed, the reduction of SPA-2,7-F $\left(\mathbf{P O P h}_{2}\right)_{2}$ and $\mathbf{S B F}\left(\mathbf{P O P h}_{2}\right)_{2}$ is exclusively driven by the acceptor part, ie 2,7(diphenylphosphine oxide)-fluorene, $\mathrm{E}_{\mathrm{p}}{ }^{\text {red }}=-1.98 \mathrm{~V} / \mathrm{SCE}$ for both. In oxidation, SPA-2,7-F $(\mathbf{P O P h})_{2}$ and SPA-F displays a similar (but not identical) first oxidation potential respectively measured at $\mathrm{E}_{\mathrm{p}}{ }^{\mathrm{ox}}=1.06 \mathrm{~V}$ and $1.00 \mathrm{~V} / \mathrm{SCE}$. Thanks to this rational design, the electrochemical energy gap of SPA-2,7-F $\left.(\mathbf{P O P h})_{2}\right)_{2}(2.78 \mathrm{eV})$ is strongly contracted compared to that of SPA-F (3.39 eV) and $\mathbf{S B F}(\mathbf{P O P h})_{2}(3.54 \mathrm{eV}){ }^{[32]}$ This is a central feature in this bipolar design if we consider the need of being able to inject and transport both kind of charge carriers. What are the consequences of this design on the mobility of charge carriers?

As mentioned in the introduction, in a SL-PhOLED, because of the device simplification (suppression of the charge carrier transporting and blocking interlayers), proper and balanced hole and electron mobilities are required to promote efficient recombination of carriers in the EML. As above discussed for oxidation/reduction potentials, SPA-2,7-F(POPh $)_{2}$ also combines the charge carrier mobilities properties of the two model compounds SPA-F and $\mathbf{S B F}(\mathbf{P O P h})_{2}$. Indeed, the authors reported $\mu_{\mathrm{h}} / \mu_{\mathrm{e}}$ of $8.2 \times 10^{-6} / 2 \times 10^{-4} \mathrm{~cm}^{2} \mathrm{~V}^{-1} \mathrm{~s}^{-1}$ for $\mathbf{S P A - 2 , 7 - F}(\mathbf{P O P h})_{2}$ very similar to that of 
their model compounds $\left(\mu_{\mathrm{h}}\right.$ of $1 \times 10^{-5} \mathrm{~cm}^{2} \mathrm{~V}^{-1} \mathrm{~s}^{-1}$ for SPA-F and $\mu_{\mathrm{e}}$ of $6.9 \times 10^{-5} \mathrm{~cm}^{2} \mathrm{~V}^{-1} \mathrm{~s}^{-1}$ for $\left.\mathbf{S B F}(\mathbf{P O P h})_{2}\right)$. The mobilities of SPA-2,7-F $(\mathbf{P O P h})_{2}$ are also rather well balanced with $\mu_{\mathrm{e}}$ only 20 times higher than $\mu_{\mathrm{h}}$.
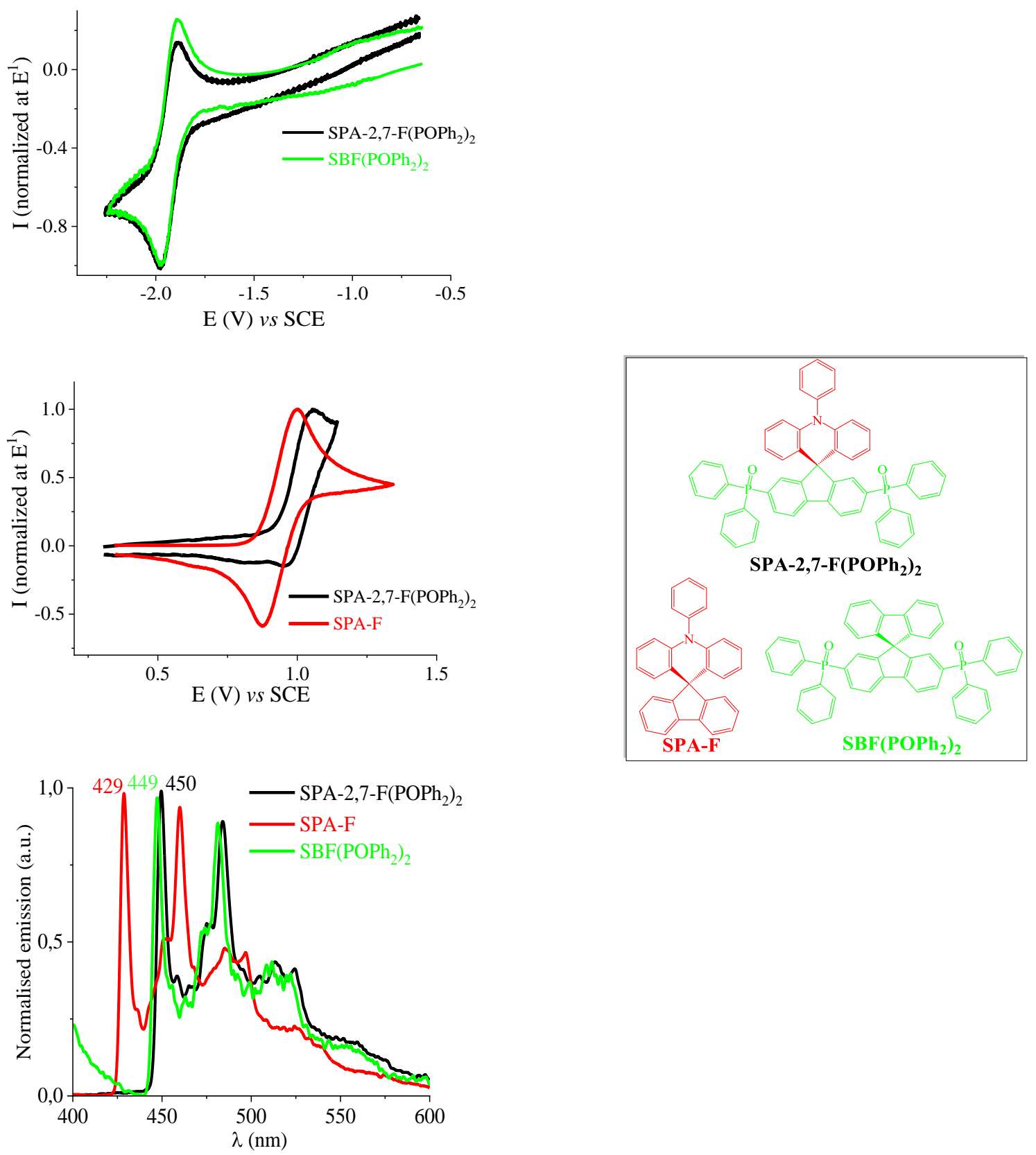

Figure 3. Top. Normalized cyclic voltammograms of SPA-2,7-F( $\mathbf{P O P h})_{2}$ (black lines), $\mathbf{S B F}(\mathbf{P O P h})_{2}$ (green lines) and SPA-F (red lines) in the cathodic (left, DMF $+\mathrm{BuN}_{4} \mathrm{PF}_{6} 0.1 \mathrm{M}$ ) or the anodic (right, $\mathrm{CH}_{2} \mathrm{Cl}_{2}+\mathrm{Bu}_{4} \mathrm{NPF}_{6} 0.2 \mathrm{M}$ ) range. Sweep-rate of $100 \mathrm{mV} \cdot \mathrm{s}^{-1}$, platinum disk working electrode. Bottom: Normalized emission spectra at $77 \mathrm{~K}$ in 2-MeTHF $\left(\lambda_{\text {exc }}=310 \mathrm{~nm}\right.$, left $)$ and molecular structures (right) of SPA-F, SBF $\left(\mathbf{P O P h}_{2}\right)_{2}$ and SPA-2,7-F $\left(\mathbf{P O P h}_{2}\right)_{2}$.

Understanding the optical properties is also important in such a design. The authors note that the phosphorescence contribution of $\mathbf{S B F}(\mathbf{P O P h})_{2}$ and that of $\mathbf{S P A}-2,7-\mathbf{F}(\mathbf{P O P h})_{2}$ are almost superimposable, meaning that the $\mathrm{E}_{\mathrm{T}}(2.76 \mathrm{eV})$ is not influenced by the donor part and hence fully governed by the 2,7-(diphenylphosphine oxide)-fluorene (Figure 3, bottom left). Thus, SPA-2,7- 
$\mathbf{F}(\mathbf{P O P h})_{2}$ provides a rational combination of the model compounds properties (electrochemical, optical and charge transport).

SPA-2,7-F(POPh $\left.)_{2}\right)_{2}$ used as host for FIrpic in device D16 displays excellent performances with a high EQE of $18 \%$, a CE of $39 \mathrm{~cd} / \mathrm{A}$ and a PE of $38.4 \mathrm{~lm} / \mathrm{W}$ (recorded at $0.04 \mathrm{~mA} / \mathrm{cm}^{2}$, Table 1). Benchmark blue SL-PhOLEDs with the two model compounds SPA-F (D20) and $\mathbf{S B F}\left(\mathbf{P O P h} \mathbf{P}_{2}\right.$ (D19) as host were also investigated and revealed very low performances (EQE <1\%) whereas their combination in SPA-2,7-F(POPh $\mathbf{P}_{2}$ leads to high performance PhOLEDs. This is a key point.

In the light of this work, the authors assigned the performances difference between SPA-2,7$\mathbf{F}(\mathbf{P O P h})_{2}$ and its model compounds to the energy levels adjustment and the bipolarity, made from the association of the two molecular fragments, ie phenylacridine and 2,7-(diphenylphosphine oxide)-fluorene, which appeared very efficient to reach high performance blue SL-PhOLEDs. ${ }^{[52]}$

Two other bipolar hosts (SPA-3,6-F(POPh $)_{2}$ and SPA-2-FPOPh $\left.\mathbf{P h}_{2}\right)$ constructed on the association of the electron-rich phenylacridine ${ }^{[53,54]}$ and the electron-poor diphenylphosphine oxide were then investigated by the same group. ${ }^{[55]}$ The position (C2 and $\mathrm{C} 7$ vs $\mathrm{C} 3$ and $\mathrm{C} 6$ ) and the number (1 vs 2) of 2,7-(diphenylphosphine oxide)-fluorene units on the fluorene backbone have been studied. Oppositely to para-substituted fluorenes (positions C2 and C7), widely developed for OE applications since 30 years, ${ }^{[57]}$ meta-substituted fluorenes (positions C3 and C6) have only been investigated recently. ${ }^{[43,44]}$ The meta-substitution leads to drastically different electronic and structural properties compared to the para-substitution and has already been advantageously used in the design of very efficient high $\mathrm{E}_{\mathrm{T}}$ materials for PhOLEDs. ${ }^{[11,37]}$ The C3-substituted fluorene is nowadays among the most efficient scaffolds in the field. ${ }^{[37]}$

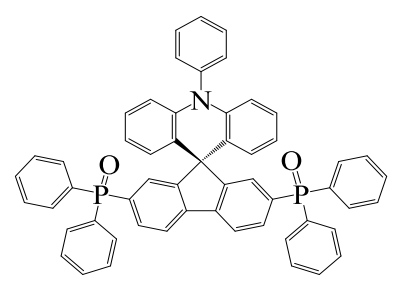

SPA-2,7-F $\left(\mathrm{POPh}_{2}\right)_{2}$

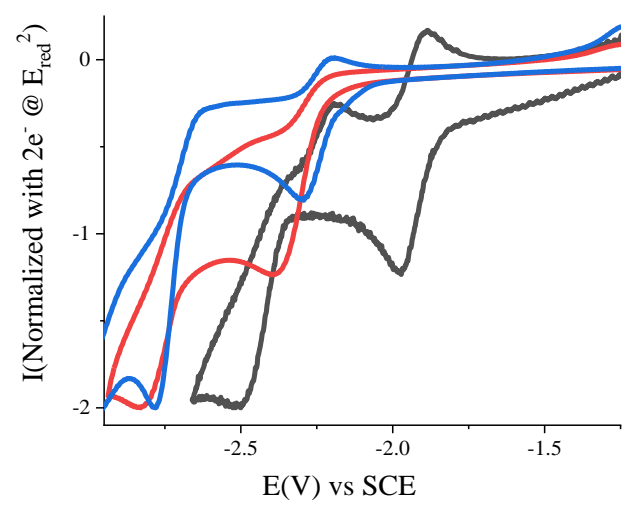

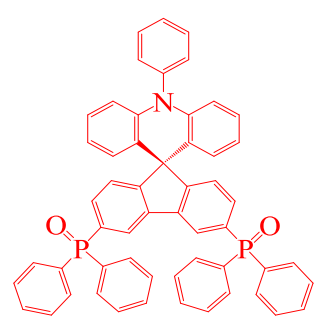

SPA-3,6-F $\left(\mathrm{POPh}_{2}\right)_{2}$

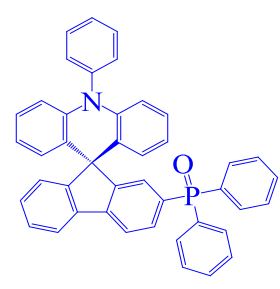

SPA-2-FPOPh

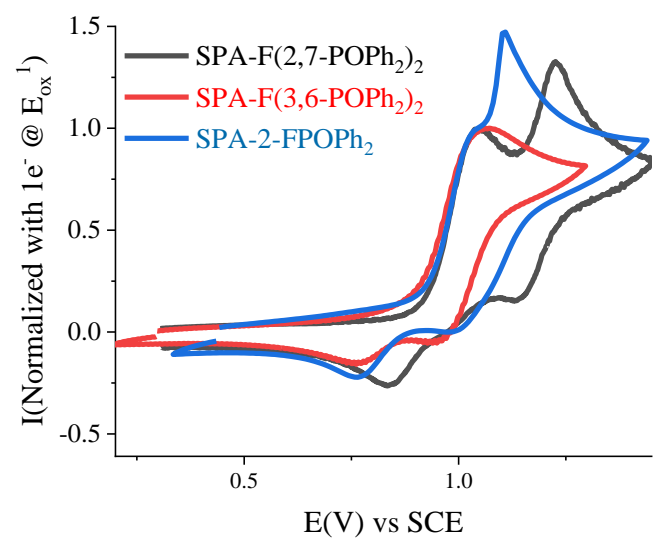

Figure 4. Normalized cyclic voltammograms of $\mathbf{S P A}-\mathbf{2 , 7 - F}(\mathbf{P O P h})_{2}$ (black lines), SPA-3,6-F(POPh $)_{2}$ (red lines) and SPA-2-FPOPh $\mathbf{H}_{2}$ (blue lines) in the cathodic (left, DMF $+\mathrm{BuN}_{4} \mathrm{PF}_{6} 0.1 \mathrm{M}$ ) or the anodic (right, $\mathrm{CH}_{2} \mathrm{Cl}_{2}+\mathrm{Bu}_{4} \mathrm{NPF}_{6} 0.2$ M) range. Sweep-rate: $100 \mathrm{mV} . \mathrm{s}^{-1}$, platinum disk working electrode.

The three molecules SPA-2,7-F(POPh $)_{2}$, SPA-2-FPOPh 2 and SPA-3,6-F $\left(\mathbf{P O P h}_{2}\right)_{2}$ display hence different electronic properties (HOMO/LUMO energy levels, absorption and emission, charge 
transport) and therefore a very different behaviour as host in PhOLEDs. The tuning of the HOMO/LUMO energy levels, which are key data for such applications, are particularly interesting. Thanks to electrochemistry in solution, the HOMO/LUMO levels have been evaluated at $-5.33 \mathrm{eV}$ for both SPA-2,7-F(POPh $)_{2}$ and SPA-2-FPOPh ${ }_{2}$ and at -5.31 eV SPA-3,6-F(POPh $)_{2}$. Similarly, the LUMO levels have respectively been evaluated at $-2.55 \mathrm{eV},-2.23 \mathrm{eV}$ and $-2.18 \mathrm{eV}$ for SPA-2,7$\mathbf{F}\left(\mathbf{P O P h}_{2}\right)_{2}$, SPA-2-FPOPh 2 and SPA-3,6-F(POPh $)_{2}$. Thus, the HOMO are lying at almost identical energy levels $(-5.31 /-5.33 \mathrm{eV})$ as the first oxidation occurs on the phenylacridine unit for the three compounds. The LUMOs display a different behaviour assigned to both the number and the position of the diphenylphosphine oxide units. Thus, SPA-2,7-F(POPh $\mathbf{2}_{2}$ displays the lowest LUMO energy level in the series due to the positions of the electron accepting diphenylphosphine oxides at $\mathrm{C} 2$ and $\mathrm{C} 7$ of the fluorene unit, which allows an electronic coupling as seen with many fluorene-based systems. ${ }^{[43,44]}$ The LUMO of SPA-2-FPOPh $\mathbf{2}(-2.23 \mathrm{eV})$ is higher than that of $\mathbf{S P A - 2 , 7 - F}(\mathbf{P O P h})_{2}$ $(-2.55 \mathrm{eV})$ as only one diphenylphosphine oxide is attached at C2. Finally, SPA-3,6-F $(\mathbf{P O P h})_{2}$ displays the highest LUMO energy $(-2.18 \mathrm{eV})$, as the diphenylphosphine oxides attached at C3/C6 (meta position of the biphenyl linkage), have a weaker electron withdrawing effect on the fluorene backbone than at C2/C7 (para position of the biphenyl linkage). ${ }^{[43]}$

The authors have also shown that the other key properties, $\mathrm{E}_{\mathrm{T}}$ and hole/electron mobilities, are modified by the molecular arrangement (Table 8). Thus, there are significant differences between $\mu_{\mathrm{h}}$ and $\mu_{\mathrm{e}}$ of SPA-2,7-F(POPh $)_{2}$, SPA-2-FPOPh 2 and SPA-3,6-F(POPh $)_{2}$ estimated to be $8.2 \times 10^{-6}$ and $2 \times 10^{-4} \mathrm{~cm}^{2} \mathrm{~V}^{-1} \mathrm{~s}^{-1}, 1.9 \times 10^{-7}$ and $1.3 \times 10^{-5} \mathrm{~cm}^{2} \mathrm{~V}^{-1} \mathrm{~s}^{-1}, 1.4 \times 10^{-8}$ and $3.1 \times 10^{-6} \mathrm{~cm}^{2} \mathrm{~V}^{-1} \mathrm{~s}^{-1}$, respectively. SPA-2,7-F(POPh$)_{2}$ displays the highest mobility both in hole and electron. In addition, SPA-2,7-F(POPh $)_{2}$ does not only possess the highest values but also the most balance charge transport. This is particularly important because when the charge transport is not balanced, the recombination zone is located close to the metal electrodes and lead to excitons quenching by the electrodes, reducing therefore the device efficiency. This is surely the reason of the better performance of SPA-2,7-F(POPh $)_{2}$ (D16) compared to SPA-3,6-F(POPh $)_{2}$ (D17) and SPA-2$\mathrm{FPOPh}_{2}(\mathrm{D} 18)$.

The sky blue SL-PhOLEDs using either SPA-3,6-F(POPh $)_{2}\left(\right.$ EQE $6.5 \%$ and $\left.\mathrm{V}_{\text {on }} 3.5 \mathrm{~V}\right)$ or SPA-2$\mathbf{F P O P h}_{2}\left(\mathrm{EQE} 8.6 \%\right.$ and $\left.\mathrm{V}_{\text {on }} 2.8 \mathrm{~V}\right)$ have shown lower performance than those of SPA-2,7$\mathbf{F}\left(\mathbf{P O P h}_{2}\right)_{2}\left(\mathrm{EQE} 18 \%\right.$ and $\left.\mathrm{V}_{\text {on }} 2.5 \mathrm{~V}\right)$ despite the $\mathrm{E}_{\mathrm{T}}$ were higher for the formers than for the latter. This shows that this parameter is not, in this case, the predominant factor. The authors have correlated the lower performances of SPA-3,6-F $\left(\mathbf{P O P h}_{2}\right)_{2}$ and SPA-2-FPOPh $\mathbf{S O}_{2}$ to many factors: gap extension leading to a $\mathrm{V}_{\text {on }}$ increase; higher LUMO energy level fitting less the LUMO of FIrpic; lower and less balanced mobility of charge carrier as exposed above. 

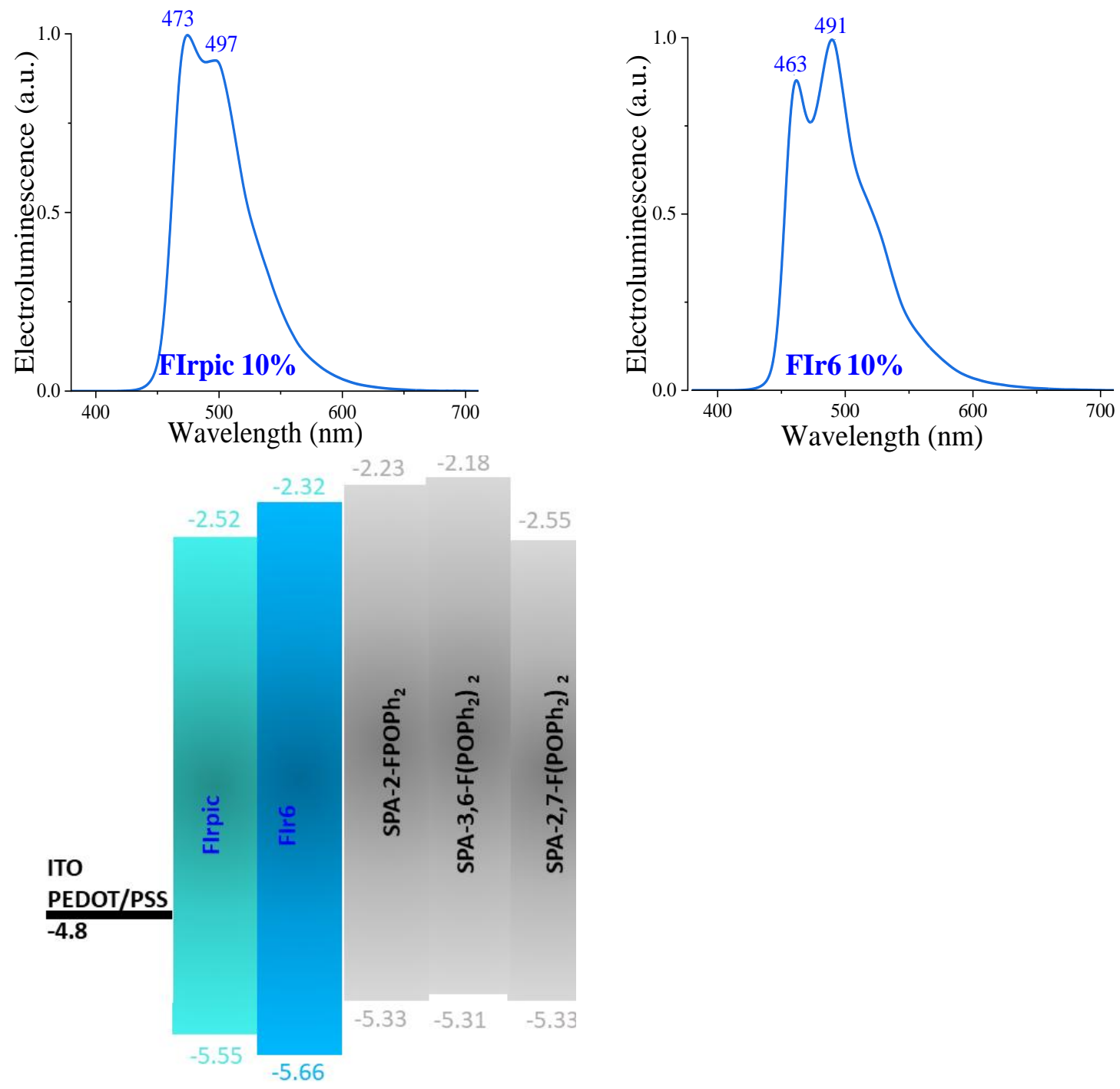

Figure 5. Top. Normalized EL spectra of FIrpic-based (Left) and FIr6-based (Right) SL-PhOLEDs using SPA-2$\mathbf{F P O P h}_{2}$ as host (D18 and D23). ${ }^{[32]}$ Bottom. Schematic energy diagrams of the different components used in the EML of blue SL-PhOLEDs in the case of SPA-F-POPh ${ }_{2}$ family.

In all these examples, FIrpic is used as emitter but its CIE coordinates are far to be in the deep blue region. FIr6 is another blue emitter, which has a blue shifted emission spectrum compared to FIrpic ( $\lambda=$ 463, $491 \mathrm{~nm}$ for FIr6 vs 473, $497 \mathrm{~nm}$ for FIrpic, Figure 5). This phosphor has been studied in ML-PhOLEDs ${ }^{[58-60]}$ but very rarely in SL-PhOLEDs. Actually, there is, as far as we know, only one example reported so $\operatorname{far}^{[32]}$ (note that one example is reported but using a polymer host/co-host strategy $\left.{ }^{[61]}\right)$. Thus, SPA-2,7-F(POPh $)_{2}, \mathbf{S P A - 3 , 6 - F (}\left(\mathbf{P O P h}_{2}\right)_{2}$ and $\mathbf{S P A - 2 - F P O P h}$ have been incorporated as host for FIr6. ${ }^{[32]}$ All the devices emit the blue emission of FIr6 and the highest performance between the three hosts was obtained for device D23 using SPA-2-FPOPh 2 as host with a maximum EQE of $9.1 \%$. The authors note that this EQE is higher than that recorded with FIrpic (D18) and assigned this feature to the LUMO level of SPA-2-FPOPh that of FIr6 (-2.23 vs $-2.32 \mathrm{eV}$, see Figure 5-Bottom). The two other hosts display EQE of $6.5 \%$ (D21 and D22). In this example, the performance of SPA-2,7-F(POPh $)_{2}$ with FIr6 appears particularly low especially when compared to that of FIrpic. This example shows that SL-PhOLED performance not only depends on the host but also on the host/guest combination. In the light of the encouraging performance reached with SPA-2-FPOPh $\mathbf{P}_{2}$, it is clear that this performance will be 
overpassed in the future with device optimization (thickness of the EML, cathode/anode modification).

To conclude, all these examples reveal how each parameter of the host matrix (HOMO/LUMO energy level adjustment with electrodes and guest, high $\mathrm{E}_{\mathrm{T}}$, high and balanced charge carriers mobility) influences the emission of the guest phosphor within the device and how a subtle combination of these parameters is required. It is difficult to provide precise chemical design guidelines as a compromise between all these parameters should always be found. Well balanced charge transport remains nevertheless a key point to reach very high performance. We believe that structure-properties relationship approaches with series of host/guest tested in identical conditions are very important to analyse the efficiency of a device and to improve the knowledge in the field. This also shows the difficulty to design universal host materials for all the colours of PhOLEDs. This is detailed below.

\section{b. Green SL-PhOLEDs}

The most popular green phosphor used in the field of green SL-PhOLEDs is the tris[2phenylpyridinato- $\mathrm{C}^{2}, N$ ]iridium(III) commonly abbreviated $\operatorname{Ir}(\mathbf{p p y})_{\mathbf{3}}{ }^{\left[{ }^{62]}\right.}$ This phosphor displays an $\mathrm{E}_{\mathrm{T}}$ of $2.43 \mathrm{eV}$ (measured in 2-MeTHF at $\mathrm{RT},{ }^{[32]}$ other values exist depending of the experimental conditions, see $\left.{ }^{[32]}\right)$ and is considered as a green emitter $\left(\lambda_{\max }=511 \mathrm{~nm}\right.$ in $\left.2-\mathrm{MeTHF}^{[32]}\right)$. Its $\mathrm{HOMO} / \mathrm{LUMO}$ energy levels obtained from electrochemical studies in $\mathrm{CH}_{2} \mathrm{Cl}_{2}+\mathrm{Bu}_{4} \mathrm{NPF}_{6} 0.2 \mathrm{M}$ are of $-4.97 /-2.19 \mathrm{eV} .^{[32]}$

In the history of PhOLEDs, green-emitting PhOLEDs have been the first to reach very high efficiency. ${ }^{[27,50,63-68]}$ The first green SL-PhOLED (D24) has been reported in 2002 by Burn, Samuel and their co6workers and has displayed an EQE of $8.1 \%$, which was a very high value at this time. ${ }^{[27]}$ In this work, the authors have used one of the most studied host material at the beginning of the field, namely, 4,4'-Bis(N-carbazolyl)-1,1'-biphenyl (CBP) to host different dendritic Iridium complexes. CBP is a hole transporting material with $\mu_{\mathrm{h}}$ one decade higher than $\mu_{\mathrm{e}}\left(\mu_{\mathrm{h}}: 21.2 \times 10^{-5} \mathrm{~cm}^{2}\right.$ $\mathrm{V}^{-1} \mathrm{~s}^{-1}$ and $\mu_{\mathrm{e}}: 2.1 \times 10^{-5} \mathrm{~cm}^{2} \mathrm{~V}^{-1} \mathrm{~s}^{-1}$ measured by TOF technique on a single crystal $\left.{ }^{[69]}\right)$. The authors noted that the performance of a dendrimer Iridium complex G1 (See structure in Figure 6) in a solution processed SL-PhOLED (ITO/EML/Ca/Al) was significantly higher than that of the classical $\operatorname{Ir}(\mathbf{p p y})_{3}$ phosphor (D25: EQE of $8.1 \%$ vs $0.8 \%$ ). This work has not only shown the efficiency of such dendritic phosphors (especially since a neat ITO is used) but has also paved the way to other simplified PhOLEDs. Indeed, more sophisticated dendritic systems incorporating the iridium metal decorated by a host shell have also been approached in literature. These SL-PhOLEDs called 'selfhost' or 'non-doped' PhOLEDs are presented below in Part II.

In 2008, Kakimoto group synthesized two bipolar host molecules combining one hole-transporting triphenylamine and three electron-transporting benzimidazole moieties through three metasubstituted phenyl links (TBBI and Me-TBBI, Figure 6). ${ }^{[70]}$ The meta-substituted and star-shaped configuration was adopted to keep a high $\mathrm{E}_{\mathrm{T}}$ and to improve the solubility and the amorphous stability of the materials. Three green SL-PhOLEDs were constructed with the following architecture: ITO/PEDOT:PSS(20nm)/Host:Ir(ppy) $6 \%(70 \mathrm{~nm}) / \mathrm{Cs}: \mathrm{BCP}(1: 1)(20 \mathrm{~nm} / \mathrm{Al}(100 \mathrm{~nm})$. In this series, solution processed Me-TBBI-based device D26 displays the highest performance with $\mathrm{EQE}=4.5 \%$, and $\mathrm{CE}=27.4 \mathrm{~cd} / \mathrm{A}(\mathrm{EQE}$ of $2.2 \%$ and $1.1 \%$ were reported for the other devices using TE-TBBI:Ir(ppy) (D27) and SP-TBBI:Ir(ppy) $_{3}$ (D28), see Table 2). All these performances are nevertheless low and the difference between the two hosts can be assigned, at least partially, to the higher $\mathrm{E}_{\mathrm{T}}$ of Me-TBBI vs TBBI (2.76 vs $2.59 \mathrm{eV}$ ). 


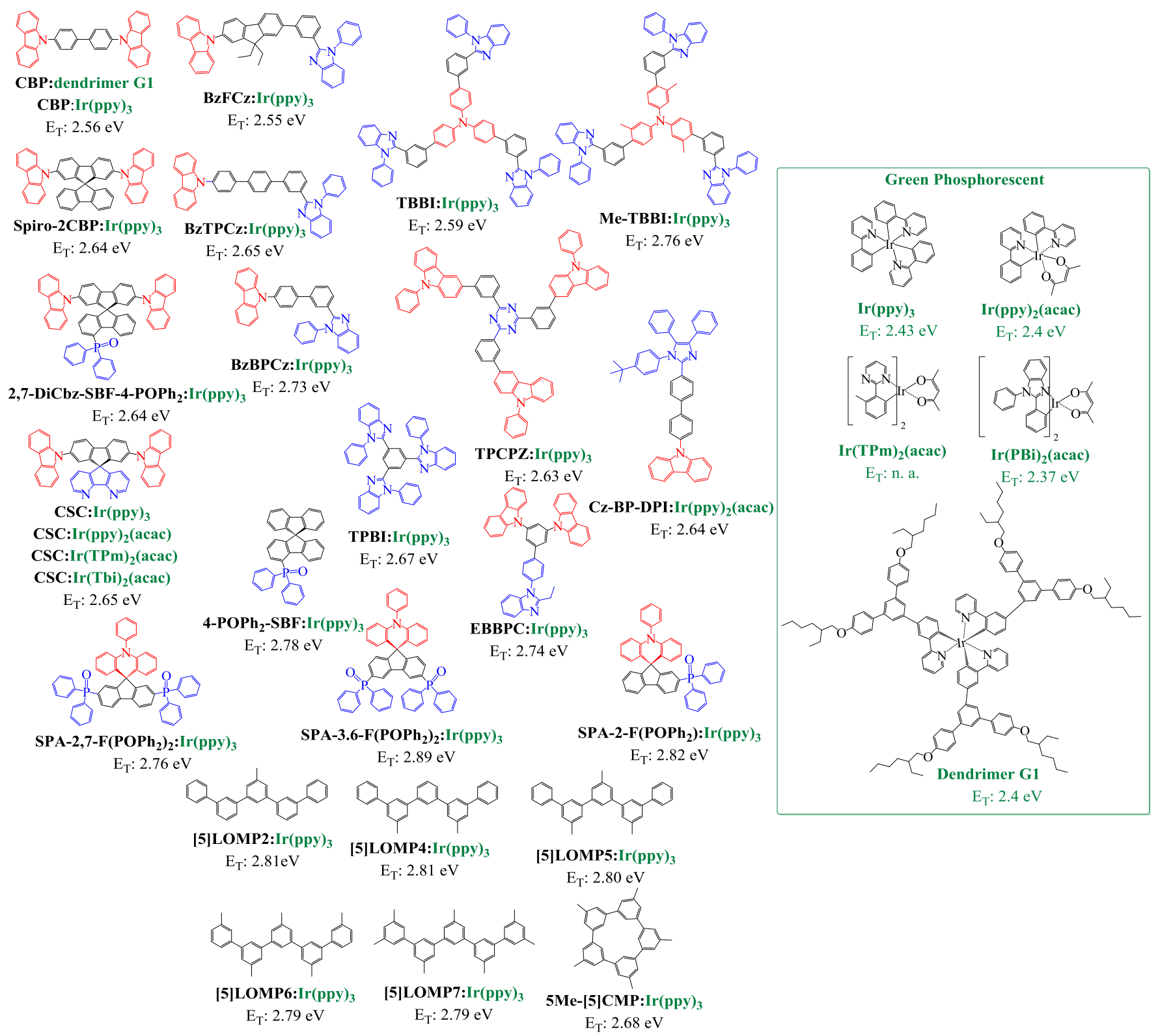

Figure 6. Molecular structure of host materials and green phosphors used in green SL-PhOLEDs. $\mathrm{E}_{\mathrm{T}}$ in black (green) is that of the host (phosphorescent emitter). In the host materials, black, blue and red fragments respectively point the $\pi$ linker, the acceptor and the donor units of the OSC.

In 2009, the donor carbazole $(\mathbf{C z})$ /acceptor benzimidazole $(\mathbf{B z})$ combination was investigated by Lin, $\mathrm{Wu}$ and their co6workers. ${ }^{[65]}$ The influence of the linker between the donor and the acceptor units on the device performance was investigated. Three different $\pi$-conjugated bridges were studied, ie biphenyl, terphenyl and phenyl-fluorenyl. Thus, BzBPCz, BzTPCz and BzFCz present very similar HOMO/LUMO energy levels (-5.65/-2.11, -5.65/-2.16 eV and $-5.62 /-2.20$, respectively) due to the very weak interaction between the donor $\mathbf{C z}$ and acceptor $\mathbf{B z}$ units. This is the consequence of the meta linkage between these two fragments, which is known to strongly disrupt the $\pi$-conjugation (despite a coupling exists ${ }^{[43,44]}$ ). However, the nature of the bridge (biphenyl in BzBPCz, terphenyl in BzTPCz or phenyl-fluorenyl in $\mathbf{B z F C z}$ ) also drives the $\mathrm{E}_{\mathrm{T}}$ values, which appear to be very different $(2.73,2.65$ and $2.55 \mathrm{eV}$ respectively, measured in toluene at $77 \mathrm{~K})$. Note that an isomer of $\mathbf{B z F C z}$ is also reported in this work, in which the benzimidazole unit is connected in para position of the pending phenyl ring (whereas it is in meta position in $\mathbf{B z F C z}$ ). This provides to this para isomer 
a lower $\mathrm{E}_{\mathrm{T}}$ of $2.39 \mathrm{eV}(2.55 \mathrm{eV}$ for $\mathbf{B z F C z})$ rendering the molecule not suitable to host $\mathbf{I r}(\mathbf{p p y})_{\mathbf{3}}\left(\mathrm{E}_{\mathrm{T}}\right.$ $=2.43 \mathrm{eV}$ ). The effect of ortho/para/meta linkages on the $\mathrm{E}_{\mathrm{T}}$ has been the subject of many studies in the last years in order to finely tune the electronic properties of host materials for OLEDs. ${ }^{[1,37,43,44,}$ 71,72] This is an important molecular design concept.

Table 2. EL performances of green SL-PhOLEDs (D24 to D61)

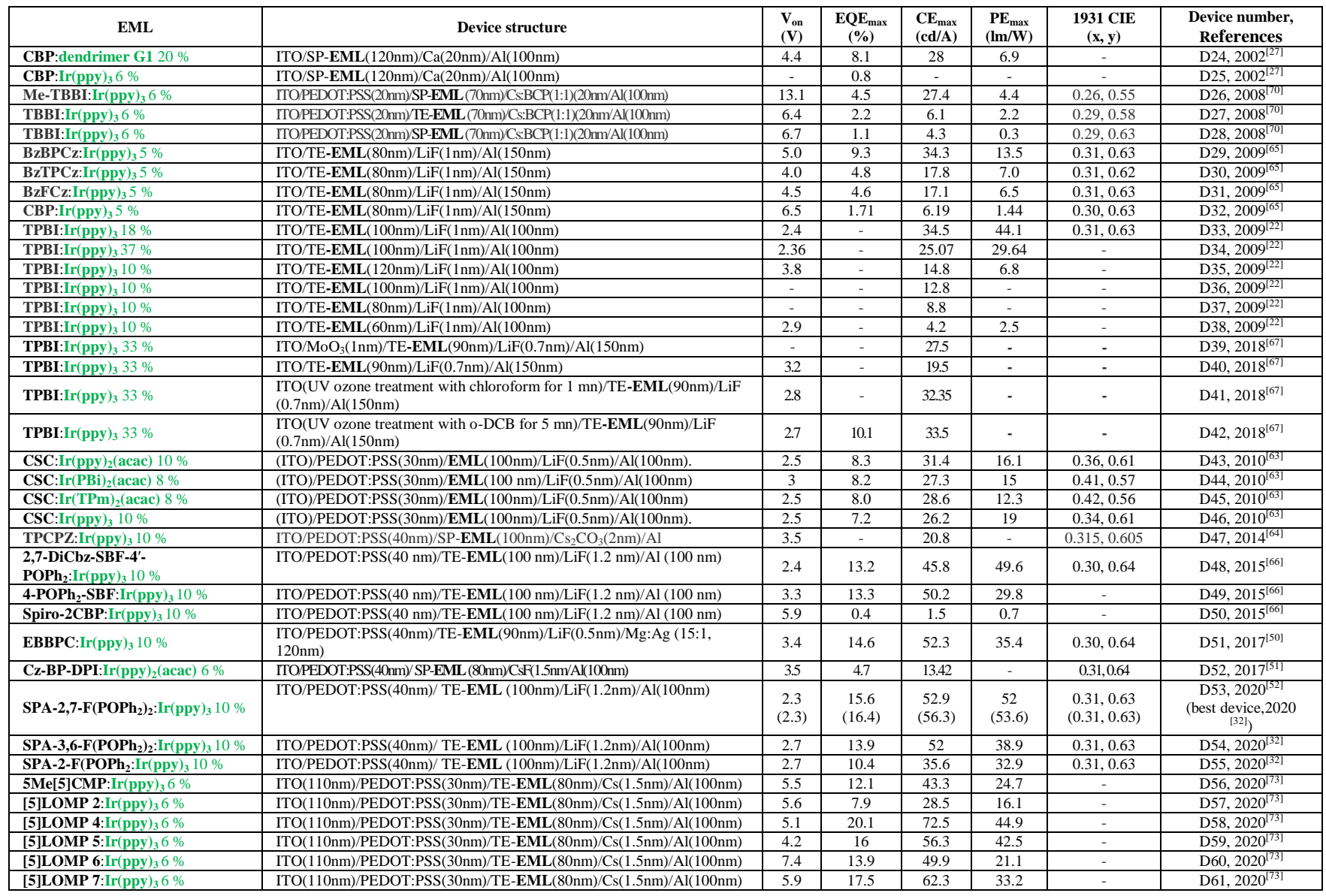

SP for solution processed and TE for thermally evaporated

BzFCz, BzTPCz and BzBPCz have been incorporated in green SL-PhOLEDs ((ITO/Host: $\operatorname{Ir}(\text { ppy })_{3}$ $5 \%(80 \mathrm{~nm}) / \mathrm{LiF}(1 \mathrm{~nm}) / \mathrm{Al}(150 \mathrm{~nm}))$ with different efficiencies. BzFCz (D31) and BzTPCz (D30) both present a low EQE of 4.6 and $4.8 \%$ respectively, whereas $\mathbf{B z B P C z}$ (D29) displays a relatively high EQE of $9.3 \%$. As BzBPCz does not display the best hole/electron mobility balance in this series $\left(\mu_{\mathrm{e}} / \mu_{\mathrm{h}}\right.$ : 0.13 for $\mathbf{B z B P C z}, 0.24$ for $\mathbf{B z T P C z}$ and 1 for $\mathbf{B z F C z}$ ) (Table 8), its highest performance can be assigned to its higher $\mathrm{E}_{\mathrm{T}}\left(\mathrm{E}_{\mathrm{T}}(\mathrm{film})=2.61,2.41\right.$ and $2.40 \mathrm{eV}$ for $\mathbf{B z B P C z}$, BzTPCz and BzFCz respectively). It is also interesting to note that a device with the same architecture using CBP as host (D32) was also fabricated and tested for comparison purpose. Although CBP ( $\mathrm{E}_{\mathrm{T}}(\mathrm{film})$ : $2.56 \mathrm{eV}$ ) has a slightly larger $\mathrm{E}_{\mathrm{T}}$ than $\mathbf{B z T P C z}$ and BzFCz, D32 displays lower performance than D30 and D31. This lower performance can be assigned to the hole/electron mobility balance in CBP $\left(\mu_{\mathrm{e}} / \mu_{\mathrm{h}}\right.$ : 0.1), which is lower than for the other compounds investigated in this study. In any case, this shows the difficulty to combine all the required properties to reach high performance devices. This also confirms the importance to synthesize series of molecules and to study them in strictly identical conditions in order to provide accurate conclusions and to make rational progresses in the materials design. In this work, it is particularly important to mention that a neat ITO is used and reaching, in these conditions, an EQE above $9 \%$ appeared particularly interesting. 
Moreover, the comparison of device D25 using a solution-processed CBP:Ir(ppy) $)_{3}$ EML with device D32 with a thermally evaporated CBP:Ir(ppy) $)_{3}$ EML, shows the higher performance of D32 (EQE: $0.8 / 1.71 \%$ for D25/D32) and points the influence of the fabrication process on the performances.

TPBI, presented above as host for blue SL-PhOLEDs (D2, Table 1) has also been used as host in green PhOLEDs with different efficiencies. ${ }^{[22]}$ The performances were dependent on (i) the thickness of the EML (D35-D38) and on (ii) the dopant concentration (D33, D34, D36) (reaching CE of 34.5 $\mathrm{cd} / \mathrm{A}$ and PE of $44.1 \mathrm{~lm} / \mathrm{W}$ with TPBI:Ir(ppy) $18 \%$ as EML, D33). Interestingly, the authors also perform device engineering works improving the efficiencies by inserting a dopant between the anode and the EML, reaching a "single-component device", which will be described in Part II (D163).

In 2018, TBPI has again been used as host material in a study centred on device engineering of SLPhOLEDs (D39-D42). First, two devices with $\mathrm{ITO} / \mathrm{MoO}_{3}$ or neat ITO as anode and a dopant concentration of $33 \%$ were constructed and tested (D39-D40). These devices reached a $\mathrm{CE}_{\max }$ of $27.5 / 19.5 \mathrm{~cd} / \mathrm{A}$ indicating similar performances than the previous device D34 $\left(\mathrm{CE}_{\max }\right.$ of $\left.25 \mathrm{~cd} / \mathrm{A}\right)$ with neat ITO anode and a dopant concentration of $37 \%$. Note that these doping concentrations (above $30 \%$ ) are very high. An interesting performance enhancement of the devices using chlorinated ITO (Cl-ITO) as the anode has then been demonstrated (D41-D42). ${ }^{[67]}$ The WF of the Cl-ITO is measured by UPS at ca $5.3 \mathrm{eV}$, whereas that of bared ITO is ca $4.7 \mathrm{eV}$. The improvement in anode WF allows the direct hole injection into the HOMO of the phosphorescent dopant. As a result, SL-PhOLEDs using TPBI as host displays a high CE of $33.5 \mathrm{~cd} / \mathrm{A}$ and an EQE of $10.1 \%$ in device D42. It should be precise that the anode modification is technically simple and consists of a UV ozone treatment of ITO anode with various chlorinated solvents (chloroform, chlorobenzene, 1,2-dichlorobenzene). The highest performances were achieved via exposing ITO to 1,2dichlorobenzene under UV radiation for $5 \mathrm{~min}$. Compared to bare ITO (D40), the performance of the device D42 was nearly twice $(19.5 \mathrm{~cd} / \mathrm{A}$ vs $33.5 \mathrm{~cd} / \mathrm{A})$. These results show that control of the hole injection from the anode to balance the carriers and increase the recombination is important to attain high CE in SL-PhOLEDs.

In 2010, the growing interest towards spiro compounds in electronics ${ }^{[44,57,74]}$ has led Wong and their co-workers to design a spiro-configured ambipolar host material, namely 4,5-diaza-2',7'bis(carbazol-9-yl)-9,9'-spirobifluorene (CSC). ${ }^{[63]}$ In this ambipolar host, the acceptor unit is a diazafluorene unit and the donor part is a carbazole/fluorene/carbazole fragment also found in the very efficient host 2,7-DiCbz-SBF-4'-POPh (detailed below). ${ }^{[66]}$ It should be mentioned that the diazafluorene unit is an interesting rigid acceptor fragment, which has not been very often studied to date in the design of host materials. ${ }^{[53,75]}$ In the design of CSC, the spiro carbon avoids a strong coupling between the donor part and the acceptor part but the presence of the two carbazole units at $\mathrm{C} 2$ and $\mathrm{C} 7$ of the fluorene unit decreases the $\mathrm{E}_{\mathrm{T}}$ to $2.65 \mathrm{eV}$ (measured at $77 \mathrm{~K}$ in ethanol). Thus, thanks to its triplet energy, suitable frontiers molecular orbitals energy levels $(\mathrm{HOMO}=-5.63 \mathrm{eV}$; LUMO $=-2.36 \mathrm{eV})$, and well-balanced carrier mobilities $\left(\mu_{\mathrm{e}}=\mu_{\mathrm{h}}=10^{-6} \mathrm{~cm}^{2} \mathrm{~V}^{-1} \mathrm{~s}^{-1}\right)$, CSC was successfully used as a host material in SL-PhOLED for a series of green iridium complexes $\operatorname{Ir}(\mathbf{p p y})_{2}(\mathbf{a c a c}), \operatorname{Ir}(\mathbf{p p y})_{3}, \operatorname{Ir}(\mathbf{P B i})_{2}(\mathbf{a c a c})$ and $\operatorname{Ir}(\mathbf{T P m})_{2}(\mathbf{a c a c})(\mathrm{D} 43-\mathrm{D} 46)$. The device architecture is ITO/PEDOT:PSS(30 nm)/CSC:dopant $(100 \mathrm{~nm}) / \mathrm{LiF}(0.5 \mathrm{~nm}) / \mathrm{Al}(100 \mathrm{~nm})$. The best device performance was reached for D43 with CSC:10 \% $\mathbf{I r}(\mathbf{p p y})_{\mathbf{2}}$ (acac) as EML for which an EQE of 8.3 $\%(\mathrm{CE}$ of $31.4 \mathrm{~cd} / \mathrm{A}, \mathrm{PE}: 16.1 \mathrm{~lm} / \mathrm{W})$ was recorded. The three other devices using $\mathbf{C S C}$ as host and different green phosphors displayed a similar efficiency with EQE/CE/PE of $8.2 \% / 27.3 \mathrm{~cd} / \mathrm{A} / 15$ $\mathrm{lm} / \mathrm{W}$ for CSC: $8 \%(\mathbf{P B i})_{2} \mathbf{I r}$ (acac) as EML (D44), with EQE/CE/PE of 8.0\%/28.6 cd/A/12.3 lm/W for CSC:8 \% (TPm) $)_{2} \mathbf{I r}$ (acac) as EML (D45) and with EQE/CE/PE of $7.2 \% / 26.2 \mathrm{~cd} / \mathrm{A} / 19 \mathrm{~lm} / \mathrm{W}$ for CSC: $10 \% \operatorname{Ir}(\mathbf{p p y})_{3}$ as EML (D46). Note that the emission was yellow green (CIE: 0.4, 0.55) with 
both $(\mathbf{P B i})_{2} \operatorname{Ir}(\mathbf{a c a c})$ and $(\mathbf{T P m})_{2} \operatorname{Ir}(\mathbf{a c a c})$ whereas it was yellowish-green (CIE: 0.3, 0.6) with $\operatorname{Ir}(\text { ppy })_{2}($ acac $)$ or $\operatorname{Ir}(\text { ppy })_{3}$.

In 2014, another interesting association was developed for green SL-PhOLEDs, also having the advantage to be solution processed. N-phenyl carbazole substituted 2,4,6-trisphenyl-triazine host material (TPCPZ) was synthesized. ${ }^{[64]}$ If the donor was the widely used N-phenyl carbazole fragment, the triazine acceptor was far less used. The latter is nevertheless nowadays an efficient acceptor recently incorporated in high performance TADF-OLEDs. ${ }^{[10,76]}$ The three carbazole units are connected in meta position via $\mathrm{C}-\mathrm{C}$ links to the central triazine core. This design resembles to that of TPBI described above and avoids a strong extension of the conjugation. The $\mathrm{E}_{\mathrm{T}}$ of TPCPZ is hence kept at $2.63 \mathrm{eV}$. The HOMO and LUMO energy levels $(-5.39 /-2.16 \mathrm{eV})$ match well with the HOMO of PEDOT:PSS (-5.35 eV) and the LUMO of $\mathrm{Cs}_{2} \mathrm{CO}_{3} / \mathrm{Al}$ bilayer cathode $(-2.2 \mathrm{eV})$ and facilitate therefore the transfer of holes and electrons. The solution-processed SL-PhOLED using TPCPZ as the host for $\operatorname{Ir}(\mathbf{p p y})_{3}$ exhibited a low $\mathrm{V}_{\text {on }}$ of $3.5 \mathrm{~V}$ and maximum $\mathrm{CE}$ of $20.8 \mathrm{~cd} / \mathrm{A}$.

In 2015, our group has reported an efficient bipolar host 2,7-DiCbz-SBF-4'-POPh ${ }_{2}$ for $\mathbf{I r}(\mathbf{p p y})_{3}$. $^{[66]}$ This molecule is a spirobifluorene substituted by two carbazole units at $\mathrm{C} 2 / \mathrm{C} 7$ and by a diphenylphosphine oxide at C4' (see X-Ray structure in Figure 7). This design resembles to that of CSC described above. Indeed, the donor unit is the same carbazole/fluorene/carbazole fragment but the diazafluorene of CSC is herein changed by a 4-diphenylphosphine oxide-fluorene. 2,7-DiCbzSBF-4'-POPh $\mathbf{P}_{2}$ judiciously uses the position C4 of the SBF core, which forms an ortho biphenyl linkage with the substituent. This position has been successfully investigated in the last years in electronics $^{[44,77]}$ especially to disrupt the $\pi$-conjugation between the fluorene core and the substituent linked, allowing to reach high $\mathrm{E}_{\mathrm{T}}$ host materials for PhOLED. ${ }^{[7,44,71,78]}$

Due to the substitution at $\mathrm{C} 2 / \mathrm{C} 7$, the $\mathrm{E}_{\mathrm{T}}$ is low $(2.64 \mathrm{eV})$ but thanks to its bipolarity, 2,7-DiCbzSBF-4'-POPh 2 appears very efficient when incorporated as host in a green SL-PhOLED (ITO/PEDOT:PSS(40 nm)/Host:Ir(ppy) $\left.)_{3}(10 \%)(100 \mathrm{~nm}) / \mathrm{LiF}(1.2 \mathrm{~nm}) / \mathrm{Al}(100 \mathrm{~nm})\right) .{ }^{[66]}$ This device (D48) possesses a high EQE of 13.2 \%, and maximum $\mathrm{CE}$ and $\mathrm{PE}$ as high as $45.8 \mathrm{~cd} / \mathrm{A}$ and 49.6 $\mathrm{lm} / \mathrm{W}$ respectively. A very low $\mathrm{V}_{\text {on }}$ of $2.4 \mathrm{~V}$ is also reported indicating excellent charge injection within the EML. In order to understand the effect of the carbazole/phosphine oxide combination on the device performance, benchmark devices using two model compounds corresponding to two fragments of the molecule, 4-POPh$-\mathbf{S B F}$ and Spiro-2CBP (Figure 6), were also investigated. Such a study is similar to that developed for SPA-2,7-F(POPh $)_{2}, \mathbf{S P A - 3 , 6 - F}\left(\mathbf{P O P h}_{2}\right)_{2}$ and SPA-2$\mathbf{F P O P h}_{2}$ and appears relevant to unravel the origin of the high performance reached by 2,7-DiCbzSBF-4'-POPh 2 . SL-PhOLED D50 using Spiro-2CBP as host displays very poor performance with an EQE of $0.4 \%$, assigned to its very bad electron transport capability. On the contrary, device D49 using 4-POPh $\mathbf{2}_{\mathbf{2}} \mathbf{- S B F}$ as host displays an EQE as high as that of 2,7-DiCbz-SBF-4'-POPh -based $^{-}$ PhOLED, ie $13.3 \%$ but with a higher $\mathrm{V}_{\text {on }}(3.3 \mathrm{~V})$. This study shows the predominant role of the phosphine oxide units on the device performance. Phosphine oxide unit is undoubtedly a key molecular fragment in the design of host materials for SL-PhOLEDs.
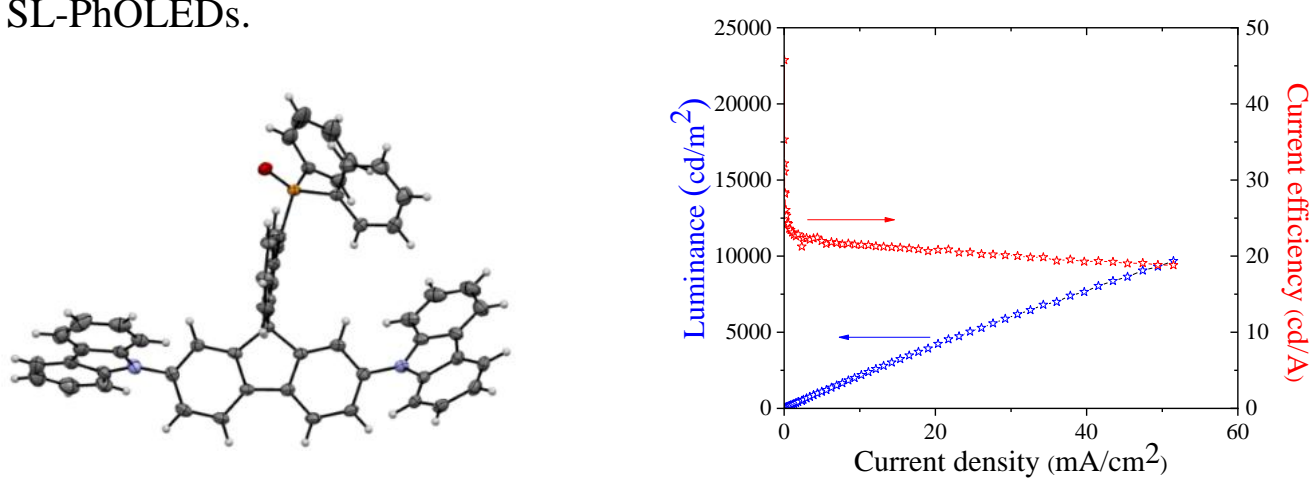
Figure 7. Left. ORTEP (50\% ellipsoid probability) of 2,7-DiCbz-SBF-4'-POPh 2 . Right. Luminance and current efficiency as a function of current density for the SL-PhOLED D48 (ITO/PEDOT:PSS/2,7-DiCbz-SBF-4'$\left.\mathbf{P O P h}_{2}: \operatorname{Ir}(\mathbf{p p y})_{\mathbf{3}}(10 \%) / \mathrm{LiF} / \mathrm{Al}\right)$.

In 2017, the performance of green SL-PhOLEDs has been increased to $14.6 \%$ with EBBPC as host for $\operatorname{Ir}(\mathbf{p p y})_{3}$ (D51). Note that the cathode of this device is $\operatorname{LiF}(0.5 \mathrm{~nm}) / \mathrm{Mg}: \mathrm{Ag}(1: 1 \mathrm{in}$ mass $)$ and not $\mathrm{LiF} / \mathrm{Al}$ as classically used. This excellent result confirms the good performance obtained with sky blue SL-PhOLEDs (FIrpic based device D14, EQE: $9.8 \%$, Table 1) and shows the versatility of EBBPC as universal host. ${ }^{[50]}$

In 2017, Cz-BP-DPI, already used as host for FIrpic (D15, Table 1), was also used as host for a green PhOLED with $\operatorname{Ir}(\mathbf{p p y})_{2}$ (acac) as phosphor (D52). Due to the similar $\mathrm{E}_{\mathrm{T}}$ values of Cz-BP-DPI and FIrpic (2.64 eV), the performance of D15 was very low (EQE: $0.0045 \%$, Table 1). In the green device D52, there is a better match between the host/guest $\mathrm{E}_{\mathrm{T}}$ values $(2.64 / 2.4 \mathrm{eV})$. Despite modest $\left(\mathrm{CE}=13.42 \mathrm{~cd} / \mathrm{A}\right.$ and $\left.\mathrm{EQE}_{\max }=4.7 \%\right)$, the performance of the green PhOLED D52 is greatly improved compared to that of D15 indicating a better energy cascade of excitons from Cz-BP-DPI to $\operatorname{Ir}(\mathbf{p p y})_{2}$ (acac). ${ }^{[51]}$
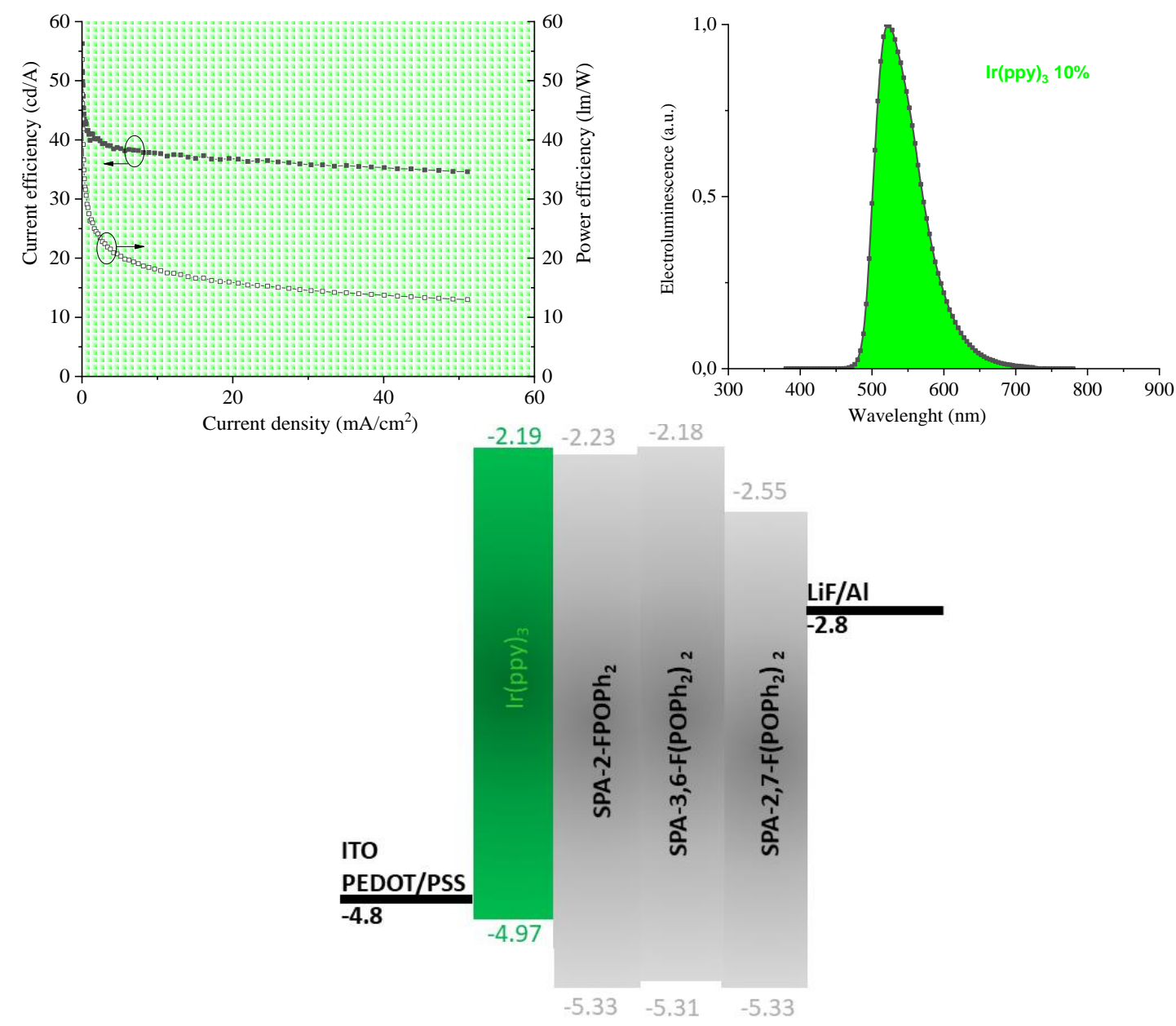

Figure 8. Top. Green emitting SL-PhOLED characteristics using as a host $\mathbf{S P A - 2 , 7 - F}(\mathbf{P O P h})_{2}$ and $\operatorname{Ir}(\mathbf{p p y})_{3}$ as emitter. Left. Current efficiency $(\mathrm{cd} / \mathrm{A})$ and power efficiency $(\mathrm{lm} / \mathrm{W})$ as a function of the current density $\left(\mathrm{mA} / \mathrm{cm}^{2}\right)$. Right. EL spectrum (D53) Bottom. Schematic energy diagrams of the different components used in the EML of green SLPhOLEDs in the case of SPA-F-POPh ${ }_{2}$ family 
As shown above for blue PhOLEDs, the phenylamine and phosphine oxide association in the host design appears to be one of the most efficient reported to date (D16-D18 and D21-D23, Table 1). SPA-2-FPOPh 2 , SPA-3,6-F(POPh $)_{2}$ and SPA-2,7-F $\left(\mathrm{POPh}_{2}\right)_{2}$ were also used as host for the green phosphor Ir(ppy) ${\text { (D53-D55, Table 2). }{ }^{[32]} \text { The lowest efficiency is reported for SPA-2-FPOPh }}_{2}$ (D55), which displays a maximal EQE of $10.4 \%$ (CE \& PE: $35.6 \mathrm{~cd} / \mathrm{A} \& 32.9 \mathrm{~lm} / \mathrm{W}$, Table 2 and Figure 8). The performances were increased with $\mathbf{S P A - 3 , 6 - F ( P O P h})_{2}$ : $\mathrm{EQE}=13.9 \%$ with corresponding $\mathrm{CE}$ of $52 \mathrm{~cd} / \mathrm{A}$ and $\mathrm{PE}$ of $38.9 \mathrm{~lm} / \mathrm{W}$ (D54). The best performance is obtained with SPA-2,7-F(POPh $)_{2}$ with an $\mathrm{EQE}_{\max }$ reaching $16.4 \%$, and corresponding $\mathrm{CE}$ of $56.3 \mathrm{~cd} / \mathrm{A}$ and $\mathrm{PE}$ of $53.6 \mathrm{~lm} / \mathrm{W}$ (D53). These performances are high for a series of structurally related hosts and show the efficiency of the phenylacridine/phosphine oxide combination.

It is interesting to note that these performances follow the trend reported for the FIrpic based PhOLEDs (D16-D18, Table 1) but not that of the FIr6 based PhOLED (D21-D23, Table 1). With an EQE of $16.4 \%$, published in 2020, SPA-2,7-F $\left.(\mathbf{P O P h})_{2}\right)_{2}$ was the highest reported at that time, ${ }^{[52]}$ but during the writing of this manuscript, this performance was overpassed (see below).

Finally, the last examples of highly efficient green SL-PhOLEDs were also reported in 2020 by Isobe and their co-workers (D56-D61). ${ }^{[73]}$ They have designed pure hydrocarbon (PHC) hosts constructed on the association of 5 phenylene units with either a cyclic architecture as 5Me-[5]CMP or a linear architecture as [5]LOMPx with $\mathrm{x}: 2,4,5,6$ or 7 (Figure 6). The linear compounds have been substituted with either one ([5]LOMP2), two ([5]LOMP4), three ([5]LOMP5), five ([5]LOMP6) or seven ([5]LOMP7) methyl substituents in order to investigate the effect of this simple chemical modification on the device performance. In $2-\mathrm{MeTHF}$ at $77 \mathrm{~K}$, these PHC materials possess an $\mathrm{E}_{\mathrm{T}}$ around $2.8 \mathrm{eV}$ for all the linear compounds and $2.68 \mathrm{eV}$ for the cyclic 5Me-[5]CMP. Interestingly, the authors also measured the $\mathrm{E}_{\mathrm{T}}$ as thin films at $77 \mathrm{~K}$ and showed that the $\mathrm{E}_{\mathrm{T}}$ are lowered by ca. 0.1 $\mathrm{eV}$ compared to the data obtained in a frozen matrix of 2-MeTHF. SL-PhOLEDs composed of a vapour deposited EML (Host:Ir(ppy) $6 \%$ ) between the anode (ITO/PEDOT:PSS) and the cathode $(\mathrm{Cs} / \mathrm{Al})$ were tested. The highest EQE $(20.1 \%)$ is recorded with the device based on [5]LOMP4 with two methyl groups (D58). Three other devices based on linear compounds have reached an EQE (17.5\%:[5]LOMP7, $16 \%:[5]$ [OMP5 and $13.9 \%:[5]$ LOMP6) higher than that based on the cyclic host 5Me-[5]CMP (EQE: 12.1\%, D56). Finally, the device based on the mono-methylated [5]LOMP2 has shown lower performance that the cyclic host 5Me-[5]CMP (EQE: $7.9 \%$ ).

To go deeper in the understanding of the PhOLED performance, the authors fabricated hole-only devices and measured the ratio of current density in a doped $\left(\mathrm{J}_{\text {doped }}\right)$ and an undoped $\left(\mathrm{J}_{\text {neat }}\right)$ film. They observed that the current density is decreased upon doping. With the cyclic 5Me-[5]CMP, the ratio $\mathrm{J}_{\text {doped }} / \mathrm{J}_{\text {neat }}$ is of $12 \%$; this behaviour designates a hole-retarding effect. With [5]LOMP4, this holeretarding effect was even more pronounced $\left(\mathrm{J}_{\text {doped }} / \mathrm{J}_{\text {neat }}: 0.002 \%\right)$ whereas with [5]LOMP2 $\left(\mathrm{J}_{\text {doped }} / \mathbf{J}_{\text {neat }}: 48.9 \%\right)$, it was weaker than in [5]LOMP4 and 5Me-[5]CMP. Retardation effects were not observed in electron-only devices. These results show the determinant role of the hole-retarding effects in the host for highly efficient SL-PhOLEDs.

Despite high $\mathrm{V}_{\text {on }}$ (from 4.2 to $7.4 \mathrm{~V}$ ), these devices present high EQE. The SL-PhOLEDs using [5]LOMP4:Ir(ppy) $6 \%$ as EML reaches an EQE of $20.1 \%$ and is nowadays the highest reported in the field of green SL-PhOLEDs. This is particularly remarkable as these hosts are PHC materials, which do not incorporate any heteroatoms to adjust their electronic properties. In the last years, PHC materials have been particularly studied in the field of OLEDs, ${ }^{[16,79]}$ as it is known that OLED instability, which is one of the main problems to be addressed at the current stage of development, is partially caused by the fragile $\mathrm{C}-\mathrm{N}, \mathrm{C}-\mathrm{P}$ and $\mathrm{C}-\mathrm{S}$ bonds of heteroatoms based hosts. ${ }^{[80-83]}$ Nevertheless, in the present series, the EQE significantly decrease when the current density increases. Note that in the field of ML-PhOLEDs, the highest performance for RGB PhOLEDs has also been recently reported with a PHC host material constructed on a spirobifluorene based 
compound. $^{[37]}$ This recent evolution proves that PHC can act as excellent universal host materials without deliberately introducing heteroatoms. PHC materials can be in the future an interesting direction for low-cost electronics.

\section{c. Red SL-PhOLEDs}

Among the three primary colours, red, green and blue, red-emitting devices have been the first to reach an EQE above $10 \%$. The first high efficiency red SL-PhOLED D62 has been reported in 2008. ${ }^{[84]}$ The optimized electrophosphorescent device incorporating $8 \%$ of the red emitter $\operatorname{Ir}(\mathbf{M p q})_{2}$ (acac) has exhibited a saturated red emission (CIE: $0.66 ; 0.34$ ) with a high EQE of $10.8 \%$ and a maximum PE of $13 \mathrm{~lm} / \mathrm{W} .{ }^{[84]}$ The ambipolar material used D2ACN acted as an effective charge conducting matrix to the host phosphor. D2ACN is a functionalized spirobifluorene substituted on one fluorene (at $\mathrm{C} 2 / \mathrm{C} 7$ ) by two diphenylamines and on the other fluorene by two cyano groups at the same positions. As detailed above for 2,7-DiCbz-SBF-4'-POPh $\mathbf{P}_{\mathbf{2}}$, the substitution at $\mathrm{C} 2 / \mathrm{C} 7$ does not allow to keep a very high $\mathrm{E}_{\mathrm{T}}$, measured at $2.4 \mathrm{eV}$ for D2ACN. Note that using the new generations of spirobifluorene isomers ${ }^{[4]}$ as central scaffold (substituted at $\mathrm{C} 4,{ }^{[7}$, ${ }^{85,86]}$ at $\mathrm{C}^{[43]}$ or at $\mathrm{C}^{[87]}$ ) should allow to increase the $\mathrm{E}_{\mathrm{T}}$ keeping the same donor/acceptor fragments. As observed for many host materials (such as the series presented above, ie SPA-2FPOPh $_{2}$, SPA-3,6-F(POPh $)_{2}$ and SPA-2,7-F(POPh $\left.)_{2}\right)$, D2ACN is only weakly fluorescent due to the spatial separation between the donor and the acceptor units. In the design of host materials, this separation is very often used to maintain a high $\mathrm{E}_{\mathrm{T}}{ }^{[53,54,88]}$ but provides bad fluorescent emitters. The HOMO and LUMO energy levels are respectively measured from electrochemistry at -5.14 and -2.58 $\mathrm{eV}$. Thanks to the presence of the two cyano groups, known to strongly depress the LUMO energy level, ${ }^{[89-92]}$ the LUMO energy level is particularly low and therefore well adapted to the cathode used in the device $(-2.8 \mathrm{eV}$ for $\mathrm{LiF} / \mathrm{Al})$. The balanced bipolar charge transport capability of D2ACN $\left(2 \times 10^{-5} \mathrm{~cm}^{2} \mathrm{~V}^{-1} \mathrm{~s}^{-1}\right.$ for $\mu_{\mathrm{e}}$ and $4.7 \times 10^{-5} \mathrm{~cm}^{2} \mathrm{~V}^{-1} \mathrm{~s}^{-1}$ for $\left.\mu_{\mathrm{h}}\right)$ is surely at the origin of the high PhOLED performance obtained. As far as we know, this work still displays nowadays the highest performance in the field of red SL-PhOLEDs using a single host. After this work, the performances of red-SL PhOLEDs have remained lower than $10 \%$ for many years.

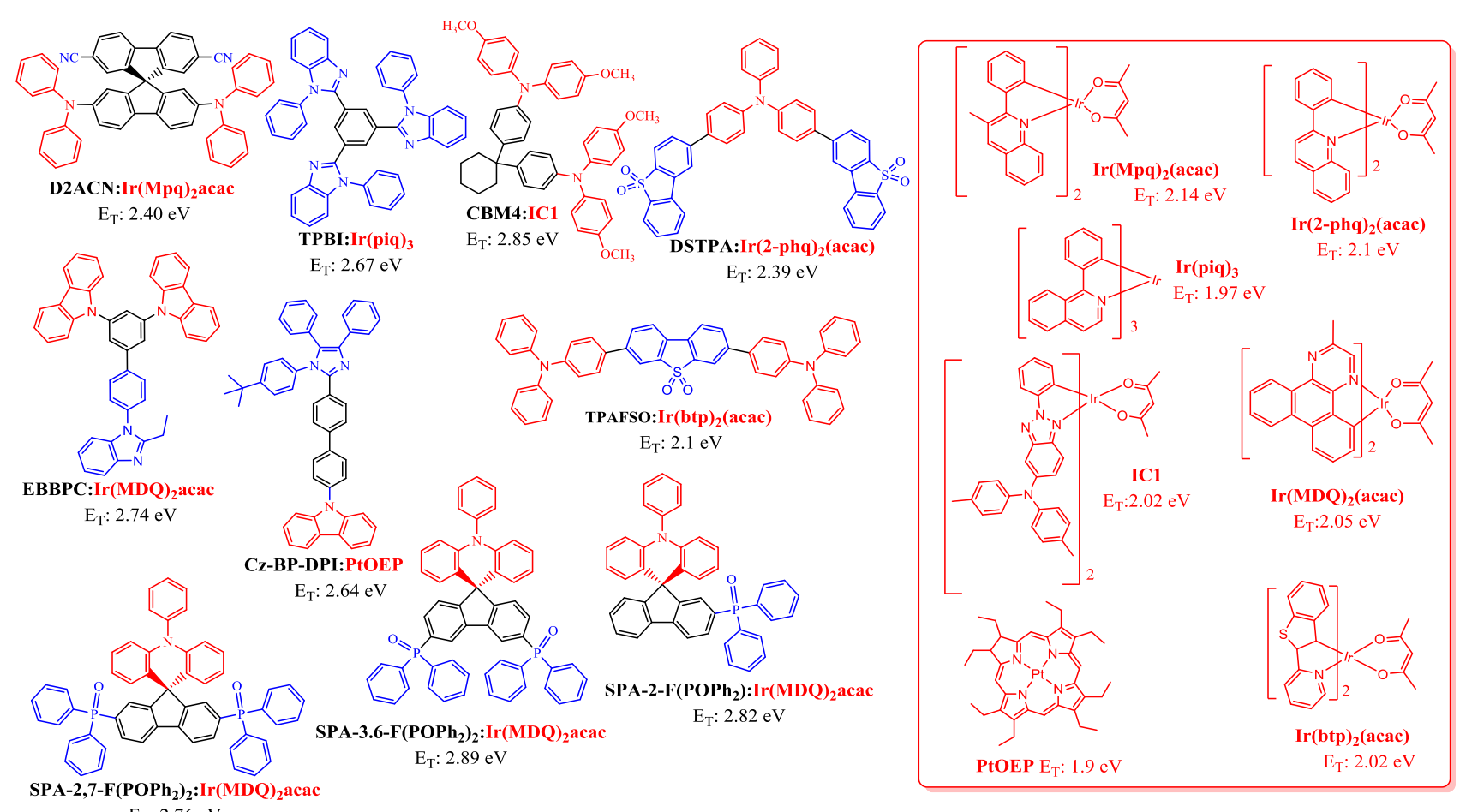


Figure 9. Molecular structure of host materials and red phosphors used in red SL-PhOLEDs $\mathrm{E}_{\mathrm{T}}$ in black (red) is that of the host (phosphorescent emitter). In the host materials, black, blue and red fragments respectively point the $\pi$-linker, the acceptor and the donor units of the OSC.

Oppositely to blue and green emission described above, it should be mentioned that many different red phosphors have been used as emitters in SL-PhOLEDs (Figure 9). In recent years, interesting performances have been obtained with $\operatorname{Ir}(\mathbf{M D Q})_{2}(\mathbf{a c a c})\left(\mathrm{D} 67\right.$, D69-D71). ${ }^{[32,50]}$ This phosphor displays an $\mathrm{E}_{\mathrm{T}}$ of $2.02 \mathrm{eV}$ (measured in 2-MeTHF at $\mathrm{RT}^{\left[{ }^{[32]}\right.}$ other values are reported in literature depending on the experimental conditions, see $\left.^{[32]}\right)$ and is considered as a red emitter $\left(\lambda_{\max }=612 \mathrm{~nm}\right.$ in 2-MeTHF ${ }^{[32]}$ ). Its $\mathrm{HOMO} / \mathrm{LUMO}$ energy levels obtained from electrochemical studies in $\mathrm{CH}_{2} \mathrm{Cl}_{2}+$ $\mathrm{Bu}_{4} \mathrm{NPF}_{6} 0.2 \mathrm{M}$ are of $-5.26 /-2.91 \mathrm{eV} .^{[32]}$

In 2009, the red SL-PhOLED D63, using TPBI doped with the red phosphor $\operatorname{Ir}(\mathbf{p i q})_{3}$ as EML, has displayed low performance $(\mathrm{CE}=3.7 \mathrm{~cd} / \mathrm{A}, \quad \mathrm{PE}=3.2 \mathrm{~lm} / \mathrm{W})$ (ITO/TPBI:Ir(piq) $321 \%$ $(100 \mathrm{~nm}) / \mathrm{LiF}(1 \mathrm{~nm}) / \mathrm{Al}(100 \mathrm{~nm}))(\mathrm{D} 63) .{ }^{[22]}$ It should be remind that this host with $\mathrm{E}_{\mathrm{T}}$ of $2.69 \mathrm{eV}$ was also used in blue (D2, $6.8 \mathrm{~cd} / \mathrm{A}, 1.9 \mathrm{~lm} / \mathrm{W})$ and green $(\mathrm{D} 27,6.1 \mathrm{~cd} / \mathrm{A}, 2.2 \mathrm{~lm} / \mathrm{W})$ SL-PhOLEDs. Despite universal, TPBI is not an efficient host.

In 2013, the 1,1-bis(4-(3',3"'-dimethoxy)triphenylamino)cyclohexane, CBM4, which only possesses electron-rich fragments has been used as host for a red-emitting 1,2,3-triazole-based iridium complex (IC1) bearing hole transporting diphenylamine moieties. ${ }^{[93]}$ With an $\mathrm{E}_{\mathrm{T}}$ of $2.85 \mathrm{eV}, \mathbf{C B M} 4$ is adapted to host IC1, which possesses an $\mathrm{E}_{\mathrm{T}}$ of $2.02 \mathrm{eV}$. EL maxima of the SL-PhOLED D64 are detected at 610 and $652 \mathrm{~nm}$ with CIE coordinates $(0.65,0.35)$, which correspond to IC1 emission. The device D64 displays however a low performance with an $\mathrm{EQE}$ of $2.29 \%(\mathrm{CE}=5.3 \mathrm{~cd} / \mathrm{A})$.

DSTPA $^{[94]}$ and TPAFSO ${ }^{[95]}$ both constructed on the association of diphenylamine and dibenzothiophene-S,S dioxide have respectively shown an EQE of $7.3 \%, \mathrm{CE}=11.7 \mathrm{~cd} / \mathrm{A}$ and $\mathrm{PE}=12.6 \mathrm{~lm} / \mathrm{W}$

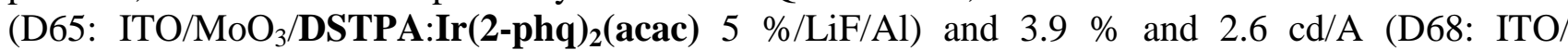
PEDOT:PSS/TPAFSO:Ir(btp) $\mathbf{2}$ (acac) $5 \% / \mathrm{CsF} / \mathrm{Al})$. In these two molecules, theoretical calculations reveal that the HOMO and LUMO are not fully separated, which endows a high quantum yield and a low $\mathrm{E}_{\mathrm{T}}$ of respectively $87 \%$ and $2.1 \mathrm{eV}$ for TPAFSO and of $98 \%$ and $2.39 \mathrm{eV}$ for DSTPA. In TPAFSO, the hole/electron mobility is relatively well balanced $1.83 \times 10^{-6} / 0.42 \times 10^{-6} \mathrm{~cm}^{2} \mathrm{~V}^{-1} \mathrm{~s}^{-1}$, whereas in DSTPA, there is one order of magnitude between the mobilities values $\left(\mu_{\mathrm{h}} / \mu_{\mathrm{e}}: 1.42 \times 10^{-3} /\right.$ $1.38 \times 10^{-4} \mathrm{~cm}^{2} \mathrm{~V}^{-1} \mathrm{~s}^{-1}$ ), which are nevertheless significantly higher.

In 2017, Cz-BP-DPI was also used as host for a red emitting platinum complex (PtOEP). ${ }^{[51]}$ The solution processed red SL-PhOLED D66 displays a low $\mathrm{V}_{\text {on }}$ of $4.3 \mathrm{~V}$ and an EQE of $2.58 \%$. This shows that the efficiency of Cz-BP-DPI as universal host for RGB phosphor increases from blue (D15: $0.045 \%$ ) to red (D66: $2.58 \%$ ) and finally green (D52: $4.7 \%$ ).

Higher performances were reached with EBBPC doped with the widely known red phosphor $\operatorname{Ir}(\mathbf{M D Q})_{2}$ (acac). EBBPC presents an $\mathrm{E}_{\mathrm{T}}(2.74 \mathrm{eV})$ significantly higher than the one of $\operatorname{Ir}(\mathbf{M D Q})_{2}$ (acac) $(2.05 \mathrm{eV}){ }^{[50]}$ The device D67 using EBBPC:Ir(MDQ) 2 (acac) $5 \%$ as EML reaches an EQE of $10.1 \%$ (CE: $16.6 \mathrm{~cd} / \mathrm{A}, \mathrm{PE}: 5.5 \mathrm{~lm} / \mathrm{W})$ and is the second device surpassing an EQE of $10 \%$ in the field of red SL-PhOLEDs. Moreover, as this host was also relatively efficient to host the blue phosphor FIrpic (D14: $9.8 \%, 21.6 \mathrm{~cd} / \mathrm{A}$ and $10.4 \mathrm{~lm} / \mathrm{W}$ ) and the green phosphor $\operatorname{Ir}(\mathbf{p p y})_{3}$ (D51: $14.6 \%, 52.3 \mathrm{~cd} / \mathrm{A}$ and $35.4 \mathrm{~lm} / \mathrm{W})$, EBBPC can be considered as a relatively efficient universal host.
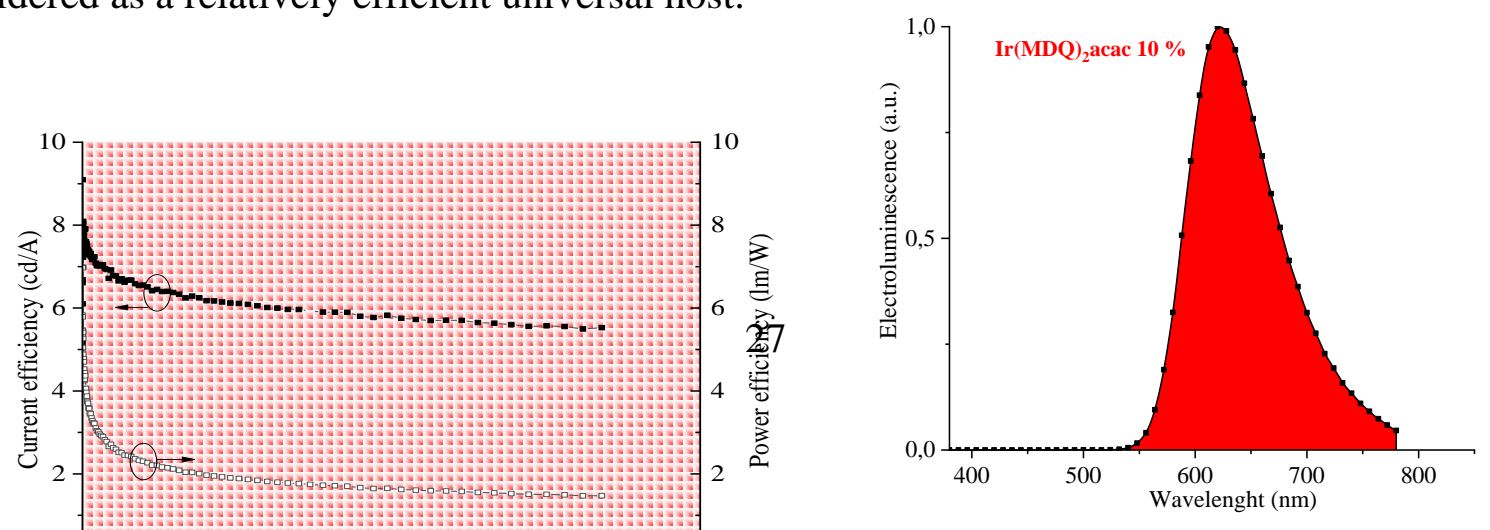


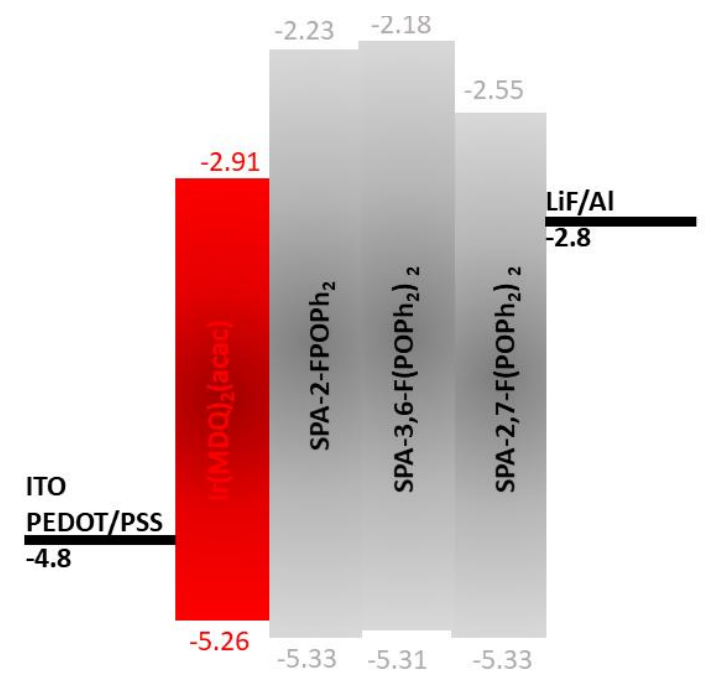

Figure 10. Top. Red emitting SL-PhOLED characteristics using as a host SPA-2,7-F(POPh $\mathbf{P}_{2}$ and as emitter $\operatorname{Ir}(\mathbf{M D Q})_{2}$ (acac). Left. Current efficiency $(\mathrm{cd} / \mathrm{A})$ and power efficiency $(\mathrm{lm} / \mathrm{W})$ as a function of the current density $\left(\mathrm{mA} / \mathrm{cm}^{2}\right)$. Right. EL spectrum (D69). Bottom. Schematic energy diagrams of the different components used in the EML of red SL-PhOLEDs in the case of $\mathrm{SPA}-\mathrm{F}-\mathrm{POPh}_{2}$ family

The last examples of red SL-PhOLEDs reported in literature are based on the universal hosts SPA-2FPOPh $_{2}, \mathbf{S P A - 3 , 6 - F}\left(\mathbf{P O P h}_{2}\right)_{2}$ and SPA-2,7-F(POPh$)_{2}$ described above in the blue and the green sections. The devices are also constructed with the red dopant $\operatorname{Ir}(\mathbf{M D Q})_{2}(\mathbf{a c a c})$ (ITO/PEDOT:PSS/Host: $\mathbf{I r}(\mathbf{M D Q})_{2}$ (acac) $\left.10 \% / \mathrm{LiF} / \mathrm{Al}\right) .{ }^{[32]}$ As observed for green and blue emitting devices, the best performance was obtained with SPA-2,7-F $(\mathbf{P O P h})_{2}(\mathrm{D} 69$ : EQE $=8.7 \%)$, the two others SPA-2-FPOPh 2 , SPA-3,6-F(POPh $)_{2}$, displaying lower performance (EQE of $4.5 \%$ (D71) and $5.3 \%$ (D70) respectively). For the three hosts, the EL spectrum is that of the red dopant (Figure 10), indicating efficient energy transfers from the hosts to the guest. The different performance can be related to the strong difference observed in term of charge carrier mobilities as exposed above. Thus, in this series, SPA-2,7-F(POPh $)_{2}$ has shown the highest efficiency for the three dopants used (EQE of 18,16 and $8.7 \%$ for FIrpic, $\operatorname{Ir}(\mathbf{p p y})_{3}, \operatorname{Ir}(\mathbf{M D Q})_{2}$ (acac) respectively), showing the versatility and the efficiency of this host. As far as we know, this is the highest performance reported for RGB SL-PhOLEDs.

Table 3. EL performances of red SL-PhOLEDs (Devices D62 to D71)

\begin{tabular}{|c|c|c|c|c|c|c|c|}
\hline \multicolumn{8}{|c|}{ Red SL-PhOLEDs } \\
\hline EML & Device structure & $\begin{array}{l}\mathbf{V}_{\text {on }} \\
(\mathbf{V})\end{array}$ & $\begin{array}{c}\mathbf{E Q E}_{\max } \\
(\%)\end{array}$ & $\begin{array}{l}\mathbf{C E}_{\max } \\
\text { (cd/A }\end{array}$ & $\begin{array}{l}\mathbf{P E}_{\max } \\
(\mathbf{I m} / \mathbf{W})\end{array}$ & $\begin{array}{c}1931 \text { CIE } \\
(x, y)\end{array}$ & $\begin{array}{l}\text { Device number, } \\
\text { References }\end{array}$ \\
\hline D2ACN:Ir(Mpq) $)_{2}(\mathbf{a c a c}) 8 \%$ & $\begin{array}{l}\text { ITO/mt-DATA }(20 \mathrm{~nm}) / \text { TE-EML } \\
(100 \mathrm{~nm}) / \mathrm{LiF}(0.5 \mathrm{~nm}) / \mathrm{Al}\end{array}$ & 1.5 & 10.8 & 10.2 & 13 & $0.66,0.34$ & D62, $2008^{[84]}$ \\
\hline
\end{tabular}




\begin{tabular}{|c|c|c|c|c|c|c|c|}
\hline TPBI:Ir(piq) $321 \%$ & ITO/ TE-EML $(100 \mathrm{~nm}) / \mathrm{LiF}(1 \mathrm{~nm}) / \mathrm{Al}(100 \mathrm{~nm})$ & - & - & 3.7 & 3.2 & $0.69,0.33$ & D63, 2009 $9^{[22]}$ \\
\hline CBM4:IC1 $10 \%$ & ITO/ TE-EML $(26 \mathrm{~nm}) / \mathrm{Ca}(40 \mathrm{~nm}) / \mathrm{Al}(200 \mathrm{~nm})$ & 4 & 2.29 & 5.3 & - & $0.63,0.35$ & $\mathrm{D} 64,2013^{[93]}$ \\
\hline DSTPA:Ir(2-phq) $)_{2}$ (acac) $5 \%$ & ITO/MoO ${ }_{3}(2 \mathrm{~nm}) / \mathrm{TE}-\mathbf{E M L}(90 \mathrm{~nm}) / \mathrm{LiF}(1.5 \mathrm{~nm}) / \mathrm{Al}$ & 2.5 & 7.3 & 11.7 & 12.6 & $0.62,0.37$ & D65, $2014^{[94]}$ \\
\hline Cz-BP-DPI:PtOEP $4 \%$ & $\begin{array}{l}\text { ITO/PEDOT:PSS(40nm)/SP-EML } \\
(80 \mathrm{~nm}) / \mathrm{CsF}(1.5 \mathrm{~nm} / \mathrm{Al}(100 \mathrm{~nm})\end{array}$ & 4.3 & 2.58 & 0.98 & - & $0.65,0.33$ & D66, 2017 $7^{[51]}$ \\
\hline EBBPC:Ir(MDQ $)_{2}($ acac $) 5 \%$ & $\begin{array}{l}\text { ITO/ PEDOT:PSS }(40 \mathrm{~nm}) / \mathrm{TE}-\mathrm{EML} \\
(90 \mathrm{~nm}) / \mathrm{LiF}(0.5 \mathrm{~nm}) / \mathrm{Mg}: \mathrm{Ag}\end{array}$ & 7.7 & 10.1 & 16.6 & 5.5 & $0.62,0.38$ & $\mathrm{D} 67,2017^{[50]}$ \\
\hline TPAFSO:Ir(btp) $)_{2}($ acac $) 5 \%$ & $\begin{array}{l}\text { ITO/PEDOT:PSS }(40 \mathrm{~nm}) / \text { SP-EML } \\
(80 \mathrm{~nm}) / \mathrm{CsF}(1.5 \mathrm{~nm}) / \mathrm{Al}(120 \mathrm{~nm})\end{array}$ & 2.9 & 3.9 & 2.6 & - & $0.68,0.32$ & D68, $2019^{[95]}$ \\
\hline $\begin{array}{l}\text { SPA-2,7-F(POPh })_{2}: \\
\operatorname{Ir}(\mathbf{M D Q})_{2}(\text { acac) } 10 \%\end{array}$ & $\begin{array}{l}\text { ITO/PEDOT:PSS(40nm)/ TE-EML } \\
(100 \mathrm{~nm}) / \mathrm{LiF}(1.2 \mathrm{~nm}) / \mathrm{Al}(100 \mathrm{~nm})\end{array}$ & 2.8 & 8.7 & 9.1 & 7.0 & $0.64,0.36$ & $\mathrm{D} 69,2020^{[32]}$ \\
\hline $\begin{array}{l}\text { SPA-3,6-F(POPh })_{2}: \\
\operatorname{Ir}(\mathbf{M D Q})_{2} \text { (acac) } 10 \%\end{array}$ & $\begin{array}{l}\text { ITO/PEDOT:PSS(40nm)/ TE-EML } \\
(100 \mathrm{~nm}) / \mathrm{LiF}(1.2 \mathrm{~nm}) / \mathrm{Al}(100 \mathrm{~nm})\end{array}$ & 3.6 & 5.3 & 5.4 & 3.0 & $0.64,0.36$ & $\mathrm{D} 70,2020^{[32]}$ \\
\hline $\begin{array}{l}\text { SPA-2-F(POPh }): \\
\operatorname{Ir}(\mathbf{M D Q})_{2}(\text { acac) } 10 \%\end{array}$ & $\begin{array}{l}\text { ITO/PEDOT:PSS(40nm)/ TE-EML } \\
(100 \mathrm{~nm}) / \mathrm{LiF}(1.2 \mathrm{~nm}) / \mathrm{Al}(100 \mathrm{~nm})\end{array}$ & 3.2 & 4.5 & 5.5 & 3.5 & $0.63,0.37$ & D71, $2020^{[32]}$ \\
\hline
\end{tabular}

$\mathrm{SP}$ for solution processed and TE for thermally evaporated

\section{d. Yellow/Orange and White SL-PhOLEDs}

In this last part, are presented the performances of Yellow/Orange and White emitting SL-PhOLEDs.

To the best of our knowledge only five SL-PhOLED devices emitting yellow-orange light have been reported in literature, these examples are gathered in Table 7. The molecular diversity of the hosts used is therefore very weak. These hosts are based either on an ambipolar spirobifluorene $\left(\mathbf{N P h}_{2}\right)$ BzImSBF, on CBM4 already used in red SL-PhOLED (see above) and on the widely known CBP. Three yellow phosphors have been used, $\operatorname{Ir}(\mathbf{f b i})_{2}$ (acac), IC2 and PO-01 (Figure 11). The devices are all different as they use different phosphors and the comparison appears hence difficult.

The highest performance was reached with $\left(\mathbf{N P h}_{\mathbf{2}}\right) \mathbf{B z I m S B F}$ with $\operatorname{Ir}(\mathbf{f b i})_{\mathbf{2}}(\mathbf{a c a c})$ as emitter with an EQE of $7.8 \%$, a CE of $22 \mathrm{~cd} / \mathrm{A}$ and a PE of $7.5 \mathrm{~lm} / \mathrm{W}$ (D72). This host is built with a Donor/Acceptor design (N-phenylamine and benzimidazole respectively) and displays a wellbalanced hole and electron mobility, $\mu_{\mathrm{e}}=11.7 \times 10^{-6} \mathrm{~cm}^{2} \mathrm{~V}^{-1} \mathrm{~s}^{-1}$ and $\mu_{\mathrm{h}}=23.8 \times 10^{-6} \mathrm{~cm}^{2} \mathrm{~V}^{-1} \mathrm{~s}^{-1}$, which is surely at the origin of the good performance obtained. Note that a structurally related compound constructed with the same functional groups has been successfully used in the challenging blue emitting fluorescent single-layer OLEDs. ${ }^{[96]}$ This shows that this combination is efficient to carry both hole and electron within a simplified device.

CBM4, already used as host for a red phosphor IC1 (device D64), has also been used as host for the orange-yellow emitting 1,2,3-triazole-based iridium complex (IC2) bearing carbazole hole transporting moieties. ${ }^{[93]}$ With an $\mathrm{E}_{\mathrm{T}}$ of $2.85 \mathrm{eV}, \mathbf{C B M 4}$ is adapted to host $\mathbf{I C 2}$, which possesses an $\mathrm{E}_{\mathrm{T}}$ of $2.11 \mathrm{eV}$. EL maxima of device D73 using CBM4:IC2 $10 \%$ as EML are recorded at 562 and $600 \mathrm{~nm}$ (CIE: 0.53, 0.47). 


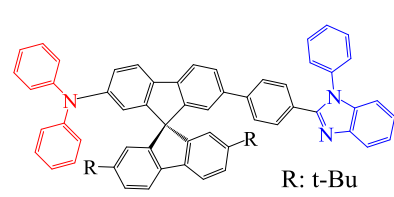

$\left(\mathrm{NPh}_{2}\right) \mathbf{B z I m S B F}$

$\mathrm{E}_{\mathrm{T}}=2.3 \mathrm{eV}$

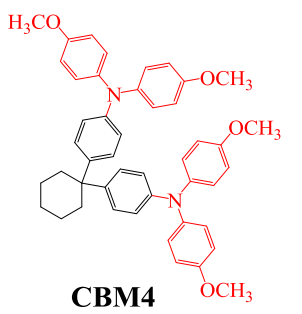

$\mathrm{E}_{\mathrm{T}}=2.85 \mathrm{eV}$

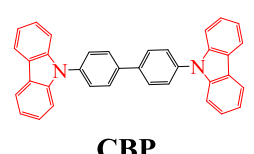

$\mathrm{E}_{\mathrm{T}}=2.56 \mathrm{eV}$

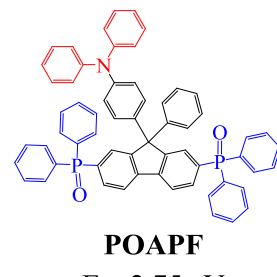

$\mathrm{E}_{\mathrm{T}}: 2.75 \mathrm{eV}$
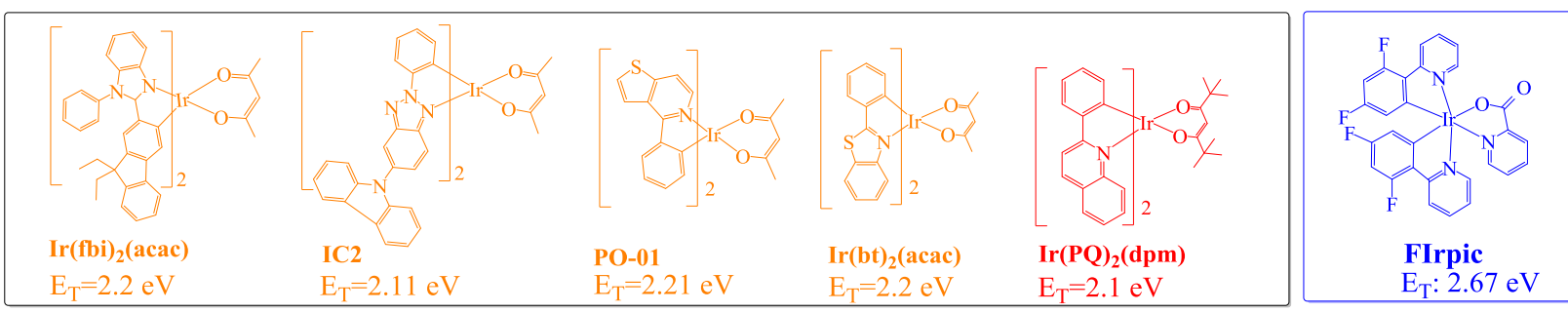

Figure 11. Molecular structure of host materials used in yellow/orange or white SL-PhOLEDs.

Table 4. EL performances of yellow-orange SL-PhOLEDs (Devices D72 to D84)

\begin{tabular}{|c|c|c|c|c|c|c|c|}
\hline \multicolumn{8}{|c|}{ Yellow-orange SL-PhOLEDS } \\
\hline EML & Device structure & $\begin{array}{l}\mathbf{V}_{\text {on }} \\
\text { (V) }\end{array}$ & $\begin{array}{c}\mathrm{EQE}_{\max } \\
(\%)\end{array}$ & $\begin{array}{l}\mathrm{CE}_{\max } \\
\text { (cd/A }\end{array}$ & $\begin{array}{c}\mathbf{P E}_{\max } \\
(\operatorname{lm} / \mathbf{W})\end{array}$ & $\begin{array}{l}1931 \text { CIE } \\
(x, y)\end{array}$ & $\begin{array}{c}\text { Device number, } \\
\text { References }\end{array}$ \\
\hline$\left(\mathbf{N P h}_{\mathbf{2}}\right) \mathbf{B z I m S B F}$ :(fbi) $)_{2} \operatorname{Ir}$ (acac) $5 \%$ & ITO/EML(80nm)/LiF(1nm)/Al(150nm) & 3.1 & 7.8 & 22 & 7.5 & $0.53,0.47$ & $\begin{array}{c}\mathrm{D} 72,2008^{[97]} \\
2009,{ }^{[65]}\end{array}$ \\
\hline CBP:PO-018\% & ITO/ $/ \mathrm{MoO}_{3}(1.5 \mathrm{~nm}) / \mathbf{E M L}(100 \mathrm{~nm}) / \mathrm{Al}$ & - & - & 0.43 & - & - & $\mathrm{D} 74,2016^{[98]}$ \\
\hline CBP:PO-01 $8 \%$ & ITO/MoO ${ }_{3}(1.5 \mathrm{~nm}) / \mathbf{E M L}(100 \mathrm{~nm}) / \mathrm{Liq}(1 \mathrm{~nm}) / \mathrm{Al}$ & - & - & 16.34 & - & - & $\mathrm{D} 75,2016^{[98]}$ \\
\hline CBP:PO-01 $8 \%$ & ITO/MoO $3(1.5 \mathrm{~nm}) / \mathbf{E M L}(100 \mathrm{~nm}) / \mathrm{Liq}(3 \mathrm{~nm}) / \mathrm{Al}$ & - & - & 16.21 & - & - & $\mathrm{D} 76,2016^{[98]}$ \\
\hline CBP:PO-018\% & ITO/MoO ${ }_{3}(1.5 \mathrm{~nm}) / \mathbf{E M L}(100 \mathrm{~nm}) / \mathrm{Liq}(5 \mathrm{~nm}) / \mathrm{Al}$ & - & - & 15.62 & - & - & D77, 2016 ${ }^{[98]}$ \\
\hline CBP:FIrpic $15 \%: P 0-018 \%$ & ITO/MoO $3(1.5 \mathrm{~nm}) / \mathbf{E M L}(110 \mathrm{~nm}) / \mathrm{Liq}(1 \mathrm{~nm}) / \mathrm{Al}$ & - & - & 28.24 & - & - & $\mathrm{D} 79,2016^{[98]}$ \\
\hline CBP:FIrpic $15 \%: \mathrm{PO}-018 \%$ & ITO/MoO $3(1.5 \mathrm{~nm}) / \mathbf{E M L}(120 \mathrm{~nm}) / \mathrm{Liq}(1 \mathrm{~nm}) / \mathrm{Al}$ & - & - & 31.38 & - & - & $\mathrm{D} 80,2016^{[98]}$ \\
\hline CBP:FIrpic $15 \%: \mathrm{PO}-018 \%$ & $\mathrm{ITO} / \mathrm{MoO}_{3}(1.5 \mathrm{~nm}) / \mathrm{ML}(130 \mathrm{~nm}) / \mathrm{Liq}(1 \mathrm{~nm}) / \mathrm{Al}$ & - & - & 30.29 & - & - & D81, 2016 $6^{[98]}$ \\
\hline \multicolumn{8}{|c|}{ White SL-PhOLED } \\
\hline EML & Device structure & $\begin{array}{l}\mathbf{V}_{\text {on }} \\
(\mathbf{V})\end{array}$ & $\begin{array}{c}\mathbf{E Q E}_{\max } \\
(\%)\end{array}$ & $\begin{array}{l}\mathbf{C E}_{\max } \\
(\mathbf{c d} / \mathbf{A}\end{array}$ & $\begin{array}{c}\mathbf{P E}_{\max } \\
(\mathbf{I m} / \mathbf{W})\end{array}$ & $\begin{array}{l}1931 \text { CIE } \\
(x, y)\end{array}$ & $\begin{array}{c}\text { Device number, } \\
\text { References }\end{array}$ \\
\hline POAPF:FIrpic $10 \%:$ :P0-01 $0.6 \%$ & ITO/PEDOT:PSS/EML(70 nm)/LiF/Mg:Ag & 3.5 & - & 31.4 & 21.9 & $0.36,0.43$ & D82, 2012 $2^{[99]}$ \\
\hline POAPF:FIrpic $10 \%: \operatorname{Ir}(\mathrm{bt})_{2}$ acac $0.9 \%$ & ITO/PEDOT:PSS/ EML $(70 \mathrm{~nm}) / \mathrm{LiF} / \mathrm{Mg}: \mathrm{Ag}$ & 3.5 & - & 26.4 & 19.6 & - & $\mathrm{D} 83,2012^{[99]}$ \\
\hline POAPF:FIrpic $10 \%$ : $\operatorname{Ir}(\mathbf{P Q})_{2}(\mathrm{dpm}) 1 \%$ & ITO/PEDOT:PSS/ EML $(70 \mathrm{~nm}) / \mathrm{LiF} / \mathrm{Mg}: \mathrm{Ag}$ & 3.5 & - & 23.4 & 17.2 & - & $\mathrm{D} 84,2012^{[99]}$ \\
\hline
\end{tabular}

In 2016, using CBP as host for the yellow Iridium complex PO-01, different devices have been constructed with the following architecture: ITO/MoO $3(1.5 \mathrm{~nm}) / \mathbf{C B P}: \mathbf{P O}-\mathbf{0 1} 8 \%$ (100nm)/Liq(x $\mathrm{nm}$ )/Al with $\mathrm{x}: 0,1,3$ or $5 \mathrm{~nm}$ (Devices D74-D77). Lithium quinolate (Liq) was used to enhance electron injection from the cathode to the EML by lowering the interfacial barrier. D74 without Liq layer exhibits the lowest efficiency among the four devices (CE: $0.43 \mathrm{~cd} / \mathrm{A}$ ). The introduction of Liq improves drastically the device performance and D75 with a $1 \mathrm{~nm}$ Liq layer shows the highest efficiency (CE: $16.34 \mathrm{~cd} / \mathrm{A})$. However, when the Liq layer is thicker, the efficiency remains similar (D76, Liq: $3 \mathrm{~nm}, \mathrm{CE}: 16.21 \mathrm{~cd} / \mathrm{A}$ and D77, Liq: $5 \mathrm{~nm}, \mathrm{CE}: 15.62 \mathrm{~cd} / \mathrm{A}$ ).

Pursuing the objective of increasing the orange SL-PhOLEDs efficiency, the same group has doped the blue FIrpic at a concentration of $15 \%$ into the CBP:PO-01 $8 \%$ previous EML (used in D75). The device architecture was the following: ITO/ $\mathrm{MoO}_{3}(1.5 \mathrm{~nm}) /$ CBP:FIrpic $15 \%:$ PO-01 $8 \%$ (z $\mathrm{nm}) / \mathrm{Liq}(1 \mathrm{~nm}) / \mathrm{Al}$ with z: 100, 110, 120 or $130 \mathrm{~nm}$ (Devices D78-D81). The four devices only present the orange emission of PO-01 without the emission of neither FIrpic nor CBP, indicating that the generated excitons are all transferred to PO-01. Device D80, with an EML thickness of 120 $\mathrm{nm}$, achieves the highest $\mathrm{CE}$ value of $31.38 \mathrm{~cd} / \mathrm{A}$. However, the four devices reached similar $\mathrm{CE}$ values (from 28.24 to $31.38 \mathrm{~cd} / \mathrm{A}$ ) that are twice that recorded without FIrpic in device D75 (CE: 
$16.34 \mathrm{~cd} / \mathrm{A})$. In order to investigate the influence of FIrpic on the transport properties of devices D78-D81, the authors fabricated hole-only and electron-only devices with architecture ITO/MoO $3(1.5 \mathrm{~nm}) / \mathrm{NPB}(35 \mathrm{~nm}) / \mathbf{C B P}$ :FIrpic $(0$ or $15 \%)(30 \mathrm{~nm}) / \mathrm{NPB}(35 \mathrm{~nm}) / \mathrm{MoO}_{3}(1.5 \mathrm{~nm}) / \mathrm{Al}$ and ITO/ Liq $(1 \mathrm{~nm}) / \mathrm{TPBI}(35 \mathrm{~nm}) /$ CBP:FIrpic $(0$ or $15 \%)(30 \mathrm{~nm}) / \mathrm{TPBI}(35 \mathrm{~nm}) / \mathrm{Liq}(1 \mathrm{~nm}) / \mathrm{Al}$. They observed that: hole-only current density increases and electron-only current density decreases when doping CBP with $15 \%$ FIrpic. These results indicate that FIrpic molecules act as hole transport channels in the doping system of CBP:FIrpic $15 \%$. Device D80 with CE of $31.38 \mathrm{~cd} / \mathrm{A}$ is among the best reported for orange SL-PhOLED. It should be concluded that yellow SL-PhOLEDs are only very rarely reported in literature. They are nevertheless very important since their yellow phosphor can be associated to greenish/blue phosphor to generate white emission. This is discussed below.

Finally, we wish to conclude this first part with the very challenging white SL-PhOLEDs. White PhOLEDs $^{[58,100-103]}$ are highly seek for the future of lighting and the SL-PhOLED counterparts represent a great challenge. As far as we know, there are only three examples of white SL-PhOLEDs reported to date. ${ }^{[99]}$ They are based on the association of two phosphors: A blue (FIrpic) and either an orange (PO-01 or $\left.\operatorname{Ir}(\mathbf{b t})_{\mathbf{2}}(\mathbf{a c a c})\right)$ or a red $\left(\operatorname{Ir}(\mathbf{P Q})_{\mathbf{2}}(\mathbf{d p m})\right)$ phosphor co-doped in POAPF host (Figure 11). ${ }^{[99]}$

The EML of Device 82 is constituted of FIrpic and PO-01 (10 and $0.6 \%$ respectively) dispersed in POAPF host. In such a system, the ratio of the two phosphors is highly important in order to reach a white emission. Indeed, as shown with Devices D78-D81, if the ratio of the orange phosphor is increased (FIrpic/PO-01: 15/8 \% respectively), only the orange emission of PO-01 is observed due to a complete excitons transfer.

With an $\mathrm{E}_{\mathrm{T}}$ of $2.75 \mathrm{eV}$, POAPF has been presented as the most efficient matrix for FIrpic with EQE reaching $20.3 \%^{[47,48]}$ (Table 1, D4-D9). Due to the high efficiency reached with FIrpic, Xie and coworkers fabricated a white SL-PhOLED, D82, with architecture ITO/PEDOT:PSS/POAPF: $10 \%$ FIrpic: $0.6 \%$ PO-01 $(70 \mathrm{~nm}) / \mathrm{LiF} / \mathrm{Mg}: \mathrm{Ag}$. Such devices reached high efficiency of $31.4 \mathrm{~cd} / \mathrm{A}$ and $21.9 \mathrm{~lm} / \mathrm{W}$ with CIE coordinates, independent of the voltage, corresponding to a white emission $(0.36,0.43)$.

Compare to devices D78-D81, in which the relative doping levels of FIrpic/PO-01 is $15 \% / 8 \%$ in CBP, in device D82, the ratio is $10 \% / 0.6 \%$ in POAPF. In the first series, FIrpic can transfer all its exciton to PO-01 which is in sufficient concentration around the blue phosphor to accept all the charged species. The emission is hence orange. In D82, as PO-01 is in low concentration, FIrpic cannot transfer all its excitons to PO-01 and emits both the blue phosphorescence of FIrpic and the orange one of PO-01, leading to a white emission.

Changing the orange dopant PO-01 by a different orange phosphor $\operatorname{Ir}(\mathbf{b t})_{\mathbf{2}}(\mathbf{a c a c})(0.9 \%$, D83) or by a red phosphor $\operatorname{Ir}(\mathbf{P Q})_{2}(\mathbf{d p m})(1 \%$, D84) does not decrease significantly the white devices performances with $\mathrm{CE}$ and $\mathrm{PE}$ reaching respectively $26.4 \mathrm{~cd} / \mathrm{A} / 19.6 \mathrm{~lm} / \mathrm{W}$ and $23.4 \mathrm{~cd} / \mathrm{A} / 17.2$ $\mathrm{lm} / \mathrm{W}$. The three phosphorescent dyes possess similar $\mathrm{E}_{\mathrm{T}}$ values $(2.21,2.2$ or $2.1 \mathrm{eV}$ for PO-01, $\operatorname{Ir}(\mathbf{b t})_{\mathbf{2}}(\mathbf{a c a c})$ or $\left.\operatorname{Ir}(\mathbf{P Q})_{\mathbf{2}}(\mathbf{d p m})\right)$ adapted to the energy transfer from FIrpic.

This last series of devices (D78-D84) shows how the design of the devices in terms of host/guest and anode/cathode combination is important to improve the device performances but also, in case of an EML including two dopants dispersed in one host, how the relative concentration of the two dopants must be finely chosen. Indeed, depending of the dopants ratio, the energy transfers from the host to the two guests lead either to the emission of only one dopant (D78-D81) or to the emission of the two dopants (D82-D84). This is a central feature in white OLEDs. 


\section{Modification of the EML of a SL-PhOLED}

In order to improve the performance of SL-PhOLEDs, various techniques have been developed (Figure 12). Herein, the two main techniques reported to date are presented. These strategies consist to modify the nature of EML either with 'all in one' molecules incorporating both host and guest in a single structure ('self-host' or non-doped approach) or with a combination of a host and co-host in order to regulate the charge flow within the device.

Non-doped / Self-tiost SL-AhCLEL MUIXEC LiOSt SL-LHCLLE ANODE HIL EML EIL CATHODE

Figure 12. Schematic representation of left: Non-doped/Self-Host SL-PhOLEDs and right: Mixed-Hosts SL-PhOLEDs.

\section{a. Non-doped or Self-host Strategy}

In this strategy, the idea consists to design a phosphorescent emitter, which can be directly used within the EML of a SL-PhOLED, without any host material. The phosphor should not only present a high efficiency in the solid state (which is rarely the case due to very long lifetime leading to emission quenching) but should also be able to efficiently carry the charges. This approach has been called either the 'non-doped' or the 'self-host' strategy depending on the authors (Figure 13-Left).

Dendrimers are solution-processable molecules composed of a core, dendrons and surface groups and a three-dimensional geometry. Light-emitting dendrimers generally consist of a light-emitting core to which dendrons are attached. They possess the advantages of the well-defined structure of small molecules together with the good solution processability of macromolecules.

To the best of our knowledge, literature only reports few examples of non-doped SL-PhOLEDs. They are presented below (D85-D97). In 2020, Mao and co-workers have reviewed the phosphorescent $\operatorname{Ir}(\mathrm{III})$ complexes used as EML in non-doped PhOLEDs, ${ }^{[104]}$ describing more than one hundred RBG dendrimers used in PhOLED. Among all these devices reported, only few of them are SL-PhOLEDs.

In 2009, a blue non-doped SL-PhOLED based on the Dendrimer B1 (Figure 13) is reported. ${ }^{[105]}$ Dendrimer B1 is constructed on a central 1-methyl-5-(4-fluorophenyl)-3-n-propyl-1H-[1,2,4triazolyl]Ir(III) blue emitting core (coloured in blue in Figure 13) decorated by two different twisted biphenyl-based dendrons. Dendrimer $\mathbf{B 1}$ is a rigid high $\mathrm{E}_{\mathrm{T}}$ dendrimer $\left(\mathrm{E}_{\mathrm{T}}\right.$ : $\left.2.83 \mathrm{eV}\right)$, which possesses similar photophysical and electrochemical properties than its central non decorated core, with however a significantly higher PL quantum yield both in solution (94\% vs $27 \%$ ) and in solid state $(60 \%$ vs $28 \%)$. This increase is due to the reduction of the non-radiative decay rate $\left(\mathrm{k}_{\mathrm{nr}}\right)$ for Dendrimer B1 ( $\mathrm{k}_{\mathrm{nr}}: 0.1710^{5} \mathrm{~s}^{-1}$ vs $5.810^{5} \mathrm{~s}^{-1}$ for the non-decorated core) attributed to a rigidifying effect due to the presence of the twisted dendrons, which reduces the geometry changes in the excited state and in turn the amount of vibrational quenching. SL-PhOLED, D85, using solution process EML based on Dendrimer B1 between an ITO anode and a $\mathrm{Ca} / \mathrm{Al}$ cathode has been 
constructed. The emission was in the blue region (CIE: $0.17,0.20)$ but the performances were very low: EQE: $0.41 \%$ and CE: $0.65 \mathrm{~cd} / \mathrm{A}$.

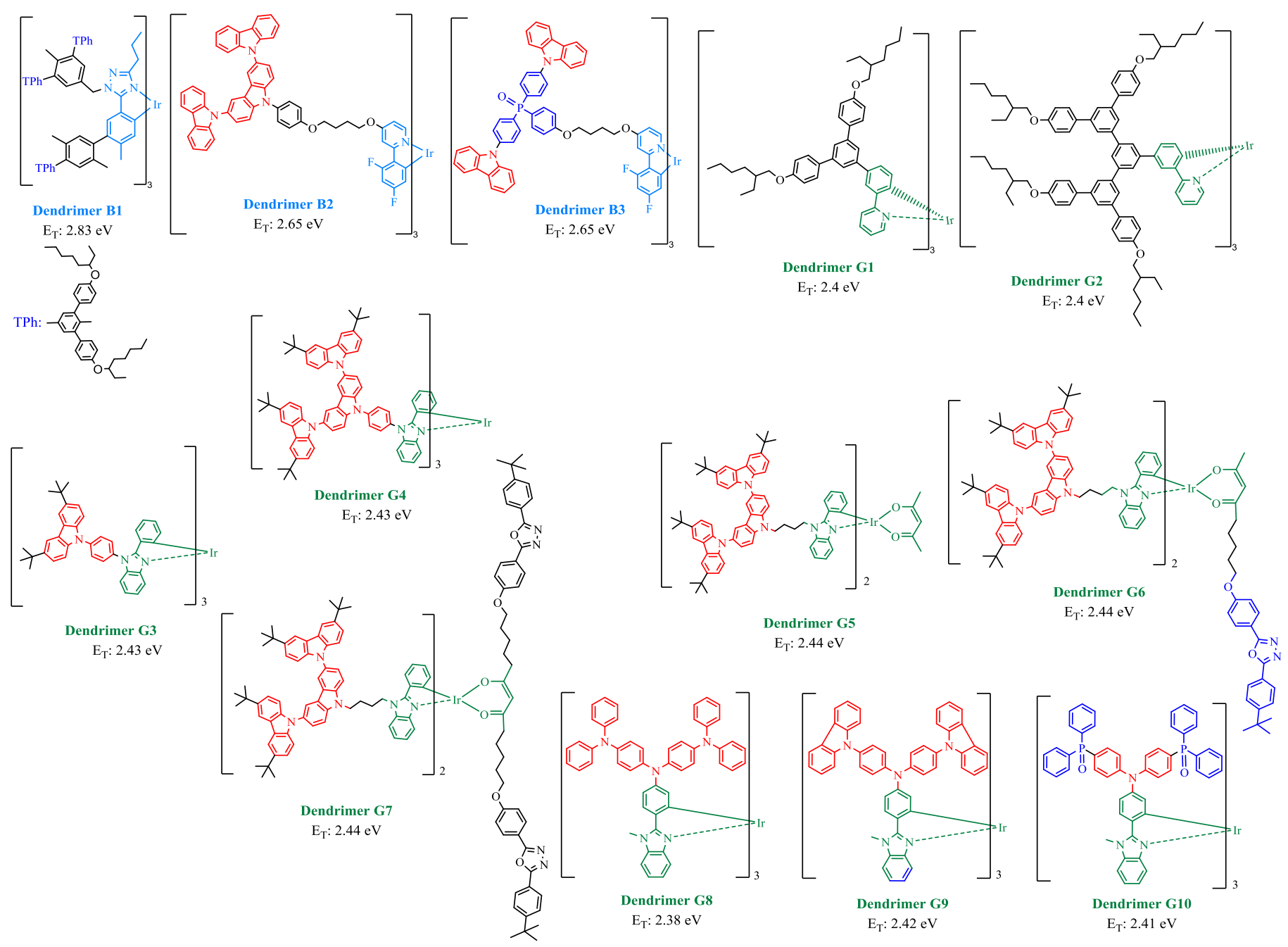

Figure 13. Molecular structure of phosphorescent dendrimers used in single-layer PhOLEDs

In 2016, two other non-doped blue SL-PhOLEDs (D86-D87) based on Dendrimer B2 and Dendrimer $\mathbf{B 3}$ were reported. ${ }^{[106]}$ Both dendrimers consist in a central bis(2,4difluorophenylpyridinato)-iridium (III) core, similar to the one of FIr6, decorated by a carbazole dendron in Dendrimer B2 or by a bipolar carbazole/triphenylphosphine oxide hybrid dendron in Dendrimer B3. The physicochemical properties of the two dendrimers were similar suggesting that the modification of the peripheral dendrons does not affect their optical and electrochemical properties. Exploration of the bipolar transporting capability of the two dendrimers shows that the hole current of Dendrimer B2 is several orders of magnitude higher than the electron current, indicative of the unipolar transporting behaviour of this dendrimer. Oppositely, for Dendrimer B3, the electron current is enhanced relative to Dendrimer B2 and becomes comparable to the hole current. This point is confirmed by the SL-PhOLED performances of D86 and D87, CE is drastically improved from $0.003 \mathrm{~cd} /$ A for D86 (Dendrimer B2) to $2.2 \mathrm{~cd} / \mathrm{A}$ (Dendrimer B3) for D87. This result confirms the key role played by the charge transport in such a device.

The first green SL-PhOLED (D24) reported in 2002 by Burn, Samuel and their co-workers has displayed an EQE of $8.1 \%$ (Table 2). ${ }^{[27]}$ In this work, the authors have used CBP to host different dendritic Iridium complexes. The authors noted that the performance of the Iridium based 
Dendrimer G1 (See structure in Figure 13) in a solution processed SL-PhOLED (ITO/EML/Ca/Al) was significantly higher than that of the classical Ir(ppy) $)_{3}$ phosphor (D25: EQE $0.8 \%$ ). In this work, the authors also prepared a second generation of dendrimer (Dendrimer G2) and designed SLPhOLEDs using neat films of dendrimers G1 or G2 (D88-D89) ${ }^{[27]}$ Performances of D88-D89 (EQE: $0.2 \%-2.1 \%$ ) are lower than that of D24 (EQE: 8.1\%). However, D88-D89 show that there is a striking dependence of the EQE on the generation of dendrimer with EQE increasing significantly from D88 with Dendrimer G1 to D89 with Dendrimer G2. The external dendrons have a significant effect on the charge transport within the device. These first results, obtained in 2002, demonstrated that light-emitting dendrimers constitute a possible approach to fabricate spin-coated phosphorescent devices.

In 2006, Cheng and Wang and co-workers synthesized two carbazole-based dendrimers with an iridium core (Dendrimer G3 and Dendrimer G4), formed high-quality films by spin-coating. ${ }^{[107]}$ These green emitters were used in neat films between an anode (ITO/PEDOT:PSS) and a cathode $(\mathrm{Ca} / \mathrm{Al})$. The performance was nevertheless very weak with maximum $\mathrm{CE}$ of less than $1 \mathrm{~cd} / \mathrm{A}$ (Dendrimer G3 (Device D90: $0.3 \mathrm{~cd} / \mathrm{A}, 0.09 \%$ ) or Dendrimer G4 (Device D91: $0.6 \mathrm{~cd} / \mathrm{A}, 0.19$ $\%)$ ). The authors ascribed these low efficiencies to the unbalanced charge transport (good holetransporting properties but poor electron-transporting properties) of the carbazole-based dendrons. This has been confirmed by adding a TPBI layer as ETL between the cathode and the EML, which has led to a device performance enhancement (EQE reaching 5.1/8.8 \% and CE reaching 17.3/29.6 cd/A with Dendrimer G3/Dendrimer G4 as EML respectively), clearly showing that the electron injection and transport were troublesome in these systems. ${ }^{[107]}$

Table 5. Performances of Self-host SL-PhOLEDs (devices D85 to D97)

\begin{tabular}{|c|c|c|c|c|c|c|}
\hline EML & Device structure & $\begin{array}{l}\text { Von } \\
\text { (V) }\end{array}$ & $\begin{array}{l}\mathrm{EQE} \\
(\%)\end{array}$ & $\begin{array}{c}\mathbf{C E} \\
(\mathbf{c d} / \mathbf{A} \\
)\end{array}$ & $\begin{array}{l}1931 \text { CIE } \\
\quad(x, y)\end{array}$ & $\begin{array}{c}\text { Device number, } \\
\text { References }\end{array}$ \\
\hline Dendrimer B1 & ITO/SP-Dendrimer B1(100nm)/Ca/Al & 10 & 0.41 & 0.65 & $0.17,0.20$ & $\mathrm{D} 85,2009^{[105]}$ \\
\hline Dendrimer B2 & ITO/PEDOT:PSS(45nm)/ SP-Dendrimer B2 (80nm)/LiF(0.5nm)/Al(100nm) & - & 0.002 & 0.003 & $0.18,0.33$ & D86, 2016 \\
\hline Dendrimer B3 & ITO/PEDOT:PSS(45nm)/SP-Dendrimer B3 (80nm)/LiF(0.5nm)/Al(100nm) & - & 1.03 & 2.2 & $0.17,0.31$ & D87, 2016 $6^{[106]}$ \\
\hline Dendrimer G1 & ITO/SP-Dendrimer G1(120nm)/Ca/Al & - & 0.2 & - & - & $\mathrm{D} 88,2002^{[27]}$ \\
\hline Dendrimer G2 & ITO/SP-Dendrimer G2 $(120 \mathrm{~nm}) / \mathrm{Ca} / \mathrm{Al}$ & - & 2.1 & - & - & $\mathrm{D} 89,2002^{[27]}$ \\
\hline Dendrimer G3 & ITO/PEDOT:PSS(40nm)/SP-Dendrimer G3/Ca/Al & - & 0.09 & 0.30 & - & $\mathrm{D} 90,2006^{[107]}$ \\
\hline Dendrimer G4 & ITO/PEDOT:PSS(40nm)/SP-Dendrimer G4/Ca/Al & - & 0.19 & 0.60 & - & D91, 2006 $6^{[107]}$ \\
\hline Dendrimer G5 & ITO/PEDOT:PSS(50nm)/ Dendrimer G5/Ca(10nm)/Al(100nm) & 5.1 & 0.8 & 2.8 & $0.38,0.58$ & D92, 2011 $1^{[108]}$ \\
\hline Dendrimer G6 & ITO/PEDOT:PSS(50nm)/ Dendrimer G6/Ca(10nm)/Al(100nm) & 5.8 & 1.1 & 3.7 & $0.37,0.59$ & $\mathrm{D} 93,2011^{[108]}$ \\
\hline Dendrimer G7 & ITO/PEDOT:PSS(50nm)/ Dendrimer G7/Ca(10nm)/Al(100nm) & 5.7 & 1.6 & 5.5 & $0.35,0.60$ & $\mathrm{D} 94,2011^{[108]}$ \\
\hline Dendrimer G8 & ITO/PEDOT:PSS/ SP-Dendrimer G8/ $\mathrm{Cs}_{2} \mathrm{CO}_{3} / \mathrm{Al}$ & 4.0 & 4.67 & 14.02 & $0.37,0.58$ & D95, 2014 ${ }^{[109]}$ \\
\hline Dendrimer G9 & ITO/PEDOT:PSS/ SP-Dendrimer G9/Cs $\mathrm{CO}_{3} / \mathrm{Al}$ & 4.3 & 6.12 & 18.35 & $0.38,0.58$ & D96, 2014 ${ }^{[109]}$ \\
\hline $\begin{array}{l}\text { Dendrimer } \\
\text { G10 }\end{array}$ & ITO/PEDOT:PSS(40nm)/ SP-Dendrimer G10/Cs ${ }_{2} \mathrm{CO}_{3}(2 \mathrm{~nm}) / \mathrm{Al}(100 \mathrm{~nm})$ & 4.6 & 7.2 & 21.6 & $0.35,0.40$ & D97, 2015 $5^{[110]}$ \\
\hline
\end{tabular}

In 2011, the same group synthesized bipolar heteroleptic green iridium dendrimers with two $\mathrm{C}^{\wedge} \mathrm{N}$ and one $\mathrm{O}^{\wedge} \mathrm{O}$ ligands: Dendrimers G5, Dendrimer G6 and Dendrimer G7. ${ }^{[107]}$ In those dendrimers, hole-transporting oligocarbazoles are linked to 2-phenyl-1H-benzoimidazole through a flexible spacer and ensure the role of the host. In Dendrimer G6 and Dendrimer G7, one or two electron-transporting oxadiazole moieties are introduced to the acetylacetonate fragment. In these two complexes, the donor oligocarbazole and the acceptor oxadiazole units are combined through non conjugated bonds. In such a situation, (i) the electronic coupling between donor and acceptor is weak, retaining the electronic properties of the iridium complex and (ii) hole and electron transporting units are independent and favourable to bipolar properties of the material.

For Dendrimer G6 and Dendrimer G7, the main physicochemical properties of Dendrimers G5 are conserved except the LUMO level, which is lowered from -1.8 (Dendrimers G5) to -1.9 (Dendrimer G6) and -2.1 eV (Dendrimer G7) thanks to the introduction of one or two oxadiazole unit(s) on the acetylacetonate ligand. SL-PhOLEDs using the pure dendrimer film as EML have been fabricated. Compared to Dendrimer G5-based device $\mathrm{D} 92\left(\mathrm{EQE}_{\max }: 0.8 \%, \mathrm{CE}_{\max }: 2.8 \mathrm{~cd} / \mathrm{A}\right)$, the 
addition of one or two electron-transporting unit(s) in Dendrimer G6 or Dendrimer G7 leads to an increase of the device efficiency (D93/Dendrimer G6: $\mathrm{EQE}_{\max }=1.1 \%$, and $\mathrm{CE}_{\max }=3.7 \mathrm{~cd} / \mathrm{A}$; D94/Dendrimer G7: $\mathrm{EQE}_{\max }=1.6 \%$ and $\left.\mathrm{CE}_{\max }=5.5 \mathrm{~cd} / \mathrm{A}\right)$. However, these performance remain very weak for phosphorescent devices.

In 2014, the efficiency of this strategy was shown with green Ir based emitter Dendrimer G8, which is constructed on a phenyl benzimidazole ligand and an oligophenyl amine. Dendrimer G8 was spin-coated on the anode (ITO/PEDOT:PSS) and used as EML in SL-PhOLED. ${ }^{[109]}$ The device D95 reaches an efficiency of $14.02 \mathrm{~cd} / \mathrm{A}$ and presents the green emission of the dendrimer (CIE: 0.37 , 0.58). Another dendritic iridium complex, Dendrimer G9, based on two phenylcarbazole units surrounded the iridium core, was also prepared in order to study the effect of the molecular rigidity on the device. It must be noted that HOMO level of Dendrimer G9 $(-5.25 \mathrm{eV})$ is lower than that of Dendrimer $\mathbf{G 8}$ by $0.25 \mathrm{eV}$ reflecting that the outer carbazole units are electron-withdrawing through an inductive $\pi$-polarization effect. Device D96 based on Dendrimer G9 reaches a CE of $18.35 \mathrm{~cd} / \mathrm{A}$. D96 shows better performance than D95 because the increased hole-injection barrier and reduced electron-injection barrier (LUMO levels of Dendrimer G8/Dendrimer G9 are respectively recorded at $-2.6 /-2.9 \mathrm{eV}$ ) tend to eliminate exciton quenching at the cathode interface. The EQE reported were respectively $6.12 \%$ and $4.67 \%$ for devices based on Dendrimer G8 and Dendrimer G9.

The comparison of devices D91 based on Dendrimer G4 and D96 based on Dendrimer G9 shows the influence of the molecular structure of the dendrimer on the device efficiencies. Indeed, the performance obtained with Dendrimer G4 (Device D91, EQE $=0.19 \%$ ) is drastically lower than that using Dendrimer G9 (Device D96, EQE $=6.12 \%$ ).

Both Dendrimer G4 and Dendrimer G9 are constructed on phenylbenzimidazole electron-deficient units and electron-rich carbazole dendrons. In Dendrimer G4, the carbazole dendrons are attached via the nitrogen atom of the phenylbenzimidazole units whereas in Dendrimer G9, they are attached on their pending phenyl ring. Such different organisation induces different intermolecular interactions and also differently orients the phenylbenzimidazole units, which are more in the centre of the molecule in Dendrimer G4 and on the surface of the dendrimer in Dendrimer G9. This 'surface effect' seems to have a positive effect in term of performance.

In 2015, the same group synthesized a new generation of bipolar iridium dendrimers containing diphenylphosphoryl groups, namely Dendrimer G10. ${ }^{[10]}$ Together with the diphenylamine groups, balance hole and electron flows are expected in the EML. In fact, the device D97 based on Dendrimer G10 reaches a CE of $21.6 \mathrm{~cd} / \mathrm{A}$ (EQE: $7.2 \%$ ) being more efficient than device D96 and as far we know is nowadays the highest reported value for non-doped green SL-PhOLEDs.

To conclude, this strategy is, in principle, appealing but controlling the charge transport, the emission wavelength, the quantum yield and the HOMO/LUMO gap appears difficult. Therefore, the performance of self-host SL-PhOLEDs has remained below those of the classical SL-PhOLEDs described in the first part (Best blue SL-PhOLED: device D9: $20.3 \%$, best blue self-host SLPhOLED: device D87: $1.03 \%$ / best green SL-PhOLED: device D58: $20.1 \%$, best green self-host SL-PhOLED: device D97: 7.2 \%). To our knowledge, no red non-doped SL-PhOLED is reported in literature.

\section{b. Mixed-hosts Strategy}

Reaching ambipolar host materials for SL-PhOLEDs is a difficult task and very often (especially at the beginning of the PhOLEDs research), these materials displayed higher hole than electron mobility leading to an unbalanced charge transport. This has been a recurrent problem in the field of OLEDs and more generally in organic electronics, as hole-transporting materials have been more rapidly developed than electron-transporting materials. Improving the electron flow in the EML of a 
SL-PhOLED (fluorescent or phosphorescent) has always been a key issue to solve. Thus, SLPhOLEDs using in the EML a mixture of host materials composed of two components, one with hole- and the other with electron-injecting/transporting properties have been imagined. This strategy using a mixture of two molecules (host and co-host) has been called the 'mixed-hosts strategy'.

In 2008, the group of Qiu has used TBCPF (Figure 14) as host for FIrpic in a classical SL-PhOLED with nevertheless low performances (D1, $\mathrm{V}_{\text {on }}: 9.7 \mathrm{~V}, \mathrm{CE}_{\max }: 3.5 \mathrm{~cd} / \mathrm{A}$, see Table 1). ${ }^{[36]}$ In order to improve the electron-injection in the EML, the authors judiciously introduced electron-transporting component, 1,3-bis[(4-tert-butylphenyl)-1,3,4-oxidiazolyl]phenylene (OXD-7), in the EML. They first studied the PL spectra of FIrpic-doped TBCPF:OXD-7 thin films to control that the emission exclusively arises from the blue phosphor. After these verifications, they built different devices with EML constructed on a mixture of TBCPF, OXD-7 and FIrpic in different proportions (D98-D101, Table 6). The performances of the devices were greatly improved from $3.5 \mathrm{~cd} / \mathrm{A}$ in D1 to $6.4-12.5$ cd/A in D98-D101. Playing with the ratio TBCPF:OXD-7 and the FIrpic concentration, the performance has been significantly improved (D101; $\left.\mathrm{V}_{\text {on }}: 7.3 \mathrm{~V}, \mathrm{CE}_{\max }: 12.5 \mathrm{~cd} / \mathrm{A}\right)$ with a ratio of TBCPF:OXD-7 60:30 in mass and FIrpic 10\%, showing the efficiency of this strategy and opening the way to the mixed-hosts based phosphorescent devices. ${ }^{[36]}$

In 2010, the same group designed blue SL-PhOLEDs using OXD-7 as electron-transporting host and hole-transporting carbazole/ $m$-terphenyl-based co-hosts (DQC or PTC) ( $\mathbf{m C P}$ has also been used as model compound in this study, Figure 14). ${ }^{[11]}$ With $10 \%$ FIrpic in the mixed-hosts EML, the solution-processed devices reach different performances with EQE between 1 and $6.5 \%$ depending on the hole-transporting component (1\% with mCP (D104), $4.6 \%$ with DQC (D103) and $6.5 \%$ with PTC (D102)). The best results were obtained with the mixed-hosts PTC:OXD-7 (60:30) with a $\mathrm{V}_{\text {on }}$ of $4.8 \mathrm{~V}$ and EQE/CE of $6.5 \% / 12.8 \mathrm{~cd} / \mathrm{A}$ (D102). Compared to the previous devices D101 with TBCPF:OXD-7 as mixed-hosts, the device D102 based on PTC:OXD-7 displays similar performance but a lower $\mathrm{V}_{\text {on }}(7.3 \mathrm{vs} 4.8 \mathrm{~V})$. It must be noted that the two series of devices present different CIE coordinates (0.21, 0.44 for TBCPF based D101 vs $0.16,0.32$ for $\mathbf{~ m C P , ~ D Q C ~ o r ~ P T C ~}$ based D102-D104). For the latters, the CIE coordinates are in accordance with a single emission of FIrpic. This is not the case for TBCPF.

In 2011, the group of Lee outperformed the precedent blue SL-PhOLEDs performances, using TAPC as hole-transporting host and $\mathbf{S B F}(\mathbf{P O P h})_{2}$ as electron-transporting co-host. ${ }^{[12]}$ Both TAPC $\left(\mathrm{E}_{\mathrm{T}}: 2.87 \mathrm{eV}\right)$ and $\mathbf{S B F}(\mathbf{P O P h})_{2}\left(\mathrm{E}_{\mathrm{T}}: 2.73 \mathrm{eV}\right)$ have an $\mathrm{E}_{\mathrm{T}}$ higher than that of FIrpic $\left(\mathrm{E}_{\mathrm{T}}: 2.65 \mathrm{eV}\right)$. TAPC with a HOMO of $-5.5 \mathrm{eV}$ and a high mobility $\left(10^{-2} \mathrm{~cm}^{2} \mathrm{~V}^{-1} \mathrm{~s}^{-1}\right)$, is appropriate as holeinjecting and hole-transporting material. ${ }^{[113]}$ On the other hand, $\mathbf{S B F}(\mathbf{P O P h})_{2}$ with a LUMO of $2.91 \mathrm{eV}$ and a $\mu_{\mathrm{e}}$ of $6.9 \times 10^{-5} \mathrm{~cm}^{2} \mathrm{~V}^{-1} \mathrm{~s}^{-1}$ is effective as electron-transporting material and for the direct electron injection from the LiF/Al cathode $(-2.9 \mathrm{eV}) .{ }^{[52]}$ The $\mathrm{V}_{\text {on }}$ of the resulting device D105 is low $(2.5 \mathrm{~V})$ due to the charge injection properties of both TAPC and $\mathbf{S B F}(\mathbf{P O P h})_{2}$. The EQE and PE were reported at high values: $15.8 \%$ and $31.4 \mathrm{~lm} / \mathrm{W}$ respectively, significantly outperforming the above described blue mixed-hosts SL-PhOLEDs (6.5\% with PTC:OXD-7 in D102). However, it must be noted that the devices based on TAPC:SBF $(\mathbf{P O P h})_{2}$ are thermally evaporated devices whereas those based on PTC:OXD-7 are solution processed devices.

In 2013, OXD-7 was used once more as electron-injecting/transporting co-host of the hole transporting SimCP2 in efficient blue SL-PhOLED D106. ${ }^{[14]}$ SimCP2 possesses ambipolar characteristics with almost identical $\mu_{\mathrm{h}}\left(4.8 \times 10^{-4} \mathrm{~cm}^{2} \mathrm{~V}^{-1} \mathrm{~s}^{-1}\right)$ and $\mu_{\mathrm{e}}\left(2.7 \times 10^{-4} \mathrm{~cm}^{2} \mathrm{~V}^{-1} \mathrm{~s}^{-1}\right)$ values. ${ }^{[15]}$ SimCP2 with HOMO lying at $-6.01 \mathrm{eV}$ and LUMO lying at $-2.44 \mathrm{eV}$ is appropriate for the electron injection at the CsF/Al cathode (WF:-2.14 eV) but suffers of a nearly $1 \mathrm{eV}$ hole injection barrier at the anode (PEDOT:PSS (WF:-5.2 eV)). Solution-processed SL-PhOLED D106 with a SimCP2:OXD-7:FIrpic (65:30:5) EML reaches a CE of $14.7 \mathrm{~cd} / \mathrm{A}(8.39 \mathrm{~lm} / \mathrm{W})$. As far as we know, the performance of device D106 is the highest recorded for solution-processed blue SL-PhOLEDs 
based on a mixed-hosts EML (D98-D104). In this work, the authors reach a further increase of the luminous efficiency up to $23 \mathrm{~cd} / \mathrm{A}$ using a brightness enhancement film at the glass surface of the device.

Following the research on mixed-hosts based devices, the same group has reported in 2014 other hole injecting/transporting molecules to be hosted with OXD-7. The device structure is similar to that of D106 presented above, with nevertheless a thinner aluminium cathode (100 nm vs $200 \mathrm{~nm}$ ). Using SimCP2, CzPAMe, CzPPO or CzPAPm as hole transporting hosts, the devices (D107-118) present higher performances than those presented in previous section using these hosts alone (D10D13, Table 1), clearly showing the efficiency of the mixed-hosts strategy. In this approach, the ratio of the Host:OXD-7 mixture is very important and the authors have shown, varying this ratio from 95:0 to 45:50 with FIrpic 5\%, that the CE can be increased from 3.43 (D11) to 9.2 (D107) cd/A with SimCP2, from 1.34 (D13) to 10.6 (D113) cd/A with CzPAMe, from 9.32 (D10) to 12.2 (D110) cd/A with CzPPO and from 2.82 (D12) to 8.15 (D116) cd/A with CzPAPm. From all these device data, it is shown that CzPPO outperforms the three other host materials in device D110 with the lowest $\mathrm{V}_{\text {on }}(4.6 \mathrm{~V})$ and the highest $\mathrm{CE}(12.2 \mathrm{~cd} / \mathrm{A})$. This may be explained by the bipolar charge transporting feature of CzPPO and was also pointed in Part I.1.a in absence of OXD-7 (D10 performance superior to D11-D13 performances).

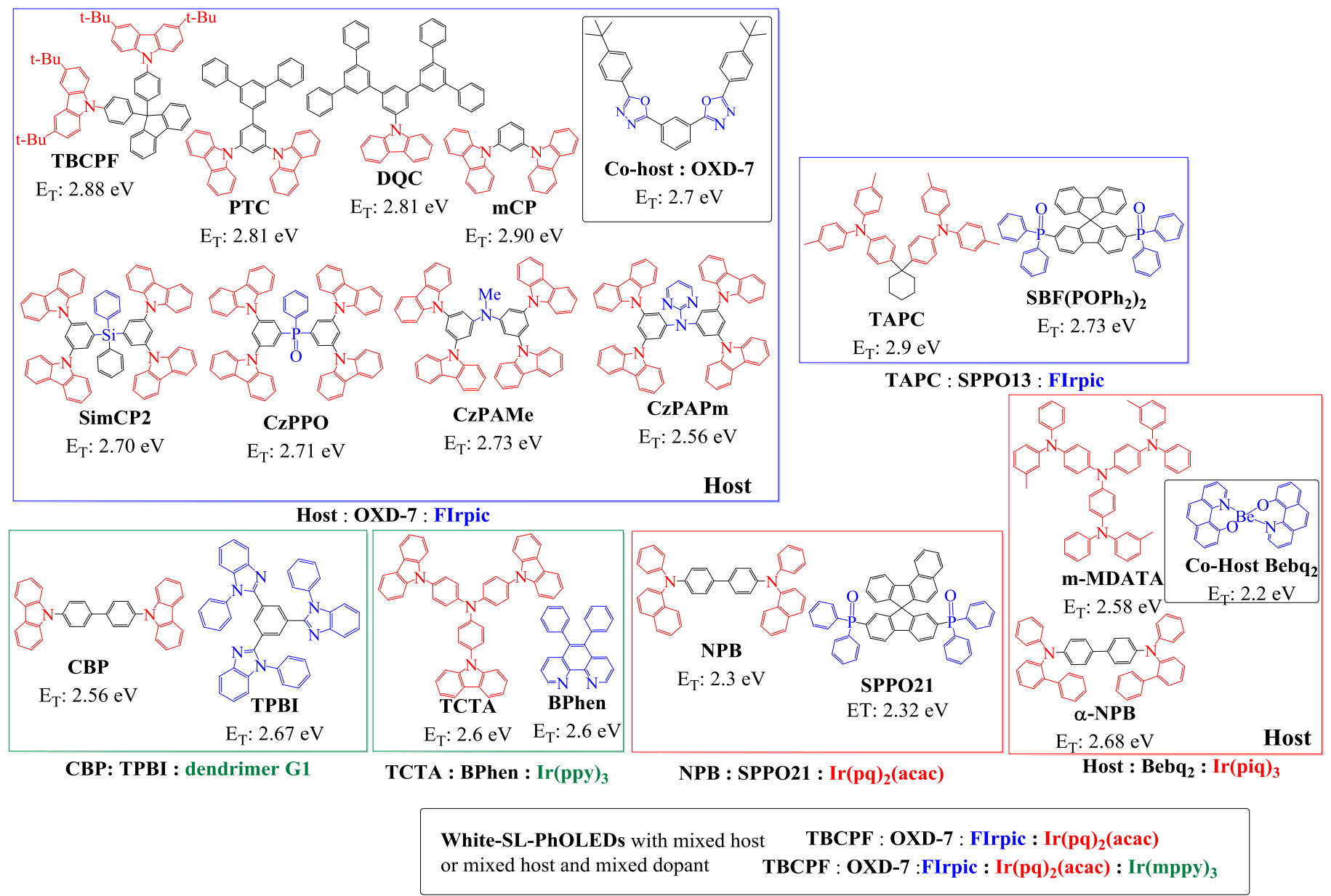

Figure 14. Molecular structure of hosts and co-hosts used in SL-PhOLEDs with mixed-hosts in EML. In the host materials, black, blue and red fragments respectively point the $\pi$-linker, the acceptor and the donor units of the OSC.

In 2002, the previously described green device D24, using as EML: CBP doped by a dendritic Iridium complex G1 reached an EQE of $8.1 \%\left(\mathrm{~V}_{\text {on }}: 4.4 \mathrm{~V}, \mathrm{CE}: 28 \mathrm{~cd} / \mathrm{A}, \mathrm{PE}: 6.9 \mathrm{~lm} / \mathrm{W}\right)$. One year 
later, the same group improved the performance of D24 using a mixed-hosts device based on the ambipolar CBP and the electron-transporting TPBI. ${ }^{[116]}$ The EQE of D119 reached $10.4 \%$ and the performance of D119 was higher than that of D24. The reason of this improvement is clearly due to the presence of TPBI as co-host. First, TPBI has a lower LUMO than CBP $(-2.7 \mathrm{eV} v s-2.3 \mathrm{eV}$ respectively), which reduces the barrier of electron injection. Second, TPBI has an electron transport character which increase $\mu_{\mathrm{e}}$ in the EML. Finally, TBPI is a hole blocking material, which helps to shift the recombination zone away from the cathode. The carrier injection/transport properties have been optimized by the authors by adjusting the composition of the EML with the optimum G1:CBP:TPBI ratio of 20:52:28 \% in mass respectively. $\mathrm{V}_{\text {on }}$ is also reduced from $4.4 \mathrm{~V}$ in D24 to $2.9 \mathrm{~V}$ in D119

In 2010, Holmes and Erickson constructed green SL-PhOLEDs D120-D121 based on a mixed-hosts EML TCTA:BPhen 1:1 doped with $5 \% \operatorname{Ir}(\mathbf{p p y})_{3}{ }^{[117]}$ TCTA works as hole-transporting host whereas BPhen works as electron-transporting host, both have been chosen for their well balance charge carrier mobilities of around $10^{-4} \mathrm{~cm}^{2} \mathrm{~V}^{-1} \mathrm{~s}^{-1}\left(\mu_{\mathrm{h}}(\text { TCTA })^{[118]}: 3 \times 10^{-4} \mathrm{~cm}^{2} \mathrm{~V}^{-1} \mathrm{~s}^{-1}\right.$ and $\mu_{\mathrm{e}}$ (BPhen) $\left.{ }^{[119]}: 4.2 \times 10^{-4} \mathrm{~cm}^{2} \mathrm{~V}^{-1} \mathrm{~s}^{-1}\right)$. In this work, the EML composition varied continuously from nearly $100 \%$ TCTA at the anode to nearly $100 \%$ BPhen at the cathode. The emitter $\operatorname{Ir}(\mathbf{p p y})_{3}$ is doped uniformly throughout the EML. First, with a 1:1 constant ratio of the two hosts constant in all the thickness of the EML, benchmark device D120 presents low performances with $\mathrm{V}_{\text {on }}$ : $5 \mathrm{~V}$, $\mathrm{EQE}_{\max }: 0.25 \%$ and PE: $0.28 \mathrm{~lm} / \mathrm{W}$, indicating poor charge balance in the EML. A second type of device (D121) was constructed with the host/co-host in graded concentration inside the EML. Concentration of TCTA decreases from 1 to 0 whereas concentration of BPhen increases from 0 to 1 from the anode/EML interface to the cathode/EML interface, leading to a 1:1 mixed-hosts ratio in the centre of the EML. Thanks to this graded mixed-hosts composition, the green PhOLED D121 emits light since $2.6 \mathrm{~V}$ and reaches $\mathrm{EQE} / \mathrm{PE}$ of $19.3 \% / 66.5 \mathrm{~lm} / \mathrm{W}$. This performance is very high and has been achieved by maximizing the charge balance in the EML by continuously grading the composition from nearly $100 \%$ TCTA at the anode to nearly $100 \%$ BPhen at the cathode.

In 2010, an efficient red SL-PhOLED using $\operatorname{Ir}(\mathbf{p q})_{\mathbf{2}}$ (acac) as emitter was constructed with NPB as hole injecting and transporting host and with SPPO21 as electron-injecting and transporting host. The relative ratio of the two hosts was varied between 10:90 to 50:50 and the device D122 with the NPB:SPPO21 ratio of 25:75 has led to the best performance with the pure emission of the red phosphor and an EQE reaching $7.3 \%(11.4 \mathrm{~cd} / \mathrm{A})$.

The same year, Kwon and their co-workers overpassed this performance. The red phosphorescent $\operatorname{Ir}(\text { piq })_{3}$ doped a mixed-hosts EML constructed on the ambipolar $\boldsymbol{\alpha}$-NPB as hole transporting host material and $\mathbf{B e b q}_{2}$ as electron-transporting host material. ${ }^{[120]}$ The ratio of these hosts was fixed to $1: 1$ and the doping concentration was varied from 1 to $4 \%(1,2$ or $4 \%)$ to optimize the device performance ((D123-D125). The best performance, $\mathrm{CE}_{\max }: 9.44 \mathrm{~cd} / \mathrm{A}$, was reached with D123 with the lowest $\operatorname{Ir}($ piq) 3 concentration of $1 \%$.

In the same work was constructed a second series of mixed-hosts devices based on a 1:1 mixture of the hole transporting $\boldsymbol{m}$-MTDATA (Figure 14) and the electron-transporting Bebq2. Compared to the previous devices, the performance of this series, D126-D128, was slightly lower with a CE independent of the red phosphor concentration $\left(8.12,8.19\right.$ and $8.04 \mathrm{~cd} / \mathrm{A}$ with $\operatorname{Ir}(\mathbf{p i q})_{\mathbf{3}}: 1,2$ and 4 $\%)$. Comparison of the two devices series provides interesting conclusions. Looking at the HOMO of m-MTDATA $(-5.1 \mathrm{eV})$, there is no barrier for hole injection from ITO (WF:-5.1 eV). Similarly, Bebq $_{2}$ with a LUMO of $-2.8 \mathrm{eV}$ fits very well the Fermi level of the cathode $(-2.9 \mathrm{eV})$ and electrons injected from the cathode move freely on the LUMO of $\mathbf{B e b q}_{2}$. Concerning $\boldsymbol{\alpha}$-NPB (HOMO: -5.4 $\mathrm{eV}$ ), there is a barrier for the hole injection from the anode to the EML. The HOMO levels of $\boldsymbol{m}$ - 
MTDATA and $\boldsymbol{\alpha}$-NPB are therefore not in accordance with the uppermost performances of the $\boldsymbol{\alpha}$ NPB-based devices. Interestingly, $\boldsymbol{\alpha}$-NPB exhibits an ambipolar transporting ability with similar $\mu_{\mathrm{e}}$ and $\mu_{\mathrm{h}}$ values $\left(9 \times 10^{-4}\right.$ and $6 \times 10^{-4} \mathrm{~cm}^{2} \mathrm{~V}^{-1} \mathrm{~s}^{-1}$ respectively) while $\mu_{\mathrm{h}}$ value of $\boldsymbol{m}$-MTDATA is $2.7 \times 10^{-5}$ $\mathrm{cm}^{2} \mathrm{~V}^{-1} \mathrm{~s}^{-1}$. Mobilities of hole carriers in the mixed-hosts SL-PhOLEDs rather than the hole injection barrier at the anode/mixed-hosts interface seems to be crucial on the device performance.

In 2010, using the same mixed-hosts composition (TBCPF:OXD-7) as is the blue devices D98-D99, Qiu group fabricated a series of solution-processed white SL-PhOLEDs (D129-D138). ${ }^{[121]}$ The access to the white emission was obtained by using two (red and blue) or three (red, green and blue) phosphorescent dyes in the mixed-hosts based EML.

Table 6. Performances of SL-PhOLEDs based on mixed-hosts EML (devices D98 to D138)

\begin{tabular}{|c|c|c|c|c|c|c|c|}
\hline \multicolumn{8}{|c|}{ Blue SL-PhOLEDs using Mixed-Hosts in their EML } \\
\hline Mixed-Hosts & Device structure & $\begin{array}{l}\text { Von } \\
\text { (V) }\end{array}$ & $\begin{array}{c}\text { EQE } \\
(\%)\end{array}$ & $\begin{array}{c}\mathbf{C E} \\
(\mathbf{c d} / \mathbf{A})\end{array}$ & $\begin{array}{c}\mathbf{P E} \\
(\mathbf{l m} / \mathbf{W})\end{array}$ & $\begin{array}{c}1931 \text { CIE } \\
(x, y)\end{array}$ & $\begin{array}{c}\text { Device number, } \\
\text { References }\end{array}$ \\
\hline $\begin{array}{l}\text { TBCPF:OXD-7 } \\
(80: 10)\end{array}$ & $\begin{array}{l}\text { ITO/PEDOT:PSS/SP-Mixed-Hosts:FIrpic } 10 \% \\
/ \mathrm{Cs}_{2} \mathrm{CO}_{3}(2 \mathrm{~nm}) / \mathrm{Al}(100 \mathrm{~nm})\end{array}$ & 8.9 & - & 6.4 & - & $0.215,0.435$ & $\mathrm{D} 98,2008^{[36]}$ \\
\hline $\begin{array}{l}\text { TBCPF:OXD-7 } \\
(70: 20)\end{array}$ & $\begin{array}{l}\text { ITO/PEDOT:PSS/SP-Mixed-Hosts:FIrpic } 10 \% \\
/ \mathrm{Cs}_{2} \mathrm{CO}_{3}(2 \mathrm{~nm}) / \mathrm{Al}(100 \mathrm{~nm})\end{array}$ & 7.6 & - & 8.9 & - & $0.217,0.438$ & D99, 2008 $8^{[36]}$ \\
\hline $\begin{array}{l}\text { TBCPF:OXD-7 } \\
(50: 40)\end{array}$ & $\begin{array}{l}\text { ITO/PEDOT:PSS/SP-Mixed-Hosts:FIrpic } 10 \% \\
/ \mathrm{Cs}_{2} \mathrm{CO}_{3}(2 \mathrm{~nm}) / \mathrm{Al}(100 \mathrm{~nm})\end{array}$ & 7.2 & - & 11.3 & - & $0.221,0.439$ & $\mathrm{D} 100,2008^{[36]}$ \\
\hline $\begin{array}{l}\text { TBCPF:OXD-7 } \\
(60: 30)\end{array}$ & $\begin{array}{l}\text { ITO/PEDOT:PSS/SP-Mixed-Hosts:FIrpic } 10 \% \\
/ \mathrm{Cs}_{2} \mathrm{CO}_{3}(2 \mathrm{~nm}) / \mathrm{Al}(100 \mathrm{~nm})\end{array}$ & 7.3 & - & 12.5 & - & $0.217,0.441$ & D101, 2008 $8^{[36]}$ \\
\hline $\begin{array}{l}\text { PTC:OXD-7 } \\
(60: 30)\end{array}$ & $\begin{array}{l}\text { ITO/PEDOT:PSS/SP-Mixed-Hosts:FIrpic } 10 \% \\
/ \mathrm{Cs}_{2} \mathrm{CO}_{3} / \mathrm{Al}\end{array}$ & 4.8 & 6.5 & 12.8 & - & $0.16,0.32$ & $\mathrm{D} 102,2010^{[111]}$ \\
\hline $\begin{array}{l}\text { DQC:OXD-7 } \\
(60: 30)\end{array}$ & $\begin{array}{l}\text { ITO/PEDOT:PSS/SP-Mixed-Hosts:FIrpic } 10 \% \\
/ \mathrm{Cs}_{2} \mathrm{CO}_{3} / \mathrm{Al}\end{array}$ & 5.0 & 4.6 & 9.2 & - & $0.16,0.32$ & $\mathrm{D} 103,2010^{[111]}$ \\
\hline $\begin{array}{l}\text { mCP:OXD-7 } \\
(60: 30)\end{array}$ & $\begin{array}{l}\text { ITO/PEDOT:PSS/SP-Mixed-Hosts:FIrpic } 10 \% \\
/ \mathrm{Cs}_{2} \mathrm{CO}_{3} / \mathrm{Al}\end{array}$ & 7.0 & 1.0 & 1.8 & - & $0.16,0.31$ & $\mathrm{D} 104,2010^{[111]}$ \\
\hline $\begin{array}{l}\text { TAPC: } \mathbf{S B F}\left(\mathbf{P O P h}_{2}\right)_{2} \\
(25: 65)\end{array}$ & 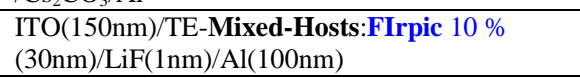 & 2.5 & 15.8 & - & 31.4 & - & $\mathrm{D} 105,2011^{[112]}$ \\
\hline $\begin{array}{l}\text { SimCP2:OXD-7 } \\
(65: 30)\end{array}$ & $\begin{array}{l}\text { ITO(100nm)/PEDOT:PSS }(65 \mathrm{~nm}) / \mathrm{SP}-M i x e d- \\
\text { Hosts: FIrpic } 5 \%(70 \mathrm{~nm}) / \mathrm{CsF}(2 \mathrm{~nm}) / \mathrm{Al}(200 \mathrm{~nm})\end{array}$ & - & - & 14.7 & 8.39 & - & $\mathrm{D} 106,2013^{[114]}$ \\
\hline $\begin{array}{l}\text { SimCP2:OXD-7 } \\
(65: 30)\end{array}$ & $\begin{array}{l}\text { ITO/PEDOT:PSS(65nm)/SP-Mixed-Hosts: } \\
\text { FIrpic } 5 \%(70 \mathrm{~nm}) / \mathrm{CsF}(2 \mathrm{~nm}) / \mathrm{Al}(100 \mathrm{~nm})\end{array}$ & 5.0 & - & 9.2 & 2.64 & $0.14,0.30$ & D107, 2014 $4^{[49]}$ \\
\hline $\begin{array}{l}\text { SimCP2:OXD-7 } \\
(45: 50)\end{array}$ & $\begin{array}{l}\text { ITO/PEDOT:PSS }(65 \mathrm{~nm}) / \text { SP-Mixed-Hosts: } \\
\text { FIrpic } 5 \%(70 \mathrm{~nm}) / \mathrm{CsF}(2 \mathrm{~nm}) / \mathrm{Al}(100 \mathrm{~nm})\end{array}$ & 5.0 & - & 6.29 & 3.85 & $0.15,0.33$ & D108, 2014 ${ }^{[49]}$ \\
\hline $\begin{array}{l}\text { SimCP2:OXD-7 } \\
(80: 15)\end{array}$ & $\begin{array}{l}\text { ITO/PEDOT:PSS(65nm)/ SP-Mixed-Hosts: } \\
\text { FIrpic } 5 \%(70 \mathrm{~nm}) / \mathrm{CsF}(2 \mathrm{~nm}) / \mathrm{Al}(100 \mathrm{~nm})\end{array}$ & 5.7 & - & 3.58 & 1.79 & $0.15,0.33$ & D109, 2014 $4^{[49]}$ \\
\hline $\begin{array}{l}\text { CzPPO:OXD-7 } \\
(45: 50)\end{array}$ & $\begin{array}{l}\text { ITO/PEDOT:PSS(65nm)/ SP-Mixed-Hosts: } \\
\text { FIrpic } 5 \%(70 \mathrm{~nm}) / \mathrm{CsF}(2 \mathrm{~nm}) / \mathrm{Al}(100 \mathrm{~nm})\end{array}$ & 4.6 & - & 12.2 & 5.38 & $0.16,0.39$ & D1 10, 2014 ${ }^{[49]}$ \\
\hline $\begin{array}{l}\text { CzPPO:OXD-7 } \\
(65: 30)\end{array}$ & $\begin{array}{l}\text { ITO/PEDOT:PSS }(65 \mathrm{~nm}) / \text { SP-Mixed-Hosts: } \\
\text { FIrpic } 5 \%(70 \mathrm{~nm}) / \mathrm{CsF}(2 \mathrm{~nm}) / \mathrm{Al}(100 \mathrm{~nm})\end{array}$ & 4.6 & - & 11.0 & 5.30 & $0.15,0.34$ & $\mathrm{D} 111,2014^{[49]}$ \\
\hline $\begin{array}{l}\text { CzPPO:OXD-7 } \\
(80: 15)\end{array}$ & $\begin{array}{l}\text { ITO/PEDOT:PSS(65nm)/ SP-Mixed-Hosts: } \\
\text { FIrpic } 5 \%(70 \mathrm{~nm}) / \mathrm{CsF}(2 \mathrm{~nm}) / \mathrm{Al}(100 \mathrm{~nm})\end{array}$ & 5.0 & - & 10.4 & 5.13 & $0.15,0.34$ & D112, 2014 $4^{[49]}$ \\
\hline $\begin{array}{l}\text { CzPAMe:OXD-7 } \\
(45: 50)\end{array}$ & $\begin{array}{l}\text { ITO/PEDOT:PSS }(65 \mathrm{~nm}) / \text { SP-Mixed-Hosts: } \\
\text { FIrpic } 5 \%(70 \mathrm{~nm}) / \mathrm{CsF}(2 \mathrm{~nm}) / \mathrm{Al}(100 \mathrm{~nm})\end{array}$ & 5.6 & - & 10.6 & 4.9 & $0.16,0.39$ & D113, 2014 ${ }^{[49]}$ \\
\hline $\begin{array}{l}\text { CzPAMe:OXD-7 } \\
(65: 30)\end{array}$ & $\begin{array}{l}\text { ITO/PEDOT:PSS }(65 \mathrm{~nm}) / \text { SP-Mixed-Hosts: } \\
\text { FIrpic } 5 \%(70 \mathrm{~nm}) / \mathrm{CsF}(2 \mathrm{~nm}) / \mathrm{Al}(100 \mathrm{~nm})\end{array}$ & 5.2 & - & 8.8 & 3.45 & $0.15,0.34$ & D114, 2014 ${ }^{[49]}$ \\
\hline $\begin{array}{l}\text { CzPAMe:OXD-7 } \\
(80: 15)\end{array}$ & $\begin{array}{l}\text { ITO/PEDOT:PSS(65nm)/ SP-Mixed-Hosts: } \\
\text { FIrpic } 5 \%(70 \mathrm{~nm}) / \mathrm{CsF}(2 \mathrm{~nm}) / \mathrm{Al}(100 \mathrm{~nm})\end{array}$ & 5.2 & - & 6.61 & 3.07 & $0.15,0.34$ & D115, 2014 $4^{[49]}$ \\
\hline $\begin{array}{l}\text { CzPAPm:OXD-7 } \\
(45: 50)\end{array}$ & $\begin{array}{l}\text { ITO/PEDOT:PSS(65nm)/ SP-Mixed-Hosts: } \\
\text { FIrpic } 5 \%(70 \mathrm{~nm}) / \mathrm{CsF}(2 \mathrm{~nm}) / \mathrm{Al}(100 \mathrm{~nm})\end{array}$ & 5.4 & - & 8.15 & 2.87 & $0.17,0.40$ & D116, 2014 ${ }^{[49]}$ \\
\hline $\begin{array}{l}\text { CzPAPm:OXD-7 } \\
(65: 30)\end{array}$ & $\begin{array}{l}\text { ITO/PEDOT:PSS(65nm)/ SP-Mixed-Hosts: } \\
\text { FIrpic } 5 \%(70 \mathrm{~nm}) / \mathrm{CsF}(2 \mathrm{~nm}) / \mathrm{Al}(100 \mathrm{~nm})\end{array}$ & 5.1 & - & 6.7 & 3.12 & $0.15,0.34$ & D117, 2014 ${ }^{[49]}$ \\
\hline $\begin{array}{l}\text { CzPAPm:OXD-7 } \\
(80: 15)\end{array}$ & $\begin{array}{l}\text { ITO/PEDOT:PSS(65nm)/ SP-Mixed-Hosts: } \\
\text { FIrpic } 5 \%(70 \mathrm{~nm}) / \mathrm{CsF}(2 \mathrm{~nm}) / \mathrm{Al}(100 \mathrm{~nm})\end{array}$ & 5.8 & - & 5.26 & 2.2 & $0.15,0.35$ & D118, 2014 ${ }^{[49]}$ \\
\hline \multicolumn{8}{|c|}{ Green or Red SL-PhOLEDs using Mixed-Hosts in their EML } \\
\hline $\begin{array}{l}\text { CBP:TPBI } \\
(20: 52)\end{array}$ & ITO/SP-Mixed-Hosts:G1-Ir $28 \% / \mathrm{LiF} / \mathrm{Al}$ & 2.9 & 10.4 & - & 12.8 & - & $\mathrm{D} 119,2003^{[16]}$ \\
\hline $\begin{array}{l}\text { TCTA:Bphen } \\
(1: 1)\end{array}$ & $\begin{array}{l}\text { ITO/PEDOT:PSS/TE-Mixed-Hosts:Ir(ppy })_{3} 2 \% \\
(100 \mathrm{~nm}) / \mathrm{Mg}: \mathrm{Ag}\end{array}$ & 5.0 & 0.25 & - & 0.28 & - & D120, 2010 $0^{[117]}$ \\
\hline $\begin{array}{l}\text { TCTA:Bphen in graded } \\
\text { concentration }(1: 0 \text { at the anode } \\
\text { side/ } 1: 1 \text { in the middle of the } \\
\text { EML/0:1 at the cathode side })\end{array}$ & $\begin{array}{l}\text { ITO/PEDOT:PSS/TE-Mixed-Hosts:Ir(ppy) } 2 \% \\
(100 \mathrm{~nm}) / \mathrm{Mg}: \mathrm{Ag}\end{array}$ & 2.6 & 19.3 & - & 66.5 & - & $\mathrm{D} 121,2010^{[117]}$ \\
\hline
\end{tabular}




\begin{tabular}{|c|c|c|c|c|c|c|c|}
\hline $\begin{array}{l}\text { NPB:SPPO21 } \\
(25: 75)\end{array}$ & $\begin{array}{l}\text { ITO/TE-Mixed-Hosts:Ir(pq) })_{2} \text { acac } 2 \%(100 \mathrm{~nm}) \\
\text { /Al }\end{array}$ & - & 7.3 & 11.4 & - & - & $\mathrm{D} 122,2010^{[122]}$ \\
\hline $\begin{array}{l}\boldsymbol{\alpha} \text {-NPB:Bebq } \\
(1: 1)\end{array}$ & $\begin{array}{l}\text { ITO/TE-Mixed-Hosts:Ir(piq) })_{3} 1 \%(100 \mathrm{~nm}) / \mathrm{LiF} \\
(0.5 \mathrm{~nm}) / \mathrm{Al}(100 \mathrm{~nm})\end{array}$ & 2.4 & 14.6 & 9.44 & 10.62 & $0.66,0.33$ & $\mathrm{D} 123,2010^{[120]}$ \\
\hline $\begin{array}{l}\boldsymbol{\alpha} \text {-NPB:Bebq } \\
(1: 1)\end{array}$ & $\begin{array}{l}\text { ITO/TE-Mixed-Hosts:Ir(piq) })_{3} 2 \%(100 \mathrm{~nm}) / \mathrm{LiF} \\
(0.5 \mathrm{~nm}) / \mathrm{Al}(100 \mathrm{~nm})\end{array}$ & 2.4 & - & 8.36 & 9.82 & $0.67,0.32$ & $\mathrm{D} 124,2010^{[120]}$ \\
\hline $\begin{array}{l}\boldsymbol{\alpha} \text {-NPB:Bebq } 2 \\
(1: 1)\end{array}$ & $\begin{array}{l}\text { ITO/TE-Mixed-Hosts:Ir(piq) })_{3} 4 \%(100 \mathrm{~nm}) / \mathrm{LiF} \\
(0.5 \mathrm{~nm}) / \mathrm{Al}(100 \mathrm{~nm})\end{array}$ & 2.4 & - & 7.04 & 8.11 & $0.66,0.33$ & $\mathrm{D} 125,2010^{[120]}$ \\
\hline $\begin{array}{l}\boldsymbol{m} \text {-MTDATA:Bebq } 2 \\
(1: 1)\end{array}$ & $\begin{array}{l}\text { ITO/TE-Mixed-Hosts:Ir(piq) })_{3} 1 \%(100 \mathrm{~nm}) / \mathrm{LiF} \\
(0.5 \mathrm{~nm} / \mathrm{Al}(100 \mathrm{~nm})\end{array}$ & 2.4 & - & 8.12 & 7.84 & $0.66,0.33$ & $\mathrm{D} 126,2010^{[120]}$ \\
\hline $\begin{array}{l}\boldsymbol{m} \text {-MTDATA:Bebq2 } \\
(1: 1)\end{array}$ & $\begin{array}{l}\text { ITO/TE-Mixed-Hosts:Ir(piq) })_{3} 2 \%(100 \mathrm{~nm}) / \mathrm{LiF} \\
(0.5 \mathrm{~nm}) / \mathrm{Al}(100 \mathrm{~nm})\end{array}$ & 2.4 & - & 8.19 & 9.86 & $0.67,0.32$ & D127, 2010 \\
\hline $\begin{array}{l}\text { m-MTDATA:Bebq } \\
(1: 1)\end{array}$ & $\begin{array}{l}\text { ITO/TE-Mixed-Hosts:Ir(piq) })_{3} 4 \%(100 \mathrm{~nm}) / \mathrm{LiF} \\
(0.5 \mathrm{~nm}) / \mathrm{Al}(100 \mathrm{~nm})\end{array}$ & 2.3 & - & 8.04 & 10.96 & $0.66,0.33$ & $\mathrm{D} 128,2010^{[120]}$ \\
\hline \multicolumn{8}{|c|}{ White SL-PhOLEDs using Mixed-Hosts or Mixed-Dopants in their EML } \\
\hline $\begin{array}{l}\text { TBCPF:OXD-7 } \\
(2: 1)\end{array}$ & $\begin{array}{l}\text { ITO/PEDOT:PSS/SP-Mixed-Hosts:FIrpic 50 \%: } \\
\operatorname{Ir}(\text { piq) })_{2} \text { (acac) } 1 \% / \mathrm{Cs}_{2} \mathrm{CO}_{3}(2 \mathrm{~nm}) / \mathrm{Al}(100 \mathrm{~nm})\end{array}$ & 4.2 & 9.7 & 15.6 & 6.3 & $0.33,0.39$ & $\mathrm{D} 129,2010^{[121]}$ \\
\hline $\begin{array}{l}\text { TBCPF:OXD-7 } \\
(2: 1)\end{array}$ & $\begin{array}{l}\text { ITO/PEDOT:PSS/SP-Mixed-Hosts:FIrpic } 40 \%: \\
\operatorname{Ir}(\text { piq) })_{2} \text { (acac) } 1 \% / \mathrm{Cs}_{2} \mathrm{CO}_{3}(2 \mathrm{~nm}) / \mathrm{Al}(100 \mathrm{~nm})\end{array}$ & 4.5 & 10.5 & 16.0 & 5.9 & $0.34,0.37$ & $\mathrm{D} 130,2010^{[121]}$ \\
\hline $\begin{array}{l}\text { TBCPF:OXD-7 } \\
(2: 1)\end{array}$ & $\begin{array}{l}\text { ITO/PEDOT:PSS/SP-Mixed-Hosts:FIrpic } 30 \%: \\
\operatorname{Ir}(\text { piq) })_{2} \text { (acac) } 1 \% / \mathrm{Cs}_{2} \mathrm{CO}_{3}(2 \mathrm{~nm}) / \mathrm{Al}(100 \mathrm{~nm})\end{array}$ & 4.6 & 7.6 & 10.6 & 4.0 & $0.39,0.37$ & $\mathrm{D} 131,2010^{[121]}$ \\
\hline $\begin{array}{l}\text { TBCPF:OXD-7 } \\
(2: 1)\end{array}$ & $\begin{array}{l}\text { ITO/PEDOT:PSS/SP-Mixed-Hosts:FIrpic } 20 \%: \\
\operatorname{Ir}(\text { piq) })_{2}(\mathbf{a c a c}) 1 \% / \mathrm{Cs}_{2} \mathrm{CO}_{3}(2 \mathrm{~nm}) / \mathrm{Al}(100 \mathrm{~nm})\end{array}$ & 4.9 & 5.9 & 7.1 & 2.6 & $0.45,0.36$ & $\mathrm{D} 132,2010^{[121]}$ \\
\hline $\begin{array}{l}\text { TBCPF:OXD-7 } \\
(2: 1)\end{array}$ & $\begin{array}{l}\text { ITO/PEDOT:PSS/SP-Mixed-Hosts:FIrpic } 50 \% \text { : } \\
\operatorname{Ir}(\text { mppy })_{3} 1 \%: \operatorname{Ir}(\text { piq })_{2}(\text { acac }) 1 \% / \mathrm{Cs}_{2} \mathrm{CO}_{3} \\
(2 \mathrm{~nm}) / \mathrm{Al}(100 \mathrm{~nm})\end{array}$ & 4.4 & 8.1 & 17.1 & 6.5 & $0.34,0.48$ & $\mathrm{D} 133,2010^{[121]}$ \\
\hline $\begin{array}{l}\text { TBCPF:OXD-7 } \\
(2: 1)\end{array}$ & $\begin{array}{l}\text { ITO/PEDOT:PSS/SP-Mixed-Hosts:FIrpic } 40 \%: \\
\operatorname{Ir}(\text { mppy })_{3} 1 \%: \operatorname{Ir}(\text { piq })_{2}(\text { acac }) 1 \% / \mathrm{Cs}_{2} \mathrm{CO}_{3} \\
(2 \mathrm{~nm}) / \mathrm{Al}(100 \mathrm{~nm})\end{array}$ & 4.8 & 8.8 & 18.2 & 6.2 & $0.35,0.48$ & $\mathrm{D} 134,2010^{[121]}$ \\
\hline $\begin{array}{l}\text { TBCPF:OXD-7 } \\
(2: 1)\end{array}$ & $\begin{array}{l}\text { ITO/PEDOT:PSS/SP-Mixed-Hosts:FIrpic } 30 \% \text { : } \\
\operatorname{Ir}(\text { mppy })_{3} 1 \%: \operatorname{Ir}(\text { piq })_{2}(\text { acac }) 1 \% / \mathrm{Cs}_{2} \mathrm{CO}_{3} \\
(2 \mathrm{~nm}) / \mathrm{Al}(100 \mathrm{~nm})\end{array}$ & 4.5 & 10.7 & 20.8 & 7.2 & $0.34,0.44$ & $\mathrm{D} 135,2010^{[121]}$ \\
\hline $\begin{array}{l}\text { TBCPF:OXD-7 } \\
(2: 1)\end{array}$ & $\begin{array}{l}\text { ITO/PEDOT:PSS/SP-Mixed-Hosts:FIrpic } 20 \% \text { : } \\
\operatorname{Ir}(\text { mppy })_{3} 1 \%: \operatorname{Ir}(\text { piq })_{2}(\text { acac }) 1 \% / \mathrm{Cs}_{2} \mathrm{CO}_{3} \\
(2 \mathrm{~nm}) / \mathrm{Al}(100 \mathrm{~nm})\end{array}$ & 4.5 & 10.0 & 19.1 & 6.9 & $0.35,0.45$ & $\mathrm{D} 136,2010^{[121]}$ \\
\hline $\begin{array}{l}\text { TBCPF:OXD-7 } \\
(2: 1)\end{array}$ & $\begin{array}{l}\text { ITO/PEDOT:PSS/SP-Mixed-Hosts:FIrpic } 30 \%: \\
\operatorname{Ir}(\text { mppy })_{3} 0.5 \%: \operatorname{Ir}(\text { piq })_{2}(\text { acac }) 1 \% / \mathrm{Cs}_{2} \mathrm{CO}_{3} \\
(2 \mathrm{~nm}) / \mathrm{Al}(100 \mathrm{~nm})\end{array}$ & 4.7 & 8.3 & 16.9 & 5.6 & $0.39,0.49$ & $\mathrm{D} 137,2010^{[121]}$ \\
\hline $\begin{array}{l}\text { TBCPF:OXD-7 } \\
(2: 1)\end{array}$ & $\begin{array}{l}\text { ITO/PEDOT:PSS/SP-Mixed-Hosts:FIrpic } 20 \%: \\
\operatorname{Ir}(\text { mppy })_{3} 0.5 \%: \operatorname{Ir}(\text { piq) })_{2} \text { (acac) } 1 \% / \mathrm{Cs}_{2} \mathrm{CO}_{3} \\
(2 \mathrm{~nm}) / \mathrm{Al}(100 \mathrm{~nm})\end{array}$ & 4.6 & 9.9 & 17.6 & 6.7 & $0.42,0.47$ & $\mathrm{D} 138,2010^{[121]}$ \\
\hline
\end{tabular}

For the doubly doped devices with FIrpic and $\operatorname{Ir}($ piq) 2 (acac), D129-D132, the EL spectra present two major peaks at $476 \mathrm{~nm}$ (from FIrpic) and $622 \mathrm{~nm}$ (from $\operatorname{Ir}(\mathbf{p i q})_{2}$ (acac)). Depending on the ratio of blue and red dopant in the mixed-hosts EML, the relative intensity of these two bands is modified and hence the emitted color of the device. D130 with TBCPF:OXD7(2:1):FIrpic:Ir(piq) 2 $_{\text {(acac)(40:1) }}$ as EML presents the highest performance (EQE/CE/LE: 10.5 $\% / 16 \mathrm{~cd} / \mathrm{A} / 5.9 \mathrm{~lm} / \mathrm{W})$ and the CIE coordinates $(0.34,0.37)$ close to the ideal CIE coordinates of pure white light $(0.33,0.33)$.

For the triply doped devices with an additional tris[2-(4-tolyl)pyridinato- $\left.\mathrm{C}^{2}, N\right]$ iridium(III), $\operatorname{Ir}(\mathbf{m p p y})_{3}$, green phosphor, the EL spectra display two emissive contributions: that of $\operatorname{Ir}(\mathbf{m p p y})_{3}$ (peaking at $500 \mathrm{~nm}$ ) and that of $\mathbf{I r}($ piq) 2 (acac) (peaking at $622 \mathrm{~nm}$ ). Device D135 (CIE 0.34, 0.44) reaches an EQE of $10.7 \%$ (CE/PE: $20.8 \mathrm{~cd} / \mathrm{A} / 7.2 \mathrm{~lm} / \mathrm{W})$.

To conclude, we have seen in this part that the mixed-host strategy is more efficient than the selfhost strategy to reach efficient SL-PhOLEDs. This is due to the difficulty to gather within a single molecule a good charge transport and a high luminescence efficiency, which are the foundations of the self-host strategy. It is indeed far easier to prepare the EML using a mixed-host strategy. 


\section{Part II: Single-Component PhOLEDs}

All the devices presented in part $\mathrm{I}$ are SL-PhOLEDs with the following structure: anode/EML/cathode. The electrodes are very often covered by a thin layer of electron- or holeinjector and the EML can have different compositions. As discussed in this review, the main difficulty in SL-PhOLED is to balance the charge carrier to maximize the charge recombination. In order to improve the efficiency of SL-PhOLED devices, some groups have developed another strategy, which consists to use the host material (additionally to its hosting role) as hole- and/or electron-transporting layer inserted between the EML and the electrode. The advantage of this type of $\mathrm{PhOLEDs}$ is linked to the fact that the same material is used both as host and as transporter/blocker. However, the Single-Component PhOLED is not literally a single-layer device. In such devices, the presence of one or two "non-doped" layer(s) has allowed to reach high device performances and hence represent an interesting way to simplify OLEDs. These devices are called two-region or three-region as a function of the number of additional layers. Some examples of these devices are summarized in Table 7.

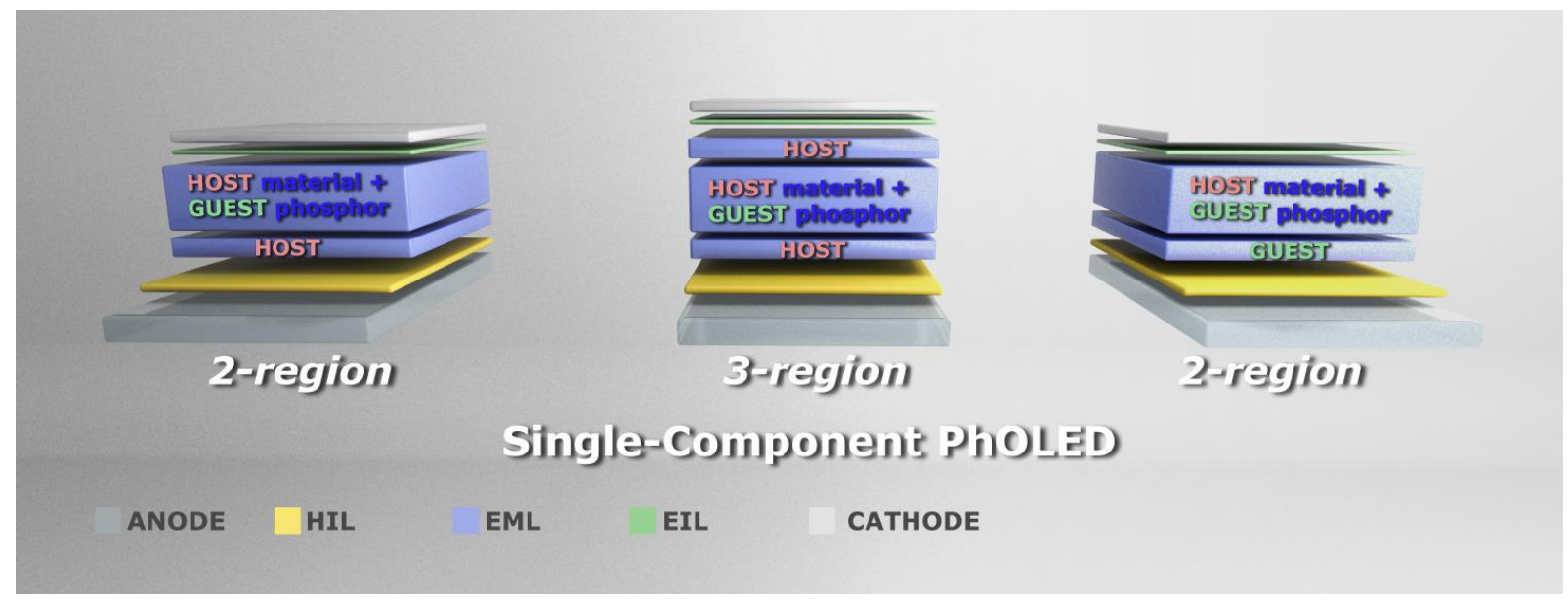

Figure 15. Schematic representation of Single-Component PhOLEDs with 3-region or 2-region

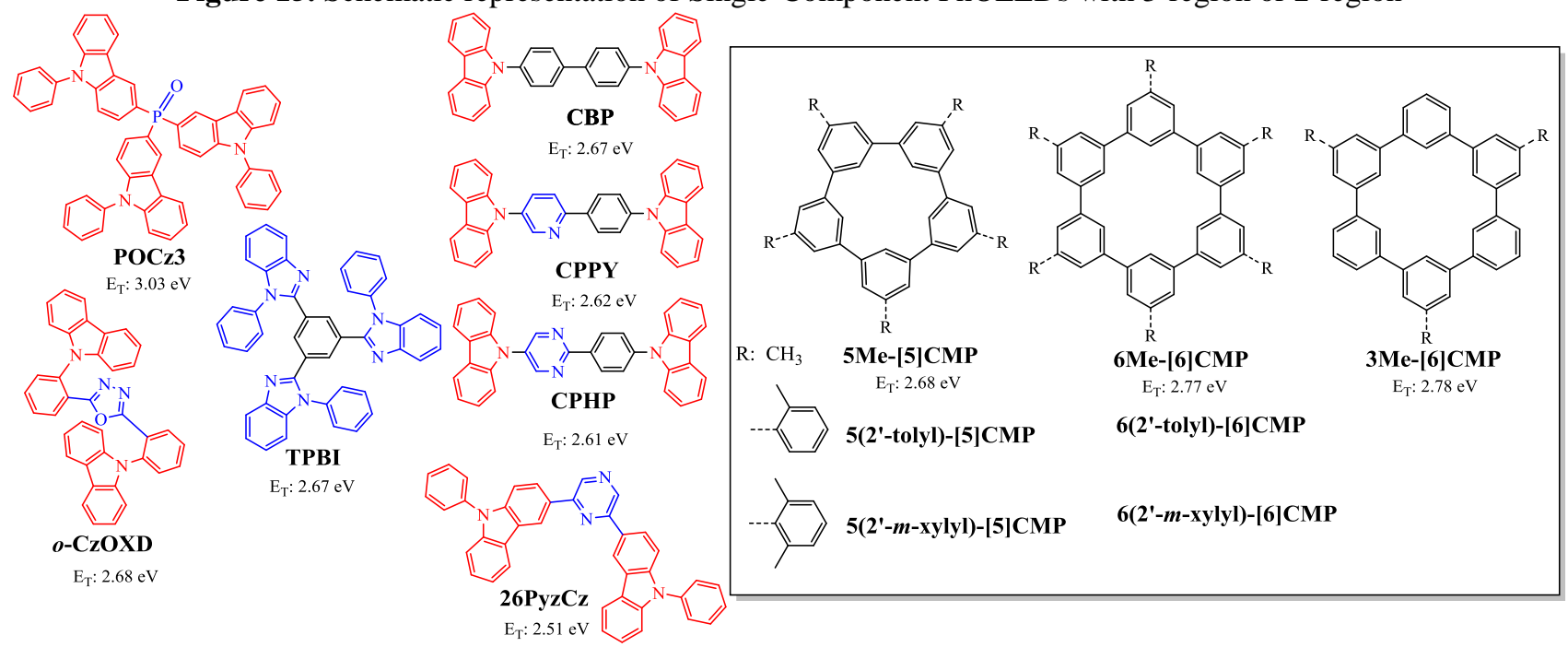

Figure 16. Molecular structure of host materials used in single-component PhOLEDs. In the host materials, black, blue and red fragments respectively point the $\pi$-linker, the acceptor and the donor units. 
In 2011, two-region single-component blue PhOLEDs (Figure 15, left) were described by Wong and co-workers, using POCz3 (see structure Figure 16) as a bipolar host for FIrpic and also as exciton confinement layer between PEDOT:PSS and the EML. ${ }^{[45]}$ Indeed, POCz3 displays a very high $\mathrm{E}_{\mathrm{T}}$ of $3.03 \mathrm{eV}$ and can efficiently be used as exciton blocker. Two devices were constructed D139-D140 with the following structure ITO/PEDOT:PSS/POCz3(x nm)/POCz3:FIrpic $10 \%(80 \mathrm{~nm}) / \mathrm{LiF} / \mathrm{Al}, \mathrm{x}$ $=3$ or 5 . The EL spectra of the two devices provide sky-blue light originated from FIrpic, showing that the triplet excitons of FIrpic are efficiently confined in the EML. The device D139 with $5 \mathrm{~nm}$ of non-doped layer of POCz3 achieves slightly higher EQE of $7.7 \%$ ( $v s$ 7\% for D140) with however an increase of $\mathrm{V}_{\text {on }}$ due to the low hole-transport ability of POCz3. However the device D140 with 3 $\mathrm{nm}$ of non-doped layer deposited on the EML reaches $7 \%$ of EQE, similar to the EQE reached by the SL-PhOLED D3 (without the additional layers, see above). In order to increase the performance, the devices were optimized and the FIrpic concentration was increased (from 10, 15, 20 to $25 \%$ ). EQE increases from $7 \%(6.7 \mathrm{~lm} / \mathrm{W})$ with $10 \%$ FIrpic (D140) to $9 \%(10.4 \mathrm{~lm} / \mathrm{W})$ with $20 \%$ FIrpic (D141) and then decreases at higher FIrpic concentration (25\%) due to well-known T1/T1 annihilation.

In 2016, Isobe group confirmed the efficiency of the two-region single-component device structures using cyclic PHC as hosts for $\operatorname{Ir}(\mathbf{p p y})_{3} \cdot{ }^{[123]}$ Two type of PHC rings were designed with five or six meta-linked phenyl units ([5]CMP and [6]CMP) and different substituents at the periphery (Figure 16). The influence of the additional non-doped pure host layer in the single-component two-region device D143 (ITO(110nm)/PEDOT:PSS(30nm)/non-doped Host $(10 \mathrm{~nm}) /$ Host:Ir(ppy) $3 \quad 6$ $(80 \mathrm{~nm}) / \mathrm{Cs}(1.5 \mathrm{~nm}) / \mathrm{Al}(100 \mathrm{~nm})$ is pointed by comparison with the classical green SL-PhOLED D56 (ITO $(110 \mathrm{~nm}) /$ PEDOT:PSS(30nm)/Host:Ir(ppy) ${ }_{3}$ 6\%(80nm)/Cs $\left.(1.5 \mathrm{~nm}) / \mathrm{Al}(100 \mathrm{~nm})\right)$. With 5Me[5]CMP as host, an increase of EQE (CE and PE) is clearly observed from $12.1 \%$ (43.3 cd/A, 24.7 $\mathrm{lm} / \mathrm{W})$ in $\mathrm{D} 56$ to $21.4 \%(75.4 \mathrm{~cd} / \mathrm{A}, 40.1 \mathrm{~lm} / \mathrm{W})$ in D143 with the additional pure host layer.

On the other hand, this study has pointed that the devices with [5]CMP derived hosts reach higher EQE (between 18.7 to $24.8 \%$, in D142-D144) than those with [6]CMP derived hosts (8.5 to $14.6 \%$, in D145-D147) showing the influence of the ring size on the efficiency of the host. Finally, the influence of the substituent is also pointed in each series with EQE increasing from 2'- $m$-xylyl (18.7 $\%, \mathrm{D} 144)$ to methyl $(21.4 \%, \mathrm{D} 143)$ and 2'-tolyl $(24.8 \%, \mathrm{D} 142)$ in the [5]CMP series and from methyl $(8.5 \%$, D147) to 2'-tolyl $(14.2 \%$, D145) and 2'-m-xylyl (14.6\%, D146) in the [6]CMP series.

To the best of our knowledge, with an EQE reaching $24.8 \%(88 \mathrm{~cd} / \mathrm{A}, 54.5 \mathrm{~lm} / \mathrm{W})$, the device D142 based on 5(2'-m-xylyl)-[5]CMP is the most efficient green "two-region single component" reported to date and surpasses the performance of the best green SL-PhOLED D54 (without the additional non-doped host layers) presented above ([5]LOMP4 reaches an EQE of $20.1 \%$, a CE of $72.5 \mathrm{~cd} / \mathrm{A}$ and a PE of $44.9 \mathrm{~lm} / \mathrm{W}$, Table 1). This shows the efficiency of this device engineering strategy.

In 2010, a bipolar host material $(\boldsymbol{o}-\mathbf{C z O X D})^{[68]}$ was constructed on the association of two donor $\mathrm{N}$ phe nylcarbazole units to facilitate the hole injection and transport and a central oxadiazole acceptor unit to facilitate the electron injection and transport. This bipolar molecule possesses a well balance charge transport $\left(\mu_{\mathrm{h}}: 0.1-5.76 \times 10^{-6} \mathrm{~cm}^{2} \mathrm{~V}^{-1} \mathrm{~s}^{-1}, \mu_{\mathrm{e}}: 0.66 \times 10^{-6} \mathrm{~cm}^{2} \mathrm{~V}^{-1} \mathrm{~s}^{-1}\right.$ ), a gap of $3 \mathrm{eV}$ (HOMO:5.55, LUMO: $-2.56 \mathrm{eV}$ ) and an $\mathrm{E}_{\mathrm{T}}$ around $2.7 \mathrm{eV}$. o-CzOXD has been used as host for green $\left(\operatorname{Ir}(\mathbf{p p y})_{3} 9 \%\right)$, red $\left(\operatorname{Ir}(\mathbf{p i q})_{2}(\mathbf{a c a c}) 5 \%\right)$ or orange-yellow $\left(\operatorname{Ir}(\mathrm{fbi})_{2}(\mathrm{acac}) 6 \%\right)$ phosphor in a threeregion device (Figure 15, middle). The device structure is: $\mathrm{ITO} / \mathrm{MoO}_{3}(5 \mathrm{~nm}) /$ non-doped $\boldsymbol{o}$ CzOXD(35nm)/doped o-CzOXD: phosphor $(35 \mathrm{~nm}) /$ non-doped $\boldsymbol{o}$-CzOXD(35nm)/LiF/Al. The presence of the two non-doped $\boldsymbol{o}$-CzOXD layers between the doped $\boldsymbol{o}$-CzOXD layer and the electrodes helps to confine the electron/hole recombination zone in the doped $\boldsymbol{o}$-CzOXD layer and to increase the performance of the devices. Due to a combination of contracted HOMO/LUMO gap and well balanced charge transport, the $\mathrm{V}_{\text {on }}$ of the three devices are measured around $3.0 \mathrm{~V}$ and the EQE 
reach 7.04, 7.28 and $12.42 \%$ for the yellow-orange D150, red D149 and green D148 devices respectively.

In 2012, more efficient three-region single-component green PhOLEDs (Figure 15, middle) were described by Wang and co-workers, using carbazole-based host materials, namely the well-known CBP and two parents molecules with either a pyridine (CPPY) or a pyrimidine (CPHP) instead of one phenyl of the central biphenyl of CBP (Figure 16). ${ }^{[124]}$ Substitution of CBP by one or two nitrogen atoms reduces the LUMO level by $0.19 \mathrm{eV}$ (LUMO: $-2.55 /-2.74 \mathrm{eV}$ for CBP/CPPY) and $0.33 \mathrm{eV}$ (LUMO: -2.55/-2.88 eV for CBP/CPHP) with no significant change in the HOMO levels measured by UPS (HOMO: $-6.05 \mathrm{eV}$ for CBP, CPPY and CPHP). $\mathrm{E}_{\mathrm{T}}$ of the three hosts were evaluated at 2.67, 2.62 and $2.61 \mathrm{eV}$ for CBP, CPPY and CPHP respectively suggesting that the three hosts would be appropriate for the green emitter $\operatorname{Ir}(\mathbf{p p y})_{2}(\mathbf{a c a c})$. A series of devices were fabricated in which a thin layer of the doped host material was deposited between two-undoped layers of the same host which act also as the ETL and the HTL in this design (devices D151-D154). D151, using CBP as host shows a peak EQE of $13.3 \%(54.4 \mathrm{~cd} / \mathrm{A}$ and $36 \mathrm{~lm} / \mathrm{W})$ significantly more efficient than devices D24 or D25 (EQE: 8.1 or $0.8 \%$ respectively) without undoped layers on both side of the EML. Device D152 with CPPY as host reach higher EQE (21.5\%) than D151 at low luminance $\left(<200 \mathrm{~cd} / \mathrm{m}^{2}\right)$, however D151 keeps better performance than D152 at high luminance. Finally, D153 using CPHP as host and undoped layers shows excellent performance at all voltages examined giving a high EQE/CE of $26.8 \% / 92.2 \mathrm{~cd} / \mathrm{A}$ and remaining as high as $21.3 \% / 73.3 \mathrm{~cd} / \mathrm{A}$ at $100 \mathrm{~cd} / \mathrm{m}^{2}$ (EQE of D151 and D152 were measured at ca $15 \%$ at $100 \mathrm{~cd} / \mathrm{m}^{2}$ ). The authors have also tested a second device based on CPHP with a wider EML (CPHP:Ir(ppy) $\mathbf{2}$ (acac) $8 \%)$ thickness (15 $\mathrm{nm}$ in D153 to $55 \mathrm{~nm}$ in D154). No significant performance improvement was observed from D153 to D154. In D154, $\mathrm{EQE}_{\max }$ reaches $25.3 \%$ and remains around $21.2 \%$ at $100 \mathrm{~cd} / \mathrm{m}^{2}$ indicating that doping in a wider region does not necessary enhance the efficiency of the device.

In 2014, a bipolar host material, 26PyzCz, containing a pyrazine/carbazole hybrid structure was designed (Figure 16). ${ }^{[125]}$ Comparing the carrier injection and transport properties of this host with those of CBP, the authors indicated that $26 \mathrm{PyzCz}$ presents similar $\mu_{\mathrm{h}}$ and higher $\mu_{\mathrm{e}}$ than $\mathbf{C B P}\left(\mu_{\mathrm{h}} / \mu_{\mathrm{e}}\right.$ : $21.2 \times 10^{-5} / 2.1 \times 10^{-5} \mathrm{~cm} / \mathrm{Vs}$ ) indicating a lower difference between $\mu_{\mathrm{e}}$ and $\mu_{\mathrm{h}}$ in $\mathbf{2 6 P y z C z}$ than in CBP. Using the ambipolar properties of this molecule, three-region single-component green and orange PhOLEDs were designed. The EML constituted of $\mathbf{2 6 P y z C z}$ as host and of either the green complex $\operatorname{Ir}(\mathbf{p p y})_{2}$ (acac) or the orange complex PO-01 was inserted between two undoped 26PyzCz layers, which serve as a hole transport layer as well as an electron transport layer. The two devices exhibit typical emissions originating from the green or orange dopants. Despite high operating voltage around $7.0 \mathrm{~V}$, the two devices show attractive EL efficiencies $(65.5 \mathrm{~cd} / \mathrm{A}, 52.1 \mathrm{~lm} / \mathrm{W}$ for the green PhOLED (D155) and $65.5 \mathrm{~cd} / \mathrm{A}, 51.9 \mathrm{~lm} / \mathrm{W}$ for the orange PhOLED (D156)). Compared to the previous green devices (D151-D154), D155 is more efficient than the device based on CBP but less efficient than the devices based on CPPY or CPHP. Compared to CBP based device D151, the improved performance of D155 may be explained by the better ambipolar properties of $\mathbf{2 6 P y z C z}$ than CBP. As 26PyCz possesses a similar LUMO level $(-2.8 \mathrm{eV})$ than CPPY $(-2.74 \mathrm{eV})$ and CPHP $(-2.88 \mathrm{eV})$ and a higher HOMO level $(-5.83 \mathrm{eV})$ than CPPY and CPHP $(-6.05 \mathrm{eV})$, the lower performance of D155 compared to D152-D154 may arise from the different cathodes used $\left(\mathrm{Cs}_{2} \mathrm{CO}_{3}(1 \mathrm{~nm}) / \mathrm{Al}\right.$ in D152-D154 vs Liq(2nm)/Al in D155) and not from charge transport or injection considerations.

The orange device D156 based on 26PyCz:PO-01 is more efficient than D150 based on $\boldsymbol{o - C z O X D}$ : $\operatorname{Ir}(\mathbf{f b i})_{2}$ (acac) (CE: 65.5 vs $18.78 \mathrm{~cd} / \mathrm{A}$ and PE: $51.9 \mathrm{vs} 9.6 \mathrm{~lm} / \mathrm{W}$ for D156 and D150 respectively). Both hosts possess an $\mathrm{E}_{\mathrm{T}}(2.5 / 2.68 \mathrm{eV}$ for $26 \mathrm{PyCz} / \boldsymbol{o}-\mathbf{C z O X D})$ higher than $2.2 \mathrm{eV}$ corresponding to the $\mathrm{E}_{\mathrm{T}}$ of the two orange dopants. As both devices are similar except their cathode ( $\mathrm{LiF} / \mathrm{Al}$ in $\mathrm{D} 150$ 
vs Liq/Al in D156), the highest performance recorded for D156 can be, at least partially, assigned to this feature. This device is among the most efficient reported to date. ${ }^{[125]}$

In 2016, Isobe group has also developed "three-region single-component" devices in which cyclic PHC materials have been used as hosts for $\operatorname{Ir}(\mathbf{p p y})_{3} .{ }^{[126]}$ The first device of this study used CBP as benchmark host (D158) and reached a modest EQE of $4.9 \%$. It must be noted that the performance of D158 is significantly lower than that of D151 (see above) with a similar three-region single component CBP-based device $(\mathrm{EQE}=13.3 \%)$ but is higher than that of device D25 with a classical SL-device $(\mathrm{EQE}=0.8 \%)$. The different device architecture, the different anodes and cathodes are at the origin of the difference of EQE and points the efficiency of the three-region single-component architecture to increase the device performances.

EQE of 5.3 and $7.3 \%$ were reached using 6Me-[6]CMP (D159) and 3Me-[6]CMP (D160) as hosts without a real increase of the performances compared to the CBP-based device D158. Contrariwise, a high efficiency of $22.8 \%$ is reached with $\mathbf{5 M e}$-[5]CMP as host (D157) surpassing the performance of the single-component two-region device D143 presented above $(21.4 \%)$. Studying the charge mobilities $\left(\mu_{\mathrm{h}} / \mu_{\mathrm{e}}\right)$ in thin films of neat host or $\operatorname{Ir}(\mathbf{p p y})_{3}$ doped host, the authors observed that $\mu_{\mathrm{e}}$ remains almost similar in neat $\left(\mu_{\mathrm{e}}: 19 \times 10^{-5}, 2 \times 10^{-5}, 6 \times 10^{-5}\right.$ and $2.4 \times 10^{-5} \mathrm{~cm}^{2} \mathrm{~V}^{-1} \mathrm{~s}^{-1}$ for $\mathbf{C B P}, \mathbf{5 M e}-$ [5]CMP, 3Me-[6]CM and 6Me-[6]CM respectively) or doped film $\left(\mu_{\mathrm{e}}: 6.8 \times 10^{-5}, 2.5 \times 10^{-5}, 6.7 \times 10^{-5}\right.$ and $3.2 \times 10^{-5} \mathrm{~cm}^{2} \mathrm{~V}^{-1} \mathrm{~s}^{-1}$ for CBP, 5Me-[5]CMP, 3Me-[6]CM and 6Me-[6]CM respectively) whereas $\mu_{\mathrm{h}}$ significantly decreases upon doping $\left(\mu_{\mathrm{h}}: 21 \times 10^{-5}, 2.2 \times 10^{-5}, 4.4 \times 10^{-5}\right.$ and $1.1 \times 10^{-5} \mathrm{~cm}^{2} \mathrm{~V}^{-1}$ $\mathrm{s}^{-1}$ for CBP, 5Me-[5]CMP, 3Me-[6]CM and 6Me-[6]CM neat films and $\mu_{\mathrm{h}}: 2.3 \times 10^{-5}, 9.3 \times 10^{-7}$, $1.2 \times 10^{-5}$ and $6.7 \times 10^{-6} \mathrm{~cm}^{2} \mathrm{~V}^{-1} \mathrm{~s}^{-1}$ for CBP, 5Me-[5]CMP, 3Me-[6]CM and 6Me-[6]CM doped films). The retardation of the hole mobility upon doping was stronger with 5Me-[5]CMP $\left(\mu_{\mathrm{h}}\right.$ : $2.2 \times 10^{-5}$ vs $9.3 \times 10^{-7} \mathrm{~cm}^{2} \mathrm{~V}^{-1} \mathrm{~s}^{-1}$ ) than with the other hosts and seems to maximise the hole and electron recombination. These results show the key role of the hole-retarding effect of the dopant in the 5Me-[5]CMP layer. The latter helps to confine the charge recombination site in the doped layer and act as a hole-blocking layer. These results confirm the importance of a subtle control of the charge transport in a SL-PhOLED.

In conclusion, 5Me-[5]CMP was demonstrated to act as host for green phosphor in 'classical' SLPhOLEDs (EQE: 12.1\%, D56), as host and hole-transporting material in single-component tworegion device (EQE: $21.4 \%, \mathrm{D} 143)$ and as host and hole-/electron-transporting materials in singlecomponent three-region device (EQE: $22.8 \%$, D157). It acts therefore as an efficient PHC macrocycle multirole material.

On these structures, Isobe group has also shown how some subtle modifications (switch from a Me to a $\mathrm{CF}_{3}$ group) can have important consequences on the device performance. Thus, when the sky blue emitter FIrpic is dispersed within 5Me-[5]CMP in a three-region blue device D161 of architecture ITO/PEDOT:PSS(30 nm)/ 5Me-[5]CMP(20 nm)/5Me-[5]CMP:FIrpic $12 \%$ (40 $\mathrm{nm}) / \mathbf{5 M e}-[\mathbf{5}] \mathbf{C M P}(30 \mathrm{~nm}) / \mathrm{Cs}(1.5 \mathrm{~nm}) / \mathrm{Al}(100 \mathrm{~nm})$, an EQE of $5.8 \%$ is reached. ${ }^{[127]}$ Modification of the periphery substituents $\left(\mathrm{Me} v s \mathrm{CF}_{3}\right)$ allows to increase the $\mathrm{E}_{\mathrm{T}}\left(2.75 \mathrm{eV}\right.$ for $\mathbf{5} \mathbf{C F}_{\mathbf{3}}$-[5]CMP and $2.82 \mathrm{eV}$ for $\mathbf{6 C F}_{3}-[\mathbf{6}] \mathbf{C M P}$ in 2-MeTHF at $77 \mathrm{~K}$ ) and the resulting device performance. In a series of

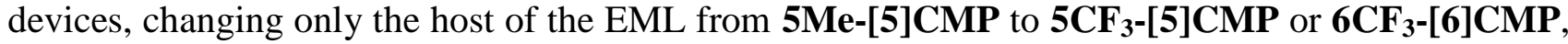
without changing the external 5Me-[5]CMP non-doped layers has a favourable effect on the device performances : EQE increases from $5.8 \%$ in D161 to $9.9 \%$ with $\mathbf{5} \mathbf{C F}_{\mathbf{3}}$-[5]CMP as host or to $6.3 \%$ with $\mathbf{6 C F}_{3}$-[6]CMP as host. However, the two last devices are not strictly three-region single component SL-PhOLEDs as the external non-doped layers are 5Me-[5]CMP, which is not the host used in the EML.

The last examples of single-component three-region devices (D162-D164) we want to expose herein are singular. A thin layer of the phosphorescent dye $\left(\right.$ FIrpic, $\operatorname{Ir}(\mathbf{p p y})_{3}$ or $\left.\operatorname{Ir}(\mathbf{p i q})_{3}\right)$ has been inserted 
between the EML (TPBI+phosphor) and the electrodes (Figure 15, right). This time, this is the charge transport properties of the phosphors which are used. This is again another strategy to improve the charge transport. Compare to their respective SL-PhOLEDs (blue D2, green D32 and red D63) presented above, the presence of the additional dopant layers leads to an increase of the performances. This increase is from $6.8 \mathrm{~cd} / \mathrm{A}(1.9 \mathrm{~lm} / \mathrm{W})$ in D2 to $9.8 \mathrm{~cd} / \mathrm{A}(2.8 \mathrm{~lm} / \mathrm{W})$ in D162 for the blue devices, from $34.5 \mathrm{~cd} / \mathrm{A}(44.1 \mathrm{~lm} / \mathrm{W})$ in $\mathrm{D} 32$ to $43.3 \mathrm{~cd} / \mathrm{A}(56.2 \mathrm{~lm} / \mathrm{W})$ in $\mathrm{D} 163$ for the green devices and from $3.7 \mathrm{~cd} / \mathrm{A}(3.2 \mathrm{~lm} / \mathrm{W})$ in D63 to $4.9 \mathrm{~cd} / \mathrm{A}(4.6 \mathrm{~lm} / \mathrm{W})$ in D164 for the red ones. There is no perturbation of the light emitted by the devices. Despite the addition of the non-doped layer, $\mathrm{V}_{\text {on }}$ decreases from $7.5 \mathrm{~V}$ in D2 to $6.3 \mathrm{~V}$ in D162 for the blue devices, from $3.7 \mathrm{~V}$ in D62 to $3.4 \mathrm{~V}$ in D164 for the red devices and remains constant at $2.4 \mathrm{~V}$ for the green devices D32 and D163. These results show that the single component strategy can also be applied to the phosphor. 
Table 7. Performances of Single-component 2-region or 3-region SL-PhOLEDs (devices D139 to D160)

\begin{tabular}{|c|c|c|c|c|c|c|c|}
\hline \multicolumn{8}{|c|}{ Single-component PhOLED, two-region SL-PhOLED } \\
\hline EML & Device structure & $\begin{array}{l}\text { Von } \\
\text { (V) }\end{array}$ & $\begin{array}{l}\text { EQE } \\
(\%)\end{array}$ & $\begin{array}{c}\mathrm{CE} \\
(\mathbf{c d} / \mathbf{A})\end{array}$ & $\begin{array}{c}\mathbf{P E} \\
(\mathbf{l m} / \mathbf{W})\end{array}$ & $\begin{array}{l}1931 \text { CIE } \\
(x, y)\end{array}$ & $\begin{array}{l}\text { Device number, } \\
\text { References }\end{array}$ \\
\hline POCz3 & $\begin{array}{l}\text { ITO/PEDOT:PSS/POCz3(5nm)/POCz3:FIrpic } 10 \%(80 \mathrm{~nm}) / \\
\mathrm{LiF} / \mathrm{Al}\end{array}$ & - & 7.7 & - & - & - & $\mathrm{D} 139,2011^{[45]}$ \\
\hline $\mathbf{P O C z 3}$ & $\begin{array}{l}\text { ITO/PEDOT:PSS/POCz3(3nm)/POCz3:FIrpic } 10 \%(80 \mathrm{~nm}) / \\
\mathrm{LiF} / \mathrm{Al}\end{array}$ & - & 7.0 & - & 6.7 & - & $\mathrm{D} 140,2011^{[45]}$ \\
\hline $\mathbf{P O C z 3}$ & $\begin{array}{l}\text { ITO/PEDOT:PSS/POCz3(3nm)/POCz3:FIrpic } 20 \%(80 \mathrm{~nm}) / \\
\text { LiF/Al }\end{array}$ & - & 9.0 & 21.3 & 10.4 & - & $\mathrm{D} 141,2011^{[45]}$ \\
\hline 5(2'-tolyl)-[5]CMP & $\begin{array}{l}\text { ITO }(110 \mathrm{~nm}) / \mathrm{PEDOT}: \mathrm{PSS}(30 \mathrm{~nm}) / \mathbf{5}(\mathbf{2} \text {-tolyl)-[5]CMP(10nm)/ } \\
\text { Host:Ir(ppy })_{3} 6 \%(80 \mathrm{~nm}) / \mathrm{Cs}(1.5 \mathrm{~nm}) / \mathrm{Al}(100 \mathrm{~nm})\end{array}$ & 5.1 & 24.8 & 88 & 54.4 & - & $\mathrm{D} 142,2016^{[123]}$ \\
\hline 5Me-[5]CMP & $\begin{array}{l}\text { ITO }(110 \mathrm{~nm}) / \mathrm{PEDOT}: \operatorname{PSS}(30 \mathrm{~nm}) / \mathbf{5 M e}-[5] \mathrm{CMP}(10 \mathrm{~nm}) / \\
\text { Host:Ir(ppy })_{3} 6 \%(80 \mathrm{~nm}) / \mathrm{Cs}(1.5 \mathrm{~nm}) / \mathrm{Al}(100 \mathrm{~nm})\end{array}$ & 5.9 & 21.4 & 75.4 & 40.1 & - & D143, 2016 \\
\hline 5(2'-m-xylyl)-[5]CMP & $\begin{array}{l}\text { ITO(110nm)/PEDOT:PSS(30nm)/ 5(2'-m-xylyl)-[5]CMP } \\
(10 \mathrm{~nm}) / \mathbf{H o s t}: \operatorname{Ir}(\text { ppy })_{3} 6 \%(80 \mathrm{~nm}) / \mathrm{Cs}(1.5 \mathrm{~nm}) / \mathrm{Al}(100 \mathrm{~nm})\end{array}$ & 5.8 & 18.7 & 67.3 & 36 & - & $\mathrm{D} 144,2016^{[123]}$ \\
\hline 6(2'-tolyl)-[6]CMP & $\begin{array}{l}\text { ITO(110nm)/PEDOT:PSS(30nm)/ 6(2'-tolyl)-[6]CMP } \\
(10 \mathrm{~nm}) / \mathrm{Host}: \operatorname{Ir}(\text { ppy })_{3} 6 \%(80 \mathrm{~nm}) / \mathrm{Cs}(1.5 \mathrm{~nm}) / \mathrm{Al}(100 \mathrm{~nm})\end{array}$ & 5.5 & 14.2 & 50.1 & 28.6 & - & $\mathrm{D} 145,2016^{[123]}$ \\
\hline 6(2'-m-xylyl)-[6]CMP & $\begin{array}{l}\text { ITO(110nm)/PEDOT:PSS(30nm)/ 6(2'-m-xylyl)-[6]CMP } \\
(10 \mathrm{~nm}) / \mathrm{Host}: \operatorname{Ir}(\mathrm{ppy})_{3} 6 \%(80 \mathrm{~nm}) / \mathrm{Cs}(1.5 \mathrm{~nm}) / \mathrm{Al}(100 \mathrm{~nm}) \\
\end{array}$ & 6.3 & 14.6 & 51.8 & 26 & - & D146, 2016 \\
\hline 6Me-[6]CMP & $\begin{array}{l}\text { ITO }(110 \mathrm{~nm}) / \mathrm{PEDOT}: \mathrm{PSS}(30 \mathrm{~nm}) / \mathbf{6 M e}-[\mathbf{6}] \mathbf{C M P}(10 \mathrm{~nm}) / \\
\text { Host:Ir(ppy) } 6 \%(80 \mathrm{~nm}) / \mathrm{Cs}(1.5 \mathrm{~nm}) / \mathrm{Al}(100 \mathrm{~nm})\end{array}$ & 4.7 & 8.5 & 30.8 & 20.3 & - & D147, 2016 \\
\hline \multicolumn{8}{|c|}{ Single-component PhOLED, three-region SL-PhOLED } \\
\hline EML & Device structure & $\begin{array}{l}\text { Von } \\
\text { (V) }\end{array}$ & $\begin{array}{c}\text { EQE } \\
(\%)\end{array}$ & $\begin{array}{c}\text { CE } \\
(\mathbf{c d} / \mathbf{A})\end{array}$ & $\begin{array}{c}\text { PE } \\
(\mathrm{lm} / \mathrm{W})\end{array}$ & $\begin{array}{l}1931 \text { CIE } \\
\quad(x, y)\end{array}$ & References \\
\hline$o-\mathrm{CzOXD}$ & $\begin{array}{l}\mathrm{ITO} / \mathrm{MoO}_{3}(5 \mathrm{~nm}) / \boldsymbol{o}-\mathbf{C z O X D}(35 \mathrm{~nm}) / \boldsymbol{o}-\mathbf{C z O X D}: \operatorname{Ir}(\mathrm{ppy})_{3} 9 \% \\
(35 \mathrm{~nm}) / \boldsymbol{o}-\mathbf{C z O X D}(35 \mathrm{~nm}) / \mathrm{LiF} / \mathrm{Al}\end{array}$ & 3.0 & 12.42 & 45.57 & 27.2 & $0.34,0.62$ & $\mathrm{D} 148,2010^{[68]}$ \\
\hline$o-\mathrm{CzOXD}$ & $\begin{array}{l}\mathrm{ITO} / \mathrm{MoO}_{3}(5 \mathrm{~nm}) / \boldsymbol{o}-\mathbf{C z O X D}(35 \mathrm{~nm}) / \boldsymbol{o}-\mathbf{C z O X D}: \operatorname{Ir}(\mathbf{p i q})_{2}(\mathrm{acac}) \\
5 \%(35 \mathrm{~nm}) / \boldsymbol{o}-\mathbf{C z O X D}(35 \mathrm{~nm}) / \mathrm{LiF} / \mathrm{Al}\end{array}$ & 3.3 & 7.28 & 5.35 & 3.1 & $0.68,0.32$ & D149, 2010 $0^{[68]}$ \\
\hline$o-\mathrm{CzOXD}$ & $\begin{array}{l}\mathrm{ITO} / \mathrm{MoO}_{3}(5 \mathrm{~nm}) / \boldsymbol{o}-\mathbf{C z O X D}(35 \mathrm{~nm}) / \boldsymbol{o}-\mathbf{C z O X D}: \operatorname{Ir}(\mathrm{fbi})_{2}(\mathrm{acac}) \\
6 \%(35 \mathrm{~nm}) / \boldsymbol{o}-\mathbf{C z O X D}(35 \mathrm{~nm}) / \mathrm{LiF} / \mathrm{Al}\end{array}$ & 3.1 & 7.04 & 18.78 & 9.6 & $0.52,0.47$ & $\mathrm{D} 150,2010^{[68]}$ \\
\hline $\begin{array}{l}\text { CBP } \\
\mathrm{E}_{\mathrm{T}}: 2.67 \mathrm{eV}\end{array}$ & $\begin{array}{l}\text { ITO/MoO } \mathrm{MoO}_{3}(1 \mathrm{~nm}) / \mathbf{C B P}(35 \mathrm{~nm}) / \mathbf{C B P}: \operatorname{Ir}(\text { ppy })_{2}(\mathrm{acac}) 8 \% \\
(15 \mathrm{~nm}) / \mathbf{C B P}(60 \mathrm{~nm}) / \mathrm{Cs}_{2} \mathrm{CO}_{3}(1 \mathrm{~nm}) / \mathrm{Al}\end{array}$ & 4.0 & 13.3 & 54.4 & 36 & $0.32,0.64$ & $\mathrm{D} 151,2012^{[124]}$ \\
\hline $\begin{array}{l}\text { CPPY } \\
\mathrm{E}_{\mathrm{T}}: 2.62 \mathrm{eV}\end{array}$ & $\begin{array}{l}\mathrm{ITO} / \mathrm{MoO}_{3}(1 \mathrm{~nm}) / \mathbf{C P P Y}(35 \mathrm{~nm}) / \mathbf{C P P Y}: \operatorname{Ir}(\mathrm{ppy})_{2}(\mathrm{acac}) 8 \% \\
(15 \mathrm{~nm}) / \mathbf{C P P Y}(60 \mathrm{~nm}) / \mathrm{Cs}_{2} \mathrm{CO}_{3}(1 \mathrm{~nm}) / \mathrm{Al}\end{array}$ & 3.8 & 21.5 & 74.9 & 56.3 & $0.32,0.64$ & $\mathrm{D} 152,2012^{[124]}$ \\
\hline $\begin{array}{l}\text { CPHP } \\
\mathrm{E}_{\mathrm{T}}: 2.61 \mathrm{eV}\end{array}$ & $\begin{array}{l}\text { ITO/MoO }{ }_{3}(1 \mathrm{~nm}) / \mathbf{C P H P}(35 \mathrm{~nm}) / \mathbf{C P H P}: \operatorname{Ir}(\text { ppy })_{2}(\text { acac }) 8 \% \\
(15 \mathrm{~nm}) / \mathbf{C P H P}(60 \mathrm{~nm}) / \mathrm{Cs}_{2} \mathrm{CO}_{3}(1 \mathrm{~nm}) / \mathrm{Al}\end{array}$ & 3.0 & 26.8 & 92.2 & 106.1 & $0.32,0.64$ & $\mathrm{D} 153,2012^{[124]}$ \\
\hline $\begin{array}{l}\text { CPHP } \\
\mathrm{E}_{\mathrm{T}}: 2.61 \mathrm{eV}\end{array}$ & $\begin{array}{l}\text { ITO/MoO }{ }_{3}(1 \mathrm{~nm}) / \mathbf{C P H P}(35 \mathrm{~nm}) / \mathbf{C P H P}: \mathrm{Ir}(\text { ppy })_{2}(\text { acac }) 8 \% \\
(55 \mathrm{~nm}) / \mathbf{C P H P}(60 \mathrm{~nm}) / \mathrm{Cs}_{2} \mathrm{CO}_{3}(1 \mathrm{~nm}) / \mathrm{Al}\end{array}$ & 2.8 & 25.3 & 87.3 & 107.7 & $0.32,0.64$ & $\mathrm{D} 154,2012^{[124]}$ \\
\hline $\begin{array}{l}\mathbf{2 6 P y z C z} \\
\mathrm{E}_{\mathrm{T}}: 2.51 \mathrm{eV}\end{array}$ & $\begin{array}{l}\mathrm{ITO} / \mathrm{MoO}_{3}(5 \mathrm{~nm}) / \mathbf{2 6 P y z C z}(40 \mathrm{~nm}) / \mathbf{2 6 P y z C z}: \operatorname{Ir}(\mathrm{ppy})_{2}(\mathrm{acac}) 6 \% \\
(30 \mathrm{~nm}) / \mathbf{2 6 P y z C z}(30 \mathrm{~nm}) / \mathrm{Liq}(2 \mathrm{~nm}) / \mathrm{Al}(120 \mathrm{~nm})\end{array}$ & 6.7 & - & 65.5 & 52.1 & $0.31,0.64$ & $\mathrm{D} 155,2014^{[125]}$ \\
\hline $\begin{array}{l}\text { 26PyzCz } \\
\mathrm{E}_{\mathrm{T}}: 2.51 \mathrm{eV}\end{array}$ & $\begin{array}{l}\mathrm{ITO} / \mathrm{MoO}_{3}(5 \mathrm{~nm}) / \mathbf{2 6 P y z C z}(40 \mathrm{~nm}) / \mathbf{2 6 P y z C z : P O}-016 \% \\
(30 \mathrm{~nm}) / \mathbf{2 6 P y z C z}(30 \mathrm{~nm}) / \mathrm{Liq}(2 \mathrm{~nm}) / \mathrm{Al}(120 \mathrm{~nm})\end{array}$ & 7.0 & - & 65.5 & 51.9 & $0.48,0.50$ & D156, $2014^{[125]}$ \\
\hline $\begin{array}{l}\text { 5Me-[5]CMP } \\
\mathrm{E}_{\mathrm{T}}: 2.68 \mathrm{eV}\end{array}$ & $\begin{array}{l}\text { ITO }(110 \mathrm{~nm}) / \mathrm{PEDOT}: \mathrm{PSS}(30 \mathrm{~nm}) / \mathbf{5 M e}-[\mathbf{5}] \mathbf{C M P}(10 \mathrm{~nm}) / \text { Host: } \\
\operatorname{Ir}(\text { ppy })_{3} 6 \%(40 \mathrm{~nm}) / \mathbf{5 M e}-[\mathbf{5}] \mathbf{C M P}(10 \mathrm{~nm}) / \mathrm{Cs}(1.5 \mathrm{~nm}) / \mathrm{Al}\end{array}$ & 5.7 & 22.8 & 94.1 & 43.5 & - & $\mathrm{D} 157,2016^{[126]}$ \\
\hline $\begin{array}{l}\text { CBP } \\
\mathrm{E}_{\mathrm{T}}: 2.68 \mathrm{eV}\end{array}$ & $\begin{array}{l}\text { ITO }(110 \mathrm{~nm}) / \mathrm{PEDOT}: \operatorname{PSS}(30 \mathrm{~nm}) / \mathbf{C B P}(10 \mathrm{~nm}) / \mathbf{C B P}: \operatorname{Ir}(\text { ppy })_{3} 6 \% \\
(40 \mathrm{~nm}) / \mathrm{CBP}(10 \mathrm{~nm}) / \mathrm{Cs}(1.5 \mathrm{~nm}) / \mathrm{Al}\end{array}$ & 3.3 & 4.9 & 9.5 & 14 & - & $\mathrm{D} 158,2016^{[126]}$ \\
\hline $\begin{array}{l}\mathbf{6 M e}-[\mathbf{6}] \mathbf{C M P} \\
\mathrm{E}_{\mathrm{T}}: 2.68 \mathrm{eV}\end{array}$ & $\begin{array}{l}\text { ITO(110nm)/PEDOT:PSS }(30 \mathrm{~nm}) / \mathbf{6 M e}-[\mathbf{6}] \mathbf{C M P}(10 \mathrm{~nm}) / \mathbf{6 M e}- \\
\text { [6]CMP:Ir(ppy })_{3} 6 \%(40 \mathrm{~nm}) / \mathbf{6 M e}-[\mathbf{6}] \mathbf{C M P}(10 \mathrm{~nm}) / \mathrm{Cs}(1.5 \mathrm{~nm}) / \mathrm{Al}\end{array}$ & 4.8 & 5.3 & 21.7 & 11.4 & - & $\mathrm{D} 159,2016^{[126]}$ \\
\hline $\begin{array}{l}\text { 3Me-[6]CMP } \\
\mathrm{E}_{\mathrm{T}}: 2.68 \mathrm{eV}\end{array}$ & $\begin{array}{l}\text { ITO(110nm)/PEDOT:PSS }(30 \mathrm{~nm}) / \mathbf{3 M e}-[\mathbf{6}] \mathbf{C M P}(10 \mathrm{~nm}) / \mathbf{3 M e}- \\
\text { [6]CMP:Ir(ppy })_{3} 6 \%(40 \mathrm{~nm}) / \mathbf{3 M e}-[\mathbf{6}] \mathbf{C M P}(10 \mathrm{~nm}) / \mathrm{Cs}(1.5 \mathrm{~nm}) / \mathrm{Al}\end{array}$ & 4.5 & 7.3 & 30.1 & 17.3 & - & $\mathrm{D} 160,2016^{[126]}$ \\
\hline $\begin{array}{l}\mathbf{5 M e}-[\mathbf{5}] \mathbf{C M P} \\
\mathrm{E}_{\mathrm{T}}: 2.68 \mathrm{eV} \\
\end{array}$ & $\begin{array}{l}\text { ITO/PEDOT:PSS(30nm)/5Me-[5]CMP(20nm)/ 5Me-[5]CMP } \\
\text { :FIrpic } 12 \%(40 \mathrm{~nm}) / \mathbf{5 M e}-[\mathbf{5}] \mathbf{C M P}(30 \mathrm{~nm}) / \mathrm{Cs}(1.5 \mathrm{~nm}) / \mathrm{Al} \\
(100 \mathrm{~nm})\end{array}$ & 7.4 & 5.8 & - & - & - & D161, 2019 ${ }^{[127]}$ \\
\hline $\begin{array}{l}\text { TPBI } \\
\mathrm{E}_{\mathrm{T}}: 2.67 \mathrm{eV}\end{array}$ & $\begin{array}{l}\text { ITO/FIrpic(10nm)/Host:FIrpic } 18 \%(100 \mathrm{~nm}) / \mathrm{LiF}(1 \mathrm{~nm}) / \mathrm{Al} \\
(100 \mathrm{~nm})\end{array}$ & 6.4 & - & 9.8 & 2.8 & $0.20,0.49$ & $\mathrm{D} 162,2009^{[22]}$ \\
\hline $\begin{array}{l}\text { TPBI } \\
\mathrm{E}_{\mathrm{T}}: 2.67 \mathrm{eV}\end{array}$ & $\begin{array}{l}\text { ITO/Ir(ppy })_{3}(10 \mathrm{~nm}) / \mathrm{Host}: \operatorname{Ir}(\mathrm{ppy})_{3} 18 \%(100 \mathrm{~nm}) / \mathrm{LiF}(1 \mathrm{~nm}) / \mathrm{Al} \\
(100 \mathrm{~nm})\end{array}$ & 2.4 & - & 43.3 & 56.2 & $0.31,0.63$ & $\mathrm{D} 163,2009^{[22]}$ \\
\hline $\begin{array}{l}\text { TPBI } \\
\mathrm{E}_{\mathrm{T}}: 2.67 \mathrm{eV}\end{array}$ & $\begin{array}{l}\text { ITO/Ir(piq) })_{3}(10 \mathrm{~nm}) / \mathrm{Host}: \operatorname{Ir}(\mathbf{p i q})_{3} 21 \%(100 \mathrm{~nm}) / \mathrm{LiF}(1 \mathrm{~nm}) / \mathrm{Al} \\
(100 \mathrm{~nm})\end{array}$ & 3.4 & - & 4.9 & 4.6 & $0.69,0.33$ & $\mathrm{D} 164,2009^{[22]}$ \\
\hline
\end{tabular}

\section{Conclusion}

Simplifying the organic electronic devices is undoubtedly a key point for the future of this technology. Reducing the complexity of the OLED devices, constituted of a stack of organic layers, can allow reducing the fabrication and energetic costs but removing the functional organic layers is far to be mastered and drastically decreases the device efficiency. This is mainly due to the difficulty to insure an excellent charge transport for both hole and electron in such a type of simplified device. However, thanks to precise molecular designs of the host material, great advances have been made in 
recent years and very high SL-PhOLEDs efficiencies have been recently reported. The host material plays undoubtedly a key role in these performances despite only a few systematic studies have been performed. Universal hosts such as SPA-2,7-F(POPh $\mathbf{P}_{2}$ have recently shown that RGB phosphors can even be efficiently hosted in SL-PhOLEDs. ${ }^{[32]}$ In the field of OLEDs, universal hosts are interesting as only one material is necessary to construct OLED of different colours. Maintaining a high $\mathrm{E}_{\mathrm{T}}$ with an ambipolar charge transport and HOMO/LUMO energy levels fitting the Fermi levels of the electrodes but also those of the phosphor are the prerequisites for an excellent host in a SLPhOLED. However, all the works performed until now show how each parameter of the host material (HOMO/LUMO energy levels, $\mathrm{E}_{\mathrm{T}}$, charge carriers mobility) influences the emission efficiency of the guest phosphor within the device and how a subtle combination of these parameters is required. ${ }^{[24]}$ In term of molecular design, and since the electron transport is often the weakest link in an EML, it is clear that diphenylphosphine oxide fragment as electron-deficient core is of high interest as different hosts based on this group have led to efficient devices performance for the three colours.

Surprisingly, PHC materials, which are only constituted of carbon and hydrogen atoms have also shown their great potential in the field of SL-PhOLEDs. ${ }^{[123]}$ As PHC materials have also been recently highlighted for their high performances in ML-PhOLEDs, ${ }^{[37]}$ they appear as a very promising class of materials for the future. Indeed, the low cost and simple synthesis of many PHC materials are beneficial for large-scale production in OLED industry and can provide new directions in terms of materials design for optoelectronics.

However, the step is still high and many challenges needs to be address in the future. In term of emission colours, efficient SL-PhOLEDs with phosphors emitting at short wavelengths (deep blue and violet) are still missing. Violet SL-PhOLEDs appear intrinsically difficult to reach because violet phosphorescent emitters possess a large gap and no efficient emitters are commercially available yet. The synthesis of stable and efficient violet phosphors is necessary in this field. The first works using blue emitter FIr6 with EQE of around 9\% appear promising but the emission wavelengths of FIr6 are still too long. ${ }^{[32]}$

Another key perspective for the future lies in white emitting SL-PhOLED. Reaching white emission in a single-layer device for lighting applications is extremely challenging and there is only one report in literature to date. ${ }^{[99]} \mathrm{A}$ way to generate a white light emission is to associate two complementary emissions and the association of a blue-greenish phosphorescent emitter with another judiciously chosen red-orange or yellow-orange phosphorescent affords an interesting strategy. If the phosphors display a high quantum yield and are judiciously dispersed in an efficient ambipolar host, this strategy can be applied to SL-PhOLEDs. We believe this is an interesting direction for the future in order to produce low-cost white light for lighting.

However, the efficiency and the emitting colour of the SL-PhOLEDs are not the only parameters to be considered. The stability is also a key point, which is very rarely studied. Precisely studying the stability of SL-PhOLEDs (and their components ${ }^{[34]}$ ) will be a future important step of development. In this context, the development of high-performance and robust phosphorescent emitters free of Iridium is highly desired. Indeed, as presented in this review, cyclometalated iridium complexes are the most used phosphorescent emitters because of their widely tunable photophysical properties. However, some of them such as FIrpic are unstable during operating device, which is a significant issue for this technology. An alternative lies in pure organic room temperature phosphorescent emitters. ${ }^{[128-130]}$ To date, this type of emitters has only been rarely incorporated in PhOLEDs and the EQE remain modest (as far as we know, the best performance reported is only $11 \%{ }^{[131]}$ ) mainly due to their long lifetimes. If bipolarity can be efficiently introduced in pure organic room temperature 
phosphorescent emitters possessing a short lifetime and a high quantum yield, they can become interesting emitters for SL-PhOLEDs. There is only one example reported to date but with a extremely low EQE. ${ }^{[132]}$ This research field is untouched to date.

To improve the device performance, more researches are also needed in device engineering. The electrodes play undoubtedly a key role. Recently, it has been shown that using chlorinated ITO as anode is an efficient technique to improve the performance of SL-PHOLEDs. ${ }^{[67]}$ Thus, for the future of this 'simplified electronic technology', precise molecular and device design will be mandatory.

Finally, one should also remember that for industrial applications and to reduce the environmental footprint, the synthesis of the host material for a SL-PhOLED should be short and high yielded, use inexpensive starting materials and avoid rare metal catalysts. This is rarely considered but is nevertheless an important point in the field. 
Table 8. Selected physical and electronic properties of host materials incorporated in blue SL-PhOLEDs

\begin{tabular}{|c|c|c|c|c|c|c|}
\hline Host & $\begin{array}{l}\text { Absorption } \\
{[\mathrm{nm}]}\end{array}$ & $\begin{array}{l}\text { Fluorescence } \\
{[\mathrm{nm}]}\end{array}$ & $\begin{array}{l}\mathbf{E}_{\mathrm{T}}(\text { measured at } \\
77 \mathrm{~K}) \\
{[\mathrm{eV}]}\end{array}$ & $\begin{array}{l}\text { HOMO }[\mathrm{eV}] \\
\text { LUMO }[\mathrm{eV}] \\
\mathbf{E}_{\mathrm{g}}^{\mathrm{opt}}[\mathrm{eV}] \\
\mu_{\mathrm{e}} / \mu_{\mathrm{h}}\left[\mathrm{cm}^{2} \mathrm{~V}^{-1} \mathrm{~s}^{-1}\right]\end{array}$ & $\begin{array}{l}\text { Thermal } \\
\text { properties } \\
{\left[{ }^{\circ} \mathrm{C}\right]}\end{array}$ & References \\
\hline Bebq $_{2}$ & - & 515 (Film) & $2.2 \mathrm{eV}$ & $\begin{array}{l}-5.5(\text { elec }) \\
-2.8\left(\mathrm{E}_{\mathrm{g}}^{\text {opt }}-\mathrm{HOMO}\right) \\
2.7 \\
\mu_{\mathrm{e}}: 10^{-4} \\
\mu_{\mathrm{h}}- \\
\end{array}$ & $\mathrm{T}_{\mathrm{m}}: 368$ & $\begin{array}{l}2010^{[122]} \\
19933^{[133]} \\
1995^{[134]} \\
2009^{[135]}\end{array}$ \\
\hline BPhen & & & 2.6 & $\mu_{\mathrm{e}}: 4.2 \times 10^{-4}$ & & $2000^{[119]}$ \\
\hline BzBPCz & $\begin{array}{l}294,308(\text { Toluene }) \\
293,304\left(\mathrm{CH}_{2} \mathrm{Cl}_{2}\right)\end{array}$ & $\begin{array}{l}355 \text { (Toluene) } \\
385\left(\mathrm{CH}_{2} \mathrm{Cl}_{2}\right) \\
387(\text { Film })\end{array}$ & $\begin{array}{l}2.73 \text { (Toluene) } \\
2.61 \text { (Film) }\end{array}$ & $\begin{array}{l}-5.65 \text { (elec) } \\
-2.11\left(\mathrm{E}_{\mathrm{g}}^{\text {opt}}-\mathrm{HOMO}\right) \\
3.54 \\
\mu_{\mathrm{e}}: 11 \times 10^{-6} \\
\mu_{\mathrm{h}}: 80.1 \times 10^{-6}\end{array}$ & $\begin{array}{l}\mathrm{T}_{\mathrm{g}}: 95 \\
\mathrm{~T}_{\mathrm{m}}: 190 \\
\mathrm{~T}_{\mathrm{d}}: 387\end{array}$ & $2009^{[65]}$ \\
\hline BzFCz & 294, 328 (Toluene, $\mathrm{CH}_{2} \mathrm{Cl}_{2}$ ) & $\begin{array}{l}375(\text { Toluene }) \\
393\left(\mathrm{CH}_{2} \mathrm{Cl}_{2}\right) \\
399(\text { Film })\end{array}$ & $\begin{array}{l}2.55 \text { (Toluene) } \\
2.40 \text { (Film) }\end{array}$ & $\begin{array}{l}-5.62 \text { (elec) } \\
-2.20\left(\mathrm{E}_{\mathrm{g}}^{\text {opt }} \text {-HOMO) }\right. \\
3.42 \\
\mu_{\mathrm{e}}: 4.52 \times 10^{-6} \\
\mu_{\mathrm{h}}: 4.36 \times 10^{-6}\end{array}$ & $\begin{array}{l}\mathrm{T}_{\mathrm{g}}: 124 \\
\mathrm{~T}_{\mathrm{m}}: 241 \\
\mathrm{~T}_{\mathrm{d}}: 430\end{array}$ & $2009^{[65]}$ \\
\hline BzTPCz & 294,310 (Toluene, $\mathrm{CH}_{2} \mathrm{Cl}_{2}$ ) & $\begin{array}{l}377 \text { (Toluene) } \\
400\left(\mathrm{CH}_{2} \mathrm{Cl}_{2}\right) \\
388(\text { Film })\end{array}$ & $\begin{array}{l}2.65 \text { (Toluene) } \\
2.41 \text { (Film) }\end{array}$ & $\begin{array}{l}-5.65(\text { elec }) \\
-2.16\left(\mathrm{E}_{\mathrm{g}}^{\text {opt }} \text {-HOMO) }\right. \\
3.49 \\
\mu_{\mathrm{e}}: 27.2 \times 10^{-6} \\
\mu_{\mathrm{h}}: 111 \times 10^{-6}\end{array}$ & $\begin{array}{l}\mathrm{T}_{\mathrm{g}}: 114 \\
\mathrm{~T}_{\mathrm{d}}: 445\end{array}$ & $2009^{[65]}$ \\
\hline CBM4 & 313 (Film) & 367 (Film) & 2.85 (Film) & $\begin{array}{l}-5.17(\mathrm{elec}) \\
-1.62\left(\mathrm{E}_{\mathrm{g}}^{\mathrm{opt}}-\mathrm{HOMO}\right) \\
3.55 \\
\mu_{\mathrm{e}} / \mu_{\mathrm{h}}-\end{array}$ & $\begin{array}{l}\mathrm{T}_{\mathrm{g}}: 48 \\
\mathrm{~T}_{\mathrm{m}}: 123 \\
\mathrm{~T}_{\mathrm{d}}: 454\end{array}$ & $2013^{\mid 93\}}$ \\
\hline CBP & $\begin{array}{l}341 \text { (Toluene) } \\
241,295,319,342\left(\mathrm{CH}_{2} \mathrm{Cl}_{2}\right)\end{array}$ & $\begin{array}{l}355(\text { Toluene }) \\
374\left(\mathrm{CH}_{2} \mathrm{Cl}_{2}\right)\end{array}$ & $\begin{array}{l}2.56 \text { (Toluene) } \\
2.66 \text { (2-MeTHF) }\end{array}$ & $\begin{array}{l}-5.54(\mathrm{elec}) /-6.0(\mathrm{UPS}) \\
-2.23\left(\mathrm{E}_{\mathrm{g}}^{\mathrm{opt}}-\mathrm{HOMO}\right) \\
3.31 \\
\mu_{\mathrm{e}}: 1.9 \times 10^{-4} \\
\mu_{\mathrm{h}:} 2.1 \times 10^{-4} \\
\end{array}$ & $T_{\mathrm{g}}: 62$ & $\begin{array}{l}2007^{[136]} \\
1999^{[137]} \\
2012^{[138]} \\
2016^{[126]} \\
2012^{[124]}\end{array}$ \\
\hline СРНP & $238,258,293,343\left(\mathrm{CH}_{2} \mathrm{Cl}_{2}\right)$ & $425\left(\mathrm{CH}_{2} \mathrm{Cl}_{2}\right)$ & 2.61 (2-MeTHF) & $\begin{array}{l}-6.05(\mathrm{UPS}) \\
-2.88(\mathrm{elec}) \\
3.15 \\
\mu_{\mathrm{e}} / \mu_{\mathrm{h}}-\end{array}$ & $\mathrm{T}_{\mathrm{c}}: 403$ & $2012^{[124]}$ \\
\hline CPPY & $238,29^{\prime}, 343\left(\mathrm{CH}_{2} \mathrm{Cl}_{2}\right)$ & $399\left(\mathrm{CH}_{2} \mathrm{Cl}_{2}\right)$ & 2.62 (2-MeTHF) & $\begin{array}{l}-6.05 \text { (UPS) } \\
-2.74(\mathrm{elec}) \\
3.33 \\
\mu_{\mathrm{e}} / \mu_{\mathrm{h}} \\
\end{array}$ & $\mathrm{T}_{\mathrm{c}}: 395$ & $2012^{[124]}$ \\
\hline CSC & $\begin{array}{l}293,344\left(\mathrm{CH}_{2} \mathrm{Cl}_{2}\right) \\
297,348 \text { (film) }\end{array}$ & $\begin{array}{l}377\left(\mathrm{CH}_{2} \mathrm{Cl}_{2}\right) \\
413 \text { (Film) }\end{array}$ & $2.65(\mathrm{EtOH})$ & $\begin{array}{l}-5.63(\mathrm{UPS}) \\
-2.36\left(\mathrm{E}_{\mathrm{g}}^{\mathrm{opt}}-\mathrm{HOMO}\right) \\
3.27 \\
\mu_{\mathrm{e}}: 5 \text { to } 8 \times 10^{-6} \\
\mu_{\mathrm{h}}: 4.1 \text { to } 5.2 \times 10^{-6}\end{array}$ & $\begin{array}{l}\mathrm{T}_{\mathrm{g}}: 179 \\
\mathrm{~T}_{\mathrm{c}}: 255 \\
\mathrm{~T}_{\mathrm{m}}: 400 \\
\mathrm{~T}_{\mathrm{d}}: 416\end{array}$ & $2010^{[63]}$ \\
\hline Cz-BP-DPI & $294,300-350$ (THF) & 411 (THF) & 2.64 (THF) & $\begin{array}{l}-5.52(\mathrm{elec}) /-5.78(\mathrm{UPS}) \\
-2.49 \mathrm{E}_{\mathrm{g}}^{\mathrm{opt}}- \\
\text { HOMO(UPS) } \\
3.29 \\
\mu_{\mathrm{e}} / \mu_{\mathrm{h}}- \\
\end{array}$ & $\begin{array}{l}\mathrm{T}_{\mathrm{g}}: 140 \\
\mathrm{~T}_{\mathrm{d}}: 416\end{array}$ & $2017^{[51]}$ \\
\hline CzPAMe & 350 (Film) & 405 (Film) & 2.73 (Film) & $\begin{array}{l}-5.96 \text { UPS } \\
-2.42\left(\mathrm{E}_{\mathrm{g}}^{\mathrm{opt}}-\mathrm{HOMO}\right) \\
3.54 \\
\mu_{\mathrm{e}} / \mu_{\mathrm{h}}-\end{array}$ & $\begin{array}{l}\mathrm{T}_{\mathrm{g}}: 159 \\
\mathrm{~T}_{\mathrm{m}}: 292 \\
\mathrm{~T}_{\mathrm{d}}: 471\end{array}$ & $2014^{[49]}$ \\
\hline CzPAPm & 350 (Film) & 426 (Film) & 2.56 (Film) & $\begin{array}{l}-5.88 \text { UPS } \\
-2.34\left(\mathrm{E}_{\mathrm{g}}^{\mathrm{opt}}-\mathrm{HOMO}\right) \\
3.54 \\
\mu_{\mathrm{e}} / \mu_{\mathrm{h}}- \\
\end{array}$ & $\begin{array}{l}\mathrm{T}_{\mathrm{g}}: 175 \\
\mathrm{~T}_{\mathrm{d}}: 473\end{array}$ & $2014^{[49]}$ \\
\hline CzPPO & 355 (Film) & 408 (Film) & 2.71 (Film) & $\begin{array}{l}-5.84 \text { (UPS) } \\
-2.35\left(\mathrm{E}_{\mathrm{g}}^{\text {opt }}-\mathrm{HOMO}\right) \\
3.49 \\
\mu_{\mathrm{e}} / \mu_{\mathrm{h}}- \\
\end{array}$ & $\begin{array}{l}\mathrm{T}_{\mathrm{g}}: 169 \\
\mathrm{~T}_{\mathrm{m}}: 328 \\
\mathrm{~T}_{\mathrm{d}}: 536\end{array}$ & $2014^{[49]}$ \\
\hline D2ACN & 300, 330, 383 (Film) & 556 (Film) & 2.4 (Ethanol) & $\begin{array}{l}-5.14(\mathrm{elec}) \\
-2.58(\mathrm{elec}) \\
3.35 \\
\mu_{\mathrm{h}}: 4.7 \times 10^{-5} \\
\mu_{\mathrm{e}}: 2 \times 10^{-5} \\
\end{array}$ & $\begin{array}{l}\mathrm{T}_{\mathrm{g}}: 116 \\
\mathrm{~T}_{\mathrm{d}}: 350\end{array}$ & $2008^{[84]}$ \\
\hline Dendrimer B1 & $256,325(\mathrm{sh})\left(\mathrm{CH}_{2} \mathrm{Cl}_{2}\right)$ & $\begin{array}{l}435,465 \text { (Toluene) } \\
438,466 \text { (Film) }\end{array}$ & $\begin{array}{l}2.85 \text { (Toluene) } \\
2.83 \text { (Film) }\end{array}$ & $\begin{array}{l}-5.4(\text { elec }) \\
-2.2\left(\mathrm{E}_{\mathrm{g}}^{\text {opt }}-\mathrm{HOMO}\right) \\
3.2 \\
\mu_{\mathrm{e}} / \mu_{\mathrm{h}}- \\
\end{array}$ & $\begin{array}{l}\mathrm{T}_{\mathrm{g}}: 148 \\
\mathrm{~T}_{\mathrm{d}}: 417\end{array}$ & $2009^{[105]}$ \\
\hline Dendrimer B2 & $264,343,385,418,449\left(\mathrm{CH}_{2} \mathrm{Cl}_{2}\right)$ & 467 (Toluene) & 2.65 (Toluene) & $\begin{array}{l}-5.28(\mathrm{elec}) \\
-2.26(\mathrm{elec}) \\
- \\
\mu_{\mathrm{e}} / \mu_{\mathrm{h}}-\end{array}$ & $\begin{array}{l}\mathrm{T}_{\mathrm{g}}: 243 \\
\mathrm{~T}_{\mathrm{d}}: 422\end{array}$ & $2016^{[106]}$ \\
\hline Dendrimer B3 & $292,316,381,417,448\left(\mathrm{CH}_{2} \mathrm{Cl}_{2}\right)$ & 467 (Toluene) & 2.65 (Toluene) & $\begin{array}{l}-5.28(\mathrm{elec}) \\
-2.26(\mathrm{elec}) \\
- \\
\mu_{\mathrm{e}} / \mu_{\mathrm{h}}:-\end{array}$ & $\begin{array}{l}\mathrm{T}_{\mathrm{g}}: 206 \\
\mathrm{~T}_{\mathrm{d}}: 423\end{array}$ & $2016^{[106]}$ \\
\hline
\end{tabular}




\begin{tabular}{|c|c|c|c|c|c|c|}
\hline Dendrimer G1 & $\begin{array}{l}300,450 \text { (Toluene) } \\
300,453 \text { (Film) }\end{array}$ & $\begin{array}{l}\text { 611, 654 (Toluene) } \\
613 \text { (Film) }\end{array}$ & 2.02 & $\begin{array}{l}-5.30(\text { elec }) \\
-2.55\left(\mathrm{E}_{\mathrm{g}}{ }^{\mathrm{opt}}-\mathrm{HOMO}\right) \\
2.75 \\
\mu_{\mathrm{e}} / \mu_{\mathrm{h}}:-\end{array}$ & $\begin{array}{l}\mathrm{T}_{\mathrm{g}}: 181 \\
\mathrm{~T}_{\mathrm{d}}: 383\end{array}$ & $2013^{[93]}$ \\
\hline Dendrimer G2 & $\begin{array}{l}292,326,340,393,433,460 \\
\text { (oluene) } \\
294,314,326,340,388,437 \text { (Tilm) }\end{array}$ & $\begin{array}{l}\text { 564, } 597 \text { (Toluene) } \\
588 \text { (Film) }\end{array}$ & 2.11 & $\begin{array}{l}-5.56(\text { elec }) \\
-2.73\left(\mathrm{E}_{\mathrm{g}}{ }^{\mathrm{opt}}-\mathrm{HOMO}\right) \\
2.83 \\
\mu_{\mathrm{e}} / \mu_{\mathrm{h}}:-\end{array}$ & $\begin{array}{l}\mathrm{T}_{\mathrm{g}}: 212 \\
\mathrm{~T}_{\mathrm{d}}: 370\end{array}$ & $2013^{[93]}$ \\
\hline Dendrimer G3 & $\begin{array}{l}239,297,313,345,376,412,457, \\
492\left(\mathrm{CH}_{2} \mathrm{Cl}_{2}\right)\end{array}$ & $\begin{array}{l}520 \text { (Toluene) } \\
529 \text { (Film) }\end{array}$ & 2.43 (Toluene) & - & - & $2006^{[107]}$ \\
\hline Dendrimer G4 & $\begin{array}{l}239,297,313,349,376,414,460, \\
493\left(\mathrm{CH}_{2} \mathrm{Cl}_{2}\right)\end{array}$ & $\begin{array}{l}522 \text { (Toluene) } \\
531 \text { (Film) }\end{array}$ & 2.43 (Toluene) & - & - & $2006^{[107]}$ \\
\hline Dendrimer G5 & $\begin{array}{l}239,268,297,315,347,414,499 \\
\left(\mathrm{CH}_{2} \mathrm{Cl}_{2}\right)\end{array}$ & $\begin{array}{l}511 \text { (Toluene) } \\
520 \text { (Film) }\end{array}$ & 2.44 (Toluene) & $\begin{array}{l}-5.1 \mathrm{eV} \text { (elec) } \\
-1.8\left(\mathrm{E}_{\mathrm{g}}^{\text {opt }} \text {-HOMO }\right)\end{array}$ & - & $2011^{[108]}$ \\
\hline Dendrimer G6 & $\begin{array}{l}239,268,297,314,348,417,497 \\
\left(\mathrm{CH}_{2} \mathrm{Cl}_{2}\right)\end{array}$ & $\begin{array}{l}512 \text { (Toluene) } \\
520 \text { (Film) }\end{array}$ & 2.44 (Toluene) & $\begin{array}{l}-5.1 \mathrm{eV}(\text { elec }) \\
-1.9\left(\mathrm{E}_{\mathrm{g}}^{\mathrm{opt}}-\mathrm{HOMO}\right)\end{array}$ & - & $2011^{[108]}$ \\
\hline Dendrimer G7 & $\begin{array}{l}239,270,298,315,348,417,497 \\
\left(\mathrm{CH}_{2} \mathrm{Cl}_{2}\right)\end{array}$ & $\begin{array}{l}512 \text { (Toluene) } \\
519 \text { (Film) }\end{array}$ & 2.44 (Toluene) & $\begin{array}{l}-5.1 \text { (elec) } \\
-2.1 \mathrm{eV}\left(\mathrm{E}_{\mathrm{g}}{ }^{\text {opt }} \text {-HOMO) }\right.\end{array}$ & - & $2011^{[108]}$ \\
\hline Dendrimer G8 & $\begin{array}{l}229,307,357,409,455,506 \\
\left(\mathrm{CH}_{2} \mathrm{Cl}_{2}\right)\end{array}$ & $\begin{array}{l}523\left(\mathrm{CH}_{2} \mathrm{Cl}_{2}\right) \\
527(\text { Film })\end{array}$ & $2.38\left(\mathrm{CH}_{2} \mathrm{Cl}_{2}\right)$ & $\begin{array}{l}-5.0 \text { (elec) } \\
-2.64 \mathrm{eV}\left(\mathrm{E}_{\mathrm{g}}^{\mathrm{opt}}-\mathrm{HOMO}\right)\end{array}$ & $\mathrm{T}_{\mathrm{d}}: 571$ & $2015^{[110]}$ \\
\hline Dendrimer G9 & $\begin{array}{l}235,294,343,399,453,501 \\
\left(\mathrm{CH}_{2} \mathrm{Cl}_{2}\right)\end{array}$ & $\begin{array}{l}515\left(\mathrm{CH}_{2} \mathrm{Cl}_{2}\right) \\
526(\text { Film })\end{array}$ & $2.42\left(\mathrm{CH}_{2} \mathrm{Cl}_{2}\right)$ & $\begin{array}{l}-5.25(\mathrm{elec}) \\
-2.88\left(\mathrm{E}_{\mathrm{g}}^{\mathrm{opt}}-\mathrm{HOMO}\right)\end{array}$ & $\mathrm{T}_{\mathrm{d}}: 609$ & $2015^{[110]}$ \\
\hline Dendrimer G10 & $229,354,397,452,501\left(\mathrm{CH}_{2} \mathrm{Cl}_{2}\right)$ & $\begin{array}{l}516\left(\mathrm{CH}_{2} \mathrm{Cl}_{2}\right) \\
520(\text { Film })\end{array}$ & $2.41\left(\mathrm{CH}_{2} \mathrm{Cl}_{2}\right)$ & $\begin{array}{l}-5.38 \mathrm{eV}(\text { elec }) \\
-2.4\left(\mathrm{E}_{\mathrm{g}}^{\text {opt }}-\mathrm{HOMO}\right)\end{array}$ & $\mathrm{T}_{\mathrm{d}}: 490$ & $2015^{[110]}$ \\
\hline $\begin{array}{l}\text { 2,7-DiCbz-SBF-4'- } \\
\text { POPh }_{2}\end{array}$ & 292, 349 (Cyclohexane) & $\begin{array}{l}362,380 \\
\text { (Cyclohexane) }\end{array}$ & 2.64 (2-MeTHF) & $\begin{array}{l}-5.11(\mathrm{elec}) \\
-2.10(\mathrm{elec}) \\
3.41 \\
\mu_{\mathrm{e}}: 4.2 \times 10^{-8} \\
\mu_{\mathrm{h}}: 8.5 \times 10^{-7}\end{array}$ & $\begin{array}{l}\mathrm{T}_{\mathrm{g}}: 193 \\
\mathrm{~T}_{\mathrm{c}}: 259 \\
\mathrm{~T}_{\mathrm{m}}: 366 \\
\mathrm{~T}_{\mathrm{d}}: 426\end{array}$ & $2015^{[66]}$ \\
\hline DQC & $\begin{array}{l}340\left(\mathrm{CH}_{2} \mathrm{Cl}_{2}\right) \\
343 \text { (Film) }\end{array}$ & $\begin{array}{l}388\left(\mathrm{CH}_{2} \mathrm{Cl}_{2}\right) \\
371 \text { (film) }\end{array}$ & 2.81 (2-MeTHF) & $\begin{array}{l}-5.67(\text { elec }) \\
-2.18\left(\mathrm{E}_{\mathrm{g}}^{\text {opt }} \text {-HOMO) }\right. \\
3.49 \\
\mu_{\mathrm{e}} / \mu_{\mathrm{h}:^{-}}\end{array}$ & $\begin{array}{l}\mathrm{T}_{\mathrm{g}}: 128 \\
\mathrm{~T}_{\mathrm{d}}: 402\end{array}$ & $2010^{[111]}$ \\
\hline DSTPA & $\begin{array}{l}\text { 288, 310, } 377 \text { (Toluene) } \\
317,401 \text { (Film) }\end{array}$ & $\begin{array}{l}438 \text { (Toluene) } \\
500(\text { Film }) \\
500\left(\mathrm{CH}_{2} \mathrm{Cl}_{2}\right)\end{array}$ & 2.39 (2-MeTHF) & $\begin{array}{l}-5.26(\mathrm{elec}) \\
-2.71(\mathrm{elec}) \\
- \\
\mu_{\mathrm{h}}: 1.42 \times 10^{-3} \\
\mu_{\mathrm{e}}: 1.38 \times 10^{-4}\end{array}$ & $\mathrm{~T}_{\mathrm{d}}: 479$ & $2014^{[94]}$ \\
\hline EBBPC & $240\left(\mathrm{CH}_{2} \mathrm{Cl}_{2}\right)$ & $400\left(\mathrm{CH}_{2} \mathrm{Cl}_{2}\right)$ & $2.74\left(\mathrm{CH}_{2} \mathrm{Cl}_{2}\right)$ & $\begin{array}{l}-5.71(\text { elec }) \\
-2.36\left(\mathrm{E}_{\mathrm{g}}^{\mathrm{opt}}-\mathrm{HOMO}\right) \\
3.35 \\
\mu_{\mathrm{e}}: 2 \times 10^{-5} \\
\mu_{\mathrm{h}}: 10^{-5}\end{array}$ & $\begin{array}{l}\mathrm{T}_{\mathrm{g}}: 142.6 \\
\mathrm{~T}_{\mathrm{d}}: 431.2\end{array}$ & $2017^{[50]}$ \\
\hline [5]LOMP2 & $252\left(\mathrm{CHCl}_{3}\right)$ & $335\left(\mathrm{CHCl}_{3}\right)$ & $\begin{array}{l}2.81 \text { (2-MeTHF) } \\
2.67 \text { (film) }\end{array}$ & - & $\begin{array}{l}\mathrm{T}_{\mathrm{g}}: 29 \\
\mathrm{~T}_{\mathrm{d}}: 326\end{array}$ & $2020^{[73]}$ \\
\hline [5]LOMP4 & $253\left(\mathrm{CHCl}_{3}\right)$ & $334\left(\mathrm{CHCl}_{3}\right)$ & $\begin{array}{l}2.81 \text { (2-MeTHF) } \\
2.70 \text { (Film) }\end{array}$ & - & $\begin{array}{l}\mathrm{T}_{\mathrm{g}}: 33 \\
\mathrm{~T}_{\mathrm{d}}: 326\end{array}$ & $2020^{[73]}$ \\
\hline [5]LOMP5 & $254\left(\mathrm{CHCl}_{3}\right)$ & $338\left(\mathrm{CHCl}_{3}\right)$ & $\begin{array}{l}2.80 \text { (2-MeTHF) } \\
2.68 \text { (Film) }\end{array}$ & - & $\begin{array}{l}\mathrm{T}_{\mathrm{g}}: 20 \\
\mathrm{~T}_{\mathrm{d}}: 339\end{array}$ & $2020^{[73]}$ \\
\hline [5]LOMP6 & $254\left(\mathrm{CHCl}_{3}\right)$ & $342\left(\mathrm{CHCl}_{3}\right)$ & $\begin{array}{l}2.79 \text { (2-MeTHF) } \\
2.68 \text { (Film) }\end{array}$ & - & $\begin{array}{l}\mathrm{T}_{\mathrm{g}}: 21 \\
\mathrm{~T}_{\mathrm{d}}: 340\end{array}$ & $2020^{[73]}$ \\
\hline [5]LOMP7 & $256\left(\mathrm{CHCl}_{3}\right)$ & $337\left(\mathrm{CHCl}_{3}\right)$ & $\begin{array}{l}2.79 \text { (2-MeTHF) } \\
2.69 \text { (Film) }\end{array}$ & - & $\begin{array}{l}\mathrm{T}_{\mathrm{g}}: 55 \\
\mathrm{~T}_{\mathrm{d}}: 347\end{array}$ & $2020^{[73]}$ \\
\hline $\mathbf{m C P}$ & 324, 338 (Film) & 340 (Film) & 2.9 & $\begin{array}{l}-6.1(\text { elec }) \\
-2.4\left(\mathrm{E}_{\mathrm{g}}^{\mathrm{opt}}-\mathrm{HOMO}\right) \\
3.7 \\
\mu_{\mathrm{e}} / \mu_{\mathrm{h}:^{-}}\end{array}$ & $\mathrm{T}_{\mathrm{g}}: 65$ & $\begin{array}{l}2014^{[139]} \\
2002^{[140]}\end{array}$ \\
\hline 5Me-[5]CMP & $256\left(\mathrm{CHCl}_{3}\right)$ & - & $\begin{array}{l}2.68 \text { (2-MeTHF) } \\
2.55 \text { (Film) }\end{array}$ & $\begin{array}{l}-6.2(\mathrm{UPS}) \\
-2.87\left(\mathrm{E}_{\mathrm{g}}^{\mathrm{opt}}-\mathrm{HOMO}\right. \\
3.33 \\
\mu_{\mathrm{h}}: 2.2 \times 10^{-5} \\
\mu_{\mathrm{e}}: 2 \times 10^{-5}\end{array}$ & $\mathrm{~T}_{\mathrm{d}}: 369$ & $\begin{array}{l}2020^{[73]} \\
2016^{[123,126]}\end{array}$ \\
\hline $3 \mathrm{Me}-[6] \mathrm{CMP}$ & - & - & 2.78 (2-MeTHF) & $\begin{array}{l}-6.04 \text { (UPS) } \\
-2.55\left(\mathrm{E}_{\mathrm{g}}^{\mathrm{opt}}-\mathrm{HOMO}\right) \\
3.49 \\
\mu_{\mathrm{e}}: 6 \times 10^{-5} \\
\mu_{\mathrm{h}:} 4.4 \times 10^{-5}\end{array}$ & $\mathrm{~T}_{\mathrm{d}}: 428$ & $2016^{[126]}$ \\
\hline 6Me-[6]CMP & $255\left(\mathrm{CHCl}_{3}\right)$ & - & 2.77 (2-MeTHF) & 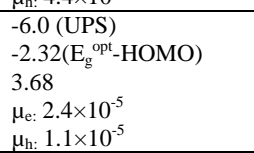 & $\mathrm{T}_{\mathrm{d}}: 433$ & $2016^{[123][126]}$ \\
\hline Me-TBBI & $302\left(\mathrm{CHCl}_{3}\right)$ & $470\left(\mathrm{CHCl}_{3}\right)$ & $2.76(-)$ & $\begin{array}{l}-5.37 \text { (UPS) } \\
-2.19\left(\mathrm{E}_{\mathrm{g}}^{\mathrm{opt}}-\mathrm{HOMO}\right) \\
3.18 \\
\mu_{\mathrm{e}} / \mu_{\mathrm{h}:-}\end{array}$ & $\begin{array}{l}\mathrm{T}_{\mathrm{g}}: 144 \\
\mathrm{~T}_{\mathrm{d}}: 515\end{array}$ & $2008^{[141]}$ \\
\hline m-MTDATA & - & 431 (Film) & - & $\begin{array}{l}-5.1(-) \\
-2.0(-) \\
- \\
\mu_{\mathrm{e}}:-\end{array}$ & $\begin{array}{l}\mathrm{T}_{\mathrm{m}}: 202 \\
\mathrm{~T}_{\mathrm{g}}: 75 \\
\mathrm{~T}_{\mathrm{c}}: 161\end{array}$ & $\begin{array}{l}2010^{[120]} \\
2001^{[142]} \\
1995^{[134]}\end{array}$ \\
\hline
\end{tabular}




\begin{tabular}{|c|c|c|c|c|c|c|}
\hline & & & & $\mu_{\mathrm{h}:} 2.7 \times 10^{-5}$ & & \\
\hline 5(2'-m-xylyl)-[5]CMP & $256\left(\mathrm{CHCl}_{3}\right)$ & - & - & $\begin{array}{l}-6.00 \text { (DFT) } \\
-1.23 \text { (DFT) }\end{array}$ & $\mathrm{T}_{\mathrm{d}}: 463$ & $2016^{[123]}$ \\
\hline 6(2'-m-xylyl)-[6]CMP & $255\left(\mathrm{CHCl}_{3}\right)$ & - & - & $\begin{array}{l}-5.96(\mathrm{DFT}) \\
-1.21 \text { (DFT) }\end{array}$ & $\mathrm{T}_{\mathrm{d}}: 518$ & $2016^{[123]}$ \\
\hline NPB & - & - & $2.3(-)$ & $\begin{array}{l}-5.5(-) /-5.1(\mathrm{UPS}) \\
-2.4 \\
\mu_{\mathrm{h}}: 2.710^{-4}\end{array}$ & $\mathrm{~T}_{\mathrm{g}}: 95$ & $\begin{array}{l}2010^{[122]} \\
1996^{[143]} \\
2013^{[144]}\end{array}$ \\
\hline$\alpha-\mathrm{NPB}$ & - & - & - & $\begin{array}{l}-5.4(-) \\
-2.3(-) \\
- \\
\mu_{\mathrm{h}}: 6.5 \times 10^{-4} \\
\mu_{\mathrm{e}}: 9 \times 10^{-4} \\
\end{array}$ & $\begin{array}{l}\mathrm{T}_{\mathrm{m}}: 232 \\
\mathrm{~T}_{\mathrm{g}}: 75 \\
\mathrm{~T}_{\mathrm{c}}: 186\end{array}$ & $\begin{array}{l}2001^{[142]} \\
2010^{[120]}\end{array}$ \\
\hline$\left(\mathrm{NPh}_{2}\right) \mathbf{B z I m S B F}$ & $\begin{array}{l}\text { 309, } 373 \text { (Ethyl acetate) } \\
309,376 \text { (Toluene) } \\
315,376\left(\mathrm{CH}_{2} \mathrm{Cl}_{2}\right)\end{array}$ & $\begin{array}{l}428 \text { (Toluene) } \\
475\left(\mathrm{CH}_{2} \mathrm{Cl}_{2}\right) \\
457(\text { Film })\end{array}$ & $\begin{array}{l}2.3 \text { (Toluene) } \\
2.2 \text { (Film) }\end{array}$ & $\begin{array}{l}-5.21(\text { elec }) \\
-2.21\left(\mathrm{E}_{\mathrm{g}}^{\mathrm{opt}}-\mathrm{HOMO}\right) \\
3.0 \\
\mu_{\mathrm{e}}: 11.7 \times 10^{-6} \\
\mu_{\mathrm{h}}: 23.8 \times 10^{-6} \\
\end{array}$ & $\begin{array}{l}\mathrm{T}_{\mathrm{m}}: 396 \\
\mathrm{~T}_{\mathrm{g}}: 170 \\
\mathrm{~T}_{\mathrm{d}}: 467\end{array}$ & $\begin{array}{l}2009^{[65]} \\
2008^{[97]}\end{array}$ \\
\hline o-CzOXD & $340\left(\mathrm{CHCl}_{3}\right)$ & $434\left(\mathrm{CHCl}_{3}\right)$ & 2.68 (Toluene) & $\begin{array}{l}-5.55(\text { elec }) \\
-2.56(\mathrm{elec}) \\
- \\
\mu_{\mathrm{e}}: 0.66 \times 10^{-6} \\
\mu_{\mathrm{h}}: 0.1 \text { to } 5.76 \times 10^{-6} \\
\end{array}$ & $\begin{array}{l}\mathrm{T}_{\mathrm{g}}: 97 \\
\mathrm{~T}_{\mathrm{d}}: 428\end{array}$ & $\begin{array}{l}2008^{[145]} \\
2010^{[68]}\end{array}$ \\
\hline OXD-7 & $292\left(\mathrm{CHCl}_{3}\right)$ & $\begin{array}{l}\text { n.a. } \\
374 \text { (Film) }\end{array}$ & $2.7(-)$ & $\begin{array}{l}-6.5 \text { (UPS) } \\
-2.8\left(\mathrm{E}_{\mathrm{g}}^{\mathrm{opt}}-\mathrm{HOMO}\right) \\
3.7\end{array}$ & - & $\begin{array}{l}1992^{[146]} \\
2002^{[147]} \\
2008^{[148],[149]}\end{array}$ \\
\hline POAPF & $\begin{array}{l}\text { 293. 305, } 315 \text { (CHex) } \\
\text { 394, 306, } 316 \text { (Benzene) } \\
294,304,315 \text { (THF) } \\
294,305,315\left(\mathrm{CH}_{2} \mathrm{Cl}_{2}\right) \\
293,303,314\left(\mathrm{CH}_{3} \mathrm{CN}\right)\end{array}$ & $\begin{array}{l}442(\mathrm{CHex}) \\
473 \text { (Benzene) } \\
515(\mathrm{THF}) \\
517\left(\mathrm{CH}_{2} \mathrm{Cl}_{2}\right) \\
554\left(\mathrm{CH}_{3} \mathrm{CN}\right) \\
\end{array}$ & 2.75 (2-MeTHF) & $\begin{array}{l}-5.26(\text { elec }) \\
-2.40(\text { elec }) \\
3.59 \\
\mu_{\mathrm{e}:} 10^{-6} \\
\mu_{\mathrm{h}:} 4.510^{-6} \\
\end{array}$ & $\begin{array}{l}\mathrm{T}_{\mathrm{g}}: 129 \\
\mathrm{~T}_{\mathrm{d}}: 466\end{array}$ & $\begin{array}{l}2009^{[150]} \\
2013^{[151]} \\
2012^{[152]} \\
2014^{[153]}\end{array}$ \\
\hline POCz3 & $260-300\left(\mathrm{CH}_{2} \mathrm{Cl}_{2}\right)$ & $351\left(\mathrm{CH}_{2} \mathrm{Cl}_{2}\right)$ & $3.03(\mathrm{EtOH})$ & $\begin{array}{l}-5.5(\mathrm{UPS}) \\
-1.8\left(\mathrm{E}_{\mathrm{g}}^{\mathrm{opt}}-\mathrm{HOMO}\right) \\
3.7 \\
\mu_{\mathrm{e}:} 1.4 \times 10^{-6} \text { to } 6.4 \times 10^{-6} \\
\mu_{\mathrm{h}}-\end{array}$ & $\begin{array}{l}\mathrm{T}_{\mathrm{g}}: 163 \\
\mathrm{~T}_{\mathrm{d}}: 395\end{array}$ & $2011^{[45]}$ \\
\hline 4-POPh $2-\mathrm{SBF}$ & $\begin{array}{l}308,322 \text { (THF) } \\
310,325 \text { (Film) }\end{array}$ & $\begin{array}{l}346 \text { (THF) } \\
353 \text { (Film) }\end{array}$ & 2.78 (THF) & $\begin{array}{l}-6.0(\text { elec }) \\
-2.10(\text { elec }) \\
3.75 \\
\mu_{\mathrm{e}}: 7 \times 10^{-4} \\
\end{array}$ & $\begin{array}{l}\mathrm{T}_{\mathrm{g}}: 127 \\
\mathrm{~T}_{\mathrm{m}}: 314 \\
\mathrm{~T}_{\mathrm{d}}: 297\end{array}$ & $\begin{array}{l}2010^{[154]} \\
2015^{[66]}\end{array}$ \\
\hline PTC & $\begin{array}{l}339\left(\mathrm{CH}_{2} \mathrm{Cl}_{2}\right) \\
341 \text { (Film) }\end{array}$ & $\begin{array}{l}389\left(\mathrm{CH}_{2} \mathrm{Cl}_{2}\right) \\
373,401,423 \text { (film) }\end{array}$ & 2.81 (2-MeTHF) & $\begin{array}{l}-5.59(\text { elec }) \\
-2.12\left(\mathrm{E}_{\mathrm{g}}^{\text {opt }} \text {-HOMO) }\right. \\
3.47 \\
\mu_{\mathrm{e}} / \mu_{\mathrm{h}:^{-}}\end{array}$ & $\begin{array}{l}\mathrm{T}_{\mathrm{g}}: 131 \\
\mathrm{~T}_{\mathrm{d}}: 407\end{array}$ & $2010^{[111]}$ \\
\hline $26 \mathrm{PyzCz}$ & - & $\begin{array}{l}418\left(\mathrm{CH}_{2} \mathrm{Cl}_{2}\right) \\
419(\text { Film })\end{array}$ & 2.51 (2-MeTHF) & $\begin{array}{l}-5.83(\mathrm{UPS}) \\
-2.8\left(\mathrm{E}_{\mathrm{g}}^{\mathrm{opt}}-\mathrm{HOMO}\right) \\
3.03 \\
\mu_{\mathrm{e}} / \mu_{\mathrm{h}:^{-}}\end{array}$ & $\begin{array}{l}\mathrm{T}_{\mathrm{g}}: 127 \\
\mathrm{~T}_{\mathrm{d}}: 410\end{array}$ & $2014^{[125]}$ \\
\hline SBF-F(POPh $)_{2}$ & 328 (CHex) & 449 (CHex) & 2.76 (2-MeTHF) & $\begin{array}{l}-6.00(\mathrm{elec}) \\
-2.46(\mathrm{elec}) \\
3.54 \\
\mu_{\mathrm{e}}: 6.9 \times 10^{-5} \\
\mu_{\mathrm{h}:-}\end{array}$ & $\begin{array}{l}\mathrm{T}_{\mathrm{g}}: 105 \\
\mathrm{~T}_{\mathrm{d}}: 382\end{array}$ & $2020^{[52]}$ \\
\hline SimCP2 & 347 (Film) & 382 (Film) & 2.70 (Film) & $\begin{array}{l}-6.01(\mathrm{UPS}) \\
-2.44\left(\mathrm{E}_{\mathrm{g}}^{\mathrm{opt}}-\mathrm{HOMO}\right) \\
3.57 \\
\mu_{\mathrm{h}}=4.8 \times 10^{-4} \\
\mu_{\mathrm{e}}=2.7 \times 10^{-4}\end{array}$ & $\begin{array}{l}T_{\mathrm{g}}: 144 \\
\mathrm{~T}_{\mathrm{d}}: 466\end{array}$ & $\begin{array}{l}2014^{[49]} \\
2009^{[115]}\end{array}$ \\
\hline SPA-2-F(POPh 2$)$ & $274,283,295,310,315$ (CHex) & 402 (CHex) & 2.82 (2-MeTHF) & $\begin{array}{l}-5.33(\mathrm{elec}) \\
-2.23(\mathrm{elec}) \\
3.10 \\
\mu_{\mathrm{h}}: 1.9 \times 10^{-7} \\
\mu_{\mathrm{e}}: 1.3 \times 10^{-5} \\
\end{array}$ & $\begin{array}{l}\mathrm{T}_{\mathrm{g}}: 118 \\
\mathrm{~T}_{\mathrm{d}}: 381 \\
\mathrm{~T}_{\mathrm{c}}: 191\end{array}$ & $2020^{[32]}$ \\
\hline SPA-2,7-F(POPh $)_{2}$ & $274,283,295,310,323$ (CHex) & 436 (CHex) & 2.76 (2-MeTHF) & $\begin{array}{l}-5.33(\text { elec }) \\
-2.55(\text { elec }) \\
2.78 \\
\mu_{\mathrm{h}}=8.2 \times 10^{-6} \\
\mu_{\mathrm{e}}=2 \times 10^{-4}\end{array}$ & $\begin{array}{l}\mathrm{T}_{\mathrm{g}}: 143 \\
\mathrm{~T}_{\mathrm{d}}: 474 \\
\mathrm{~T}_{\mathrm{c}}: 218\end{array}$ & $2020^{[32]}$ \\
\hline SPA-3,6-F(POPh $)_{2}$ & $273,304,316$ (CHex) & $368(\mathrm{CHex})$ & 2.90 (2-MeTHF) & $\begin{array}{l}-5.31(\text { elec }) \\
-2.18(\text { elec }) \\
3.13 \\
\mu_{\mathrm{h}}: 1.4 \times 10^{-8} \\
\mu_{\mathrm{e}}: 3.1 \times 10^{-6}\end{array}$ & $\begin{array}{l}T_{\mathrm{g}}: 165 \\
\mathrm{~T}_{\mathrm{d}}: 41\end{array}$ & $2020^{[32]}$ \\
\hline SPA-F & 309 (CHex) & 429 (CHex) & 2.90 (2-MeTHF) & $\begin{array}{l}-5.33(\mathrm{elec}) \\
-1.94(\mathrm{elec}) \\
3.29 \\
\mu_{\mathrm{h}}: 1 \times 10^{-5} \\
\mu_{\mathrm{e}:^{-}}\end{array}$ & $\begin{array}{l}\mathrm{T}_{\mathrm{g}}: 90 \\
\mathrm{~T}_{\mathrm{d}}: 286\end{array}$ & $2020^{[32]}$ \\
\hline Spiro-2CBP & $\begin{array}{l}299,308,339 \text { (Toluene) } \\
344\left(\mathrm{CHCl}_{3}\right)\end{array}$ & $\begin{array}{l}370 \text { (Toluene) } \\
367\left(\mathrm{CHCl}_{3}\right) \\
384,406(\text { Film })\end{array}$ & 2.64 (2-MeTHF) & $\begin{array}{l}-5.51(\text { elec }) \\
-2.00(\text { elec }) \\
3.36 \\
\mu_{\mathrm{h}}: 1.5 \times 10^{-4} \\
\mu_{\mathrm{e}}:-\end{array}$ & $\begin{array}{l}\mathrm{T}_{\mathrm{g}}: 174 \\
\mathrm{~T}_{\mathrm{d}}: 587\end{array}$ & $\begin{array}{l}2015^{[66]} \\
2007^{[155]} \\
2010^{[156]}\end{array}$ \\
\hline
\end{tabular}




\begin{tabular}{|c|c|c|c|c|c|c|}
\hline SPPO21 & - & - & $2.32(-)$ & $\begin{array}{l}-6.12(-) \\
-2.57(-) \\
\end{array}$ & & $2010^{[122]}$ \\
\hline TAPC & - & - & $2.87(-)$ & $\begin{array}{l}-5.5(-) \\
-2.0(-) \\
- \\
\mu_{\mathrm{e}:-}^{-} \\
\mu_{\mathrm{h}}: 10^{-2} \\
\end{array}$ & $\mathrm{~T}_{\mathrm{g}}: 78$ & $\begin{array}{l}2008^{[157]} \\
2002^{[158]} \\
1991^{[113]}\end{array}$ \\
\hline TBBI & $295,352\left(\mathrm{CHCl}_{3}\right)$ & $510\left(\mathrm{CHCl}_{3}\right)$ & $2.59(-)$ & $\begin{array}{l}-5.49 \text { (UPS) } \\
-2.41\left(\mathrm{E}_{\mathrm{g}}^{\mathrm{opt}}-\mathrm{HOMO}\right) \\
3.08 \\
\mu_{\mathrm{e}} / \mu_{\mathrm{h:}}-\end{array}$ & $\begin{array}{l}\mathrm{T}_{\mathrm{g}}: 148 \\
\mathrm{~T}_{\mathrm{d}}: 552\end{array}$ & $2008^{[70]}$ \\
\hline TBCPF & $298,333,347\left(\mathrm{CH}_{2} \mathrm{Cl}_{2}\right)$ & $\begin{array}{l}355,370\left(\mathrm{CH}_{2} \mathrm{Cl}_{2}\right) \\
357,374(\text { Film })\end{array}$ & 2.88 (2-MeTHF) & $\begin{array}{l}-5.5 \text { (elec) } \\
-2.1\left(\text { Eg }_{\mathrm{g} t} \text {-HOMO) }\right. \\
3.4 \\
\mu_{\mathrm{e}} / \mu_{\mathrm{h}:-}\end{array}$ & $\begin{array}{l}\mathrm{T}_{\mathrm{g}}: 212 \\
\mathrm{~T}_{\mathrm{c}}: 319 \\
\mathrm{~T}_{\mathrm{d}}: 540\end{array}$ & $2008^{[36]}$ \\
\hline TCTA & - & 403 (Film) & 2.6 & $\begin{array}{l}5.7 \text { (elec) } \\
2.4\left(\mathrm{E}_{\mathrm{g}}^{\mathrm{opt}}-\mathrm{HOMO}\right) \\
3.3 . \\
\mu_{\mathrm{h}}: 3 \times 10^{-4}\end{array}$ & $\mathrm{~T}_{\mathrm{g}}: 150$ & $\begin{array}{l}2014^{[139]} \\
2021^{[159]} \\
2007^{[118]}\end{array}$ \\
\hline 5(2'-tolyl)-[5]CMP & $257\left(\mathrm{CHCl}_{3}\right)$ & - & - & $\begin{array}{l}-5.95 \text { (DFT) } \\
-1.17 \text { (DFT) }\end{array}$ & $\mathrm{T}_{\mathrm{d}}: 476$ & $2016^{[123]}$ \\
\hline 6(2'-tolyl)-[6]CMP & $258\left(\mathrm{CHCl}_{3}\right)$ & - & - & $\begin{array}{l}-5.91 \text { (DFT) } \\
-1.14 \text { (DFT) } \\
\end{array}$ & $\mathrm{T}_{\mathrm{d}}: 509$ & $2016^{[123]}$ \\
\hline TPAFSO & 298,403 (Toluene) & $\begin{array}{l}438(\text { n-hexane }) \\
498(\mathrm{THF}) \\
553\left(\mathrm{CH}_{3} \mathrm{CN}\right) \\
524(\mathrm{Film})\end{array}$ & 2.1 (THF) & $\begin{array}{l}-5.24 \text { (elec) } \\
-2.61 \text { (elec) } \\
- \\
\mu_{\mathrm{h}}: 1.83 \times 10^{-6} \\
\mu_{\mathrm{e}}: 0.42 \times 10^{-6}\end{array}$ & $\begin{array}{l}\mathrm{T}_{\mathrm{g}}: 142 \\
\mathrm{~T}_{\mathrm{c}}: 215 \\
\mathrm{~T}_{\mathrm{m}}: 254 \\
\mathrm{~T}_{\mathrm{d}}: 481\end{array}$ & $2019^{[95]}$ \\
\hline TPBI & $304\left(\mathrm{CH}_{2} \mathrm{Cl}_{2}\right)$ & $\begin{array}{l}376\left(\mathrm{RT}, \mathrm{CH}_{2} \mathrm{Cl}_{2}\right) \\
368 \text { (RT, THF) } \\
375 \text { (Film) }\end{array}$ & 2.67 (2-MeTHF) & $\begin{array}{l}-6.02(\text { elec }) /-6.2(\mathrm{UPS}) \\
-2.10(\mathrm{elec}) /-2.7\left(\mathrm{E}_{\mathrm{g}}{ }^{\text {ppt }}\right. \\
\text { HOMO) } \\
3.5 \\
\mu_{\mathrm{e}}=6.53 \times 10^{-5} \\
\mu_{\mathrm{h}}:-\end{array}$ & $\begin{array}{l}\mathrm{T}_{\mathrm{g}}: 127 \\
\mathrm{~T}_{\mathrm{d}}: 430\end{array}$ & $\begin{array}{l}2009^{[38]} \\
1999^{[40]} \\
2005^{[160]} \\
2011^{[161]} \\
2014^{[162]} \\
2000^{[163]} \\
2017^{7^{[41]}}\end{array}$ \\
\hline TPCPZ & $223,252,289,335$ (Hexane) & 405 (Hexane) & 2.63 (2-MeTHF) & $\begin{array}{l}-5.39 \text { (elec) } \\
-2.16\left(\mathrm{E}_{\mathrm{g}}^{\mathrm{opt}}-\mathrm{HOMO}\right) \\
3.23\end{array}$ & $\begin{array}{l}\mathrm{T}_{\mathrm{g}}: 165 \\
\mathrm{~T}_{\mathrm{d}}: 559\end{array}$ & $2014^{[64]}$ \\
\hline 5(2'-xylyl)-[5]CMP & $256\left(\mathrm{CHCl}_{3}\right)$ & - & - & $\begin{array}{l}-6.0 \text { (DFT) } \\
-1.23 \text { (DFT) }\end{array}$ & $\mathrm{T}_{\mathrm{d}}: 463$ & $2016^{[123]}$ \\
\hline 6(2'-xylyl)-[6]CMP & $255\left(\mathrm{CHCl}_{3}\right)$ & - & - & $\begin{array}{l}-5.96 \text { (DFT) } \\
-1.21 \text { (DFT) }\end{array}$ & $\mathrm{T}_{\mathrm{d}}: 518$ & $2016^{[123]}$ \\
\hline
\end{tabular}




\section{Acknowledgments}

The authors would like to highly thank all their co-workers, which have allowed over the years the development of SL-PhOLEDs in the group. Fabien Lucas, Clément Brouillac and Dr Cassandre Quinton (Rennes) are particularly thanked. We also would like to thank Dr J. F. Bergamini for the conception for the schematic representation of the PhOLEDs within this manuscript. We also thank the ANR (19-CE05-0024) for financial support, the Région Bretagne (DIADEM project) and the ADEME for PhD grants.

\section{REFERENCES}

[1]Z.-Q. Jiang, C. Poriel, N. Leclerc, Mater. Chem. Front. 2020, 4, 2497-2498.

[2]M. A. Baldo, D. F. O'Brien, Y. You, A. Shoustikov, S. Sibley, M. E. Thompson, S. R. Forrest, Nature 1998, 395, 151-154.

[3]Y. Tao, C. Yang, J. Qin, Chem. Soc. Rev. 2011, 40, 2943-2970.

[4]Y. Im, S. Y. Byun, J. H. Kim, D. R. Lee, C. S. Oh, K. S. Yook, J. Y. Lee, Adv. Funct. Mater. 2017, 27, 1603007.

[5]J.-H. Lee, C.-H. Chen, P.-H. Lee, H.-Y. Lin, M.-k. Leung, T.-L. Chiu, C.-F. Lin, J. Mater. Chem. C 2019, 7, 5874-5888.

[6]K. S. Yook, J. Y. Lee, Chem. Rec. 2016, 16, 159-172.

[7]C. Poriel, J. Rault-Berthelot, J. Mater. Chem. C 2017, 5, 3869-3897

[8]L. Xiao, Z. Chen, B. Qu, J. Luo, S. Kong, Q. Gong, J. Kido, Adv. Mater. 2011, 23, 926-952.

[9]Y. Wang, J. H. Yun, L. Wang, J. Y. Lee, Adv. Funct. Mater. 2020, n/a, 2008332.

[10]C. C. Peng, S. Y. Yang, H. C. Li, G. H. Xie, L. S. Cui, S. N. Zou, C. Poriel, Z. Q. Jiang, L. S. Liao, Adv. Mater. 2020, 32, 2003885.

[11]L. J. Sicard, H.-C. Li, Q. Wang, X.-Y. Liu, O. Jeannin, J. Rault-Berthelot, L.-S. Liao, Z.-Q. Jiang, C. Poriel, Angew. Chem. Int. Ed. 2019, 58, 3848-3853.

[12]A. Maheshwaran, V. G. Sree, H.-Y. Park, H. Kim, S. H. Han, J. Y. Lee, S.-H. Jin, Adv. Funct. Mater. 2018, 28, 1802945.

[13]W. Li, J. Li, D. Liu, Q. Jin, ACS Appl. Mater. Interfaces. 2016, 8, 22382-22391.

[14]J.-J. Huang, Y.-H. Hung, P.-L. Ting, Y.-N. Tsai, H.-J. Gao, T.-L. Chiu, J.-H. Lee, C.-L. Chen, P.-T. Chou, M.-k. Leung, Org. Lett. 2016, 18, 672-675.

[15]L. Ding, S.-C. Dong, Z.-Q. Jiang, H. Chen, L. S. Liao, Adv. Funct. Mater. 2015, 25, 645-650.

[16]L.-S. Cui, Y.-M. Xie, Y.-K. Wang, C. Zhong, Y.-L. Deng, X.-Y. Liu, Z.-Q. Jiang, L.-S. Liao, Adv. Mater. 2015, 27, 4213-4217.

[17]K. Udagawa, H. Sasabe, C. Cai, J. Kido, Adv. Mater. 2014, 26, 5062-5066.

[18]C. W. Lee, J. Y. Lee, Adv. Mater. 2013, 25, 5450-5454.

[19]X. Tang, X.-Y. Liu, Y. Yuan, Y.-J. Wang, H.-C. Li, Z.-Q. Jiang, L.-S. Liao, ACS Appl. Mater. Interfaces 2018, 10, 29840-29847.

[20]M. Kim, J. Y. Lee, ACS Appl. Mater. Interfaces 2014, 6, 14874-14880.

[21]X. Li, J. Zhang, Z. Zhao, L. Wang, H. Yang, Q. Chang, N. Jiang, Z. Liu, Z. Bian, W. Liu, Z. Lu, C. Huang, Adv. Mater. 2018, 30, 1705005.

[22]Z. Liu, M. G. Helander, Z. Wang, Z. Lu, Org. Electron. 2009, 10, 1146-1151.

[23]K. S. Yook, J. Y. Lee, Adv. Mater. 2012, 24, 3169-3190.

[24]C. Poriel, J. Rault - Berthelot, Adv. Funct. Mat. 2020, 30, 1910040.

[25]H. Sasabe, J. Kido, Eur. J. Org. Chem. 2013, 1653-1663.

[26]K. S. Yook, J. Y. Lee, Adv. Mater. 2014, 26, 4218-4233.

[27]J. P. J. Markham, S.-C. Lo, S. W. Magennis, P. L. Burn, I. D. W. Samuel, App. Phys. Lett. 2002, 80, 2645-2647.

[28]T.-C. Li, R.-C. Chang, Int. J. of Precis. Eng. and Manuf.-Green Tech. 2014, 1, 329-334. 
[29]Q. Zhang, B. Li, S. Huang, H. Nomura, H. Tanaka, C. Adachi, Nat. Photonics 2014, 8, 326-332. [30]J. Lee, H.-F. Chen, T. Batagoda, C. Coburn, P. I. Djurovich, M. E. Thompson, S. R. Forrest, Nat. Mater. 2016, 15, 92-98.

[31]E. Baranoff, B. F. E. Curchod, Dalton Trans. 2015, 44, 8318-8329.

[32]F. Lucas, C. Quinton, S. Fall, T. Heiser, D. Tondelier, B. Geffroy, N. Leclerc, J. Rault-Berthelot, C. Poriel, J. Mater. Chem. C 2020, 8, 16354-16367.

[33]C. Jeong, C. Coburn, M. Idris, Y. Li, P. I. Djurovich, M. E. Thompson, S. R. Forrest, Org. Electron. 2019, 64, 15-21.

[34]M. Penconi, M. Cazzaniga, W. Panzeri, A. Mele, F. Cargnoni, D. Ceresoli, A. Bossi, Chem. Mater. 2019, 31, 2277-2285.

[35]R. J. Holmes, B. W. D’Andrade, S. R. Forrest, X. Ren, J. Li, M. E. Thompson, App. Phys. Lett. 2003, 83, 3818-3820.

[36]L. Hou, L. Duan, J. Qiao, W. Li, D. Zhang, Y. Qiu, App. Phys. Lett. 2008, 92, 263301.

[37]Q. Wang, F. Lucas, C. Quinton, Y.-K. Qu, J. Rault-Berthelot, O. Jeannin, S.-Y. Yang, F.-C. Kong, S. Kumar, L.-S. Liao, C. Poriel, Z.-Q. Jiang, Chem. Sci. 2020, 11, 4887-4894.

[38]S.-y. Takizawa, V. A. Montes, P. Anzenbacher, Chem. Mater. 2009, 21, 2452-2458.

[39]J. Meyer, S. Hamwi, T. Bülow, H.-H. Johannes, T. Riedl, W. Kowalsky, App. Phys. Lett. 2007, 91, 113506.

[40]Z. Q. Gao, C. S. Lee, I. Bello, S. T. Lee, S. K. Wu, Z. L. Yan, X. H. Zhang, Synth. Met. 1999, 105, 141-144.

[41]L. Liu, S. Li, Y. M. Zhou, L. Y. Liu, X. A. Cao, Microelectronics Reliability 2017, 71, 106-110.

[42]J.-D. Peltier, B. Heinrich, B. Donnio, O. Jeannin, J. Rault-Berthelot, C. Poriel, Chem. Eur. J. 2017, 23, 17290-17303.

[43]L. Sicard, C. Quinton, J.-D. Peltier, D. Tondelier, B. Geffroy, U. Biapo, R. Métivier, O. Jeannin, J. Rault-Berthelot, C. Poriel, Chem. Eur. J. 2017, 23, 7719-7723.

[44]C. Poriel, L. Sicard, J. Rault-Berthelot, Chem. Comm. 2019, 55, 14238-14254.

[45]H.-H. Chang, W.-S. Tsai, C.-P. Chang, N.-P. Chen, K.-T. Wong, W.-Y. Hung, S.-W. Chen, Org. Electron. 2011, 12, 2025-2032.

[46]F.-M. Hsu, C.-H. Chien, C.-F. Shu, C.-H. Lai, C.-C. Hsieh, K.-W. Wang, P.-T. Chou, Adv. Funct. Mater. 2009, 19, 2834-2843.

[47]Y. Yin, X. Wen, J. Yu, L. Zhang, W. Xie, IEEE Photon. Technol. Lett. 2013, 25, 1041-1135.

[48]F.-M. Hsu, L.-J. Chien, K.-T. Chen, Y.-Z. Li, S.-W. Liu, Org. Electron. 2014, 15, 3327-3332.

[49]Y.-T. Lee, Y.-T. Chang, M.-T. Lee, P.-H. Chiang, C.-T. Chen, C.-T. Chen, J. Mater. Chem. C 2014, 2, 382-391.

[50]C. Zang, X. Peng, H. Wang, Z. Yu, L. Zhang, W. Xie, H. Zhao, Org. Electron. 2017, 50, 106114.

[51]P. Wang, S. Fan, J. Liang, L. Ying, J. You, S. Wang, X. Li, Dyes Pigm. 2017, 142, 175-182.

[52]F. Lucas, O. A. Ibraikulov, C. Quinton, L. Sicard, T. Heiser, D. Tondelier, B. Geffroy, N. Leclerc, J. Rault-Berthelot, C. Poriel, Adv. Opt. Mater. 2020, 8, 1901225.

[53]M. Romain, D. Tondelier, O. Jeannin, B. Geffroy, J. Rault-Berthelot, C. Poriel, J. Mater. Chem. C 2015, 3, 97010-97014.

[54]M. Romain, D. Tondelier, B. Geffroy, O. Jeannin, E. Jacques, J. Rault-Berthelot, C. Poriel, Chem. Eur. J. 2015, 21, 9426-9439,.

[55]S. E. Jang, C. W. Joo, J. Y. Lee, Thin Solid Films 2010, 906-910.

[56]S. E. Jang, K. S. Yook, J. Y. Lee, Org. Electron. 2010, 11, 1154-1157.

[57]T. P. I. Saragi, T. Spehr, A. Siebert, T. Fuhrmann-Lieker, J. Salbeck, Chem. Rev. 2007, 107, 1011-1065.

[58]C. Wu, B. Wang, Y. Wang, J. Hu, J. Jiang, D. Ma, Q. Wang, J. Mater. Chem. C 2019, 7, 558566. 
[59]K. Gao, K. Liu, X.-L. Li, X. Cai, D. Chen, Z. Xu, Z. He, B. Li, Z. Qiao, D. Chen, Y. Cao, S.-J. Su, J. Mater. Chem. C 2017, 5, 10406-10416.

[60]H.-H. Chou, C.-H. Cheng, Adv. Mater. 2010, 22, 2468-2471.

[61]C. Fan, Y. Li, C. Yang, H. Wu, J. Qin, Y. Cao, Chem. Mater. 2012, 24, 4581-4587.

[62]J.-H. Seo, N.-S. Han, H.-S. Shim, J.-H. Kwon, J.-K. Song, Bull. Korean Chem. Soc. 2011, 32, 1415-1418.

[63]W.-Y. Hung, T.-C. Wang, H.-C. Chiu, H.-F. Chen, K.-T. Wong, Phys. Chem. Chem. Phys. 2010, 12, 10685-10687.

[64]B. Huang, W. Jiang, J. Tang, X. Ban, R. Zhu, H. Xu, W. Yang, Y. Sun, Dyes Pigm. 2014, 101, 9-14.

[65]C.-H. Chen, W.-S. Huang, M.-Y. Lai, W.-C. Tsao, J. T. Lin, Y.-H. Wu, T.-H. Ke, L.-Y. Chen, C.-C. Wu, Adv. Funct. Mater. 2009, 19, 2661-2670.

[66]S. Thiery, D. Tondelier, B. Geffroy, E. Jacques, M. Robin, R. Métivier, O. Jeannin, J. RaultBerthelot, C. Poriel, Org. Lett. 2015, 17, 4682-4685.

[67]Z. Wu, Z. Yang, K. Xue, C. Fei, F. Wang, M. Yan, H. Zhang, D. Ma, W. Huang, RSC Adv. 2018, 8, 11255-11261.

[68]X. Qiao, Y. Tao, Q. Wang, D. Ma, C. Yang, L. Wang, J. Qin, F. Wang, J. Appl. Phys. 2010, $108,034508$.

[69]H. Y. Li, L. Chen, J. Qiao, L. Duan, D. Zhang, G. Dong, L. Wang, Y. Qiu, Sci. China Chem. 2012, 55, 2428-2432.

[70]Z. Ge, T. Hayakawa, S. Ando, M. Ueda, T. Akiike, H. Myamoto, T. Kajita, M.-a. Kakimoto, Chem. Mater. 2008, 20, 2532-2537.

[71]C. Quinton, S. Thiery, O. Jeannin, D. Tondelier, B. Geffroy, E. Jacques, J. Rault-Berthelot, C. Poriel, ACS Appl. Mater. Interfaces. 2017, 9, 6194-6206.

[72]C. Poriel, J. Rault - Berthelot, Acc. Chem. Res. 2018, 51, 1818-1830.

[73]A. Yoshii, Y. Onaka, K. Ikemoto, T. Izumi, S. Sato, H. Kita, H. Taka, H. Isobe, Chem. Asian J. 2020, 15, 2181-2186.

[74]L.-H. Xie, J. Liang, J. Song, C.-R. Yin, W. Huang, Curr. Org. Chem. 2010, 14, 2169-2195.

[75]S. Thiery, D. Tondelier, B. Geffroy, O. Jeannin, J. Rault-Berthelot, C. Poriel, Chem. Eur. J. 2016, 22, 10136-10149.

[76]X. Tang, L.-S. Cui, H.-C. Li, A. J. Gillett, F. Auras, Y.-K. Qu, C. Zhong, S. T. E. Jones, Z.-Q. Jiang, R. H. Friend, L.-S. Liao, Nat. Mater. 2020, 19, 1232-1238.

[77]J. Jalkh, S. Thiery, J.-F. Bergamini, P. Hapiot, C. Poriel, Y. R. Leroux, J. Phys. Chem. C 2017, $121,14228-14237$.

[78]S. Thiery, C. Declairieux, D. Tondelier, G. Seo, B. Geffroy, O. Jeannin, R. Métivier, J. RaultBerthelot, C. Poriel, Tetrahedron 2014, 70, 6337-6351.

[79]F. Barrière, C. Poriel, J. Rault-Berthelot, Electrochim. Acta 2013, 110, 735-740.

[80]N. Lin, J. Qiao, L. Duan, L. Wang, Y. Qiu, J. Phys. Chem. C 2014, 118, 7569-7578.

[81]N. Lin, J. Qiao, L. Duan, H. Li, L. Wang, Y. Qiu, J. Phys. Chem. C 2012, 116, 19451-19457.

[82]D. Y. Kondakov, W. C. Lenhart, W. F. Nichols, J. Appl. Phys. 2007, 101, 024512.

[83]S. Scholz, D. Kondakov, B. Lüssem, K. Leo, Chem. Rev 2015, 115, 8449-8503.

[84]W.-Y. Hung, T.-C. Tsai, S.-Y. Ku, L.-C. Chi, K.-T. Wong, Phys. Chem. Chem. Phys. 2008, 10, 5822-5825.

[85]S. Thiery, B. Heinrich, B. Donnio, C. Poriel, F. Camerel, J. Phys. Chem. C 2015, 119, 1056410575.

[86]S. Thiery, D. Tondelier, C. Declairieux, B. Geffroy, O. Jeannin, R. Métivier, J. Rault-Berthelot, C. Poriel, J. Phys. Chem. C 2015, 119, 5790-5805.

[87]L. Sicard, C. Quinton, F. Lucas, O. Jeannin, J. Rault-Berthelot, C. Poriel, J. Phys. Chem. C 2019, 123, 19094-19104. 
[88]C. Poriel, J. Rault-Berthelot, S. Thiery, C. Quinton, O. Jeannin, U. Biapo, B. Geffroy, D. Tondelier, Chem. Eur. J. 2016, 22, 17930-17935.

[89]S. Bebiche, P. Cisneros-Perez, T. Mohammed-Brahim, M. Harnois, J. Rault - Berthelot, C. Poriel, E. Jacques, Mater. Chem. Front. 2018, 2, 1631-1641.

[90]J.-D. Peltier, B. Heinrich, B. Donnio, E. Jacques, J. Rault-Berthelot, C. Poriel, ACS Appl. Mater. Interfaces 2017, 9, 8219-8232.

[91]M. Romain, M. Chevrier, S. Bebiche, T. Mohammed-Brahim, J. Rault-Berthelot, E. Jacques, C. Poriel, J. Mater. Chem. C 2015, 3, 5742-5753.

[92]J.-D. Peltier, B. Heinrich, B. Donnio, O. Jeannin, J. Rault-Berthelot, E. Jacques, C. Poriel, J. Mater. Chem. C 2018, 6, 13197-13210.

[93]D. Tomkute-Luksiene, J. Keruckas, T. Malinauskas, J. Simokaitiene, V. Getautis, J. V. Grazulevicius, D. Volyniuk, V. Cherpak, P. Stakhira, V. Yashchuk, V. Kosach, G. Luka, J. Sidaravicius, Dyes Pigm. 2013, 96, 278-286.

[94]J. Ye, Z. Chen, K. Wang, F. An, Y. Yuan, W. Chen, Q. Yang, X. Zhang, C.-S. Lee, Chem. Eur. J. 2014, 20, 13762-13769.

[95]Q. Jiang, Y. Xu, T. Yu, X. Qiu, R. Zhao, D. Zhao, N. Zheng, D. Hu, Z. Xie, Y. Ma, New. J. Chem. 2019, 43, 6721-6727.

[96]D. Thirion, J. Rault-Berthelot, L. Vignau, C. Poriel, Org. Lett. 2011, 13, 4418-4421.

[97]M.-Y. Lai, C.-H. Chen, W.-S. Huang, J. T. Lin, T.-H. Ke, L.-Y. Chen, M.-H. Tsai, C.-C. Wu, Angew. Chem. Int. Ed. 2008, 47, 581-585.

[98]L. Zuo, G. Han, R. Sheng, K. Xue, Y. Duan, P. Chen, Y. Zhao, RSC Adv. 2016, 6, 55017-55021.

[99]Y. Yin, X. Piao, Y. Wang, J. Liu, K. Xu, W. Xie, App. Phys. Lett. 2012, 101, 063306.

[100]Y.-L. Zhang, Q. Ran, Q. Wang, J. Fan, L.-S. Liao, J. Mater. Chem. C 2019, 7, 7267-7272.

[101]D. Xia, C. Duan, S. Liu, D. Ding, M. Baumgarten, M. Wagner, D. Schollmeyer, H. Xu, K. Müllen, New J. Chem. 2019, 43, 3788-3792.

[102]Y.-K. Wang, Q. Sun, S.-F. Wu, Y. Yuan, Q. Li, Z.-Q. Jiang, M.-K. Fung, L.-S. Liao, Adv. Funct. Mat. 2016, 26, 7929-7936.

[103]P. Tourneur, F. Lucas, C. Quinton, Y. Olivier, R. Lazzaroni, P. Viville, J. Cornil, C. Poriel, J. Mater. Chem. C 2020, 8, 14462-14468.

[104]H.-T. Mao, G.-F. Li, G.-G. Shan, X.-L. Wang, Z.-M. Su, Coord. Chem. Rev. 2020, 413, 213283.

[105]S.-C. Lo, R. E. Harding, C. P. Shipley, S. G. Stevenson, P. L. Burn, I. D. W. Samuel, J. Am. Chem. Soc. 2009, 131, 16681-16688.

[106]Y. Wang, Y. Lu, B. Gao, S. Wang, J. Ding, L. Wang, X. Jing, F. Wang, ACS Appl. Mater. Interfaces 2016, 8, 29600-29607.

[107]J. Ding, J. Gao, Y. Cheng, Z. Xie, L. Wang, D. Ma, X. Jing, F. Wang, Adv. Funct. Mater. 2006, 16, 575-581.

[108]L. Chen, J. Ding, Y. Cheng, Z. Xie, L. Wang, X. Jing, F. Wang, Chem. Asian J. 2011, 6, 13721380.

[109]W. Tian, C. Yi, B. Song, Q. Qi, W. Jiang, Y. Zheng, Z. Qi, Y. Sun, J. Mater. Chem. C 2014, 2, 1104-1115.

[110]W. Tian, Q. Qi, B. Song, C. Yi, W. Jiang, X. Cui, W. Shen, B. Huang, Y. Sun, J. Mater. Chem. C 2015, 3, 981-984.

[111]W. Jiang, L. Duan, J. Qiao, D. Zhang, G. Dong, L. Wang, Y. Qiu, J. Mater. Chem. 2010, 20, 6131-6137.

[112]S. E. Jang, J. Y. Lee, J. Lumin. 2011, 131, 2788-2791.

[113]P. M. Borsenberger, L. Pautmeier, R. Richert, H. Bässler, J. Chem. Phys. 1991, 94, 8276-8281.

[114]Y.-T. Chang, S.-W. Liu, C.-H. Yuan, Y.-H. Ho, K.-Y. Chen, Y.-T. Lee, M.-F. Wu, C.-C. Lee, P.-K. Wei, C.-T. Chen, C.-I. Wu, J. Appl. Phys. 2013, 114, 173106.

[115]T. Tsuboi, S.-W. Liu, M.-F. Wu, C.-T. Chen, Org. Electron. 2009, 10, 1372-1377. 
[116]T. D. Anthopoulos, J. P. J. Markham, E. B. Namdas, I. D. W. Samuel, S.-C. Lo, P. L. Burn, App. Phys. Lett. 2003, 82, 4824-4826.

[117]N. C. Erickson, R. J. Holmes, App. Phys. Lett. 2010, 97, 083308.

[118]J.-W. Kang, S.-H. Lee, H.-D. Park, W.-I. Jeong, K.-M. Yoo, Y.-S. Park, J.-J. Kim, App. Phys. Lett. 2007, 90, 223508.

[119]S. Naka, H. Okada, H. Onnagawa, T. Tsutsui, App. Phys. Lett. 2000, 76, 197-199.

[120]W. S. Jeon, T. J. Park, K. H. Kim, R. Pode, J. Jang, J. H. Kwon, Org. Electron. 2010, 11, 179183.

[121]L. Hou, L. Duan, J. Qiao, D. Zhang, G. Dong, L. Wang, Y. Qiu, Org. Electron. 2010, 11, 13441350.

[122]C. W. Joo, S. O. Jeon, K. S. Yook, J. Y. Lee, Org. Electron. 2010, 11, 36-40.

[123]K. Ikemoto, A. Yoshii, T. Izumi, H. Taka, H. Kita, J. Y. Xue, R. Kobayashi, S. Sato, H. Isobe, J. Org. Chem. 2016, 81, 662-666.

[124]Z. M. Hudson, Z. Wang, M. G. Helander, Z.-H. Liu, S. Wang, Adv. Mater. 2012, 24, $2922-$ 2928.

[125]Y. Liu, L.-S. Cui, M.-F. Xu, X.-B. Shi, D.-Y. Zhou, Z.-K. Wan, Z.-Q. Jiang, L.-S. Liao, J. Mater. Chem. C 2014, 2, 2488-2495

[126]J. Y. Xue, T. Izumi, A. Yoshii, K. Ikemoto, T. Koretsune, R. Akashi, R. Arita, H. Taka, H. Kita, S. Sato, H. Isobe, Chem. Sci. 2016, 7, 896-904.

[127]A. Yoshii, K. Ikemoto, T. Izumi, H. Taka, H. Kita, S. Sato, H. Isobe, Org. Lett. 2019, 21, 27592762.

[128]Kenry, C. Chen, B. Liu, Nat. Comm. 2019, 10, 2111.

[129]G. Zhan, Z. Liu, Z. Bian, C. Huang, Front. Chem. 2019, 7, 305-305.

[130]Q. Peng, H. Ma, Z. Shuai, Acc. Chem. Res. 2020.

[131]J. Wang, J. Liang, Y. Xu, B. Liang, J. Wei, C. Li, X. Mu, K. Ye, Y. Wang, J. Phys. Chem. Lett. 2019, 10, 5983-5988.

[132]D. Chaudhuri, E. Sigmund, A. Meyer, L. Röck, P. Klemm, S. Lautenschlager, A. Schmid, S. R. Yost, T. Van Voorhis, S. Bange, S. Höger, J. M. Lupton, Angew. Chem. Int. Ed. 2013, 52, 13449-13452.

[133]H. Yuji, S. Takeshi, F. Masayuki, F. Takanon, N. Yoshitaka, S. Kenichi, Chem. Lett. 1993, 22, 905-906.

[134]Y. Hamada, T. Sano, K. Shibata, K. Kuroki, Jpn J. Appl. Phys. 1995, 34, L824.

[135]W. S. Jeon, T. J. Park, J. H. Kwon, J. Inf. Disp. 2009, 10, 87-91.

[136]M.-H. Tsai, Y.-H. Hong, C.-H. Chang, H.-C. Su, C.-C. Wu, A. Matoliukstyte, J. Simokaitiene, S. Grigalevicius, J. V. Grazulevicius, C.-P. Hsu, Adv. Mater. 2007, 19, 862-866.

[137]I. G. Hill, A. Kahn, J. Appl. Phys. 1999, 86, 4515-4519.

[138]S. Gong, X. He, Y. Chen, Z. Jiang, C. Zhong, D. Ma, J. Qin, C. Yang, J. Mater. Chem. 2012, 22, 2894-2899.

[139]B. S. Kim, J. Y. Lee, Adv. Funct. Mater. 2014, 24, 3970-3977.

[140]V. Adamovich, J. Brooks, A. Tamayo, A. M. Alexander, P. I. Djurovich, B. W. D'Andrade, C. Adachi, S. R. Forrest, M. E. Thompson, New. J. Chem. 2002, 26, 1171-1178.

[141]Z. Ge, T. Hayakawa, S. Ando, M. Ueda, T. Akiike, H. Miyamoto, T. Kajita, M.-a. Kakimoto, Chem. Mater. 2008, 20, 2532-2537.

[142]Y. Shirota, K. Okumoto, Proceeding Vol. 4105, Organic Light-Emitting Diodes and devices IV-International Symposium on Optical Science and Technology 2001.

[143]S. A. V. Slyke, C. H. Chen, C. W. Tang, App. Phys. Lett. 1996, 69, 2160-2162.

[144]D. H. Huh, G. W. Kim, G. H. Kim, C. Kulshreshtha, J. H. Kwon, Synth. Met. 2013, 180, 79-84. [145]W. Q. Tao Youtian, Yang Chuluo, Wang Qi, Zhang Zhiqiang, Zou Taotao, Qin Jingui, Ma Dongge, Angew. Chem. Int. Ed. 2008, 47, 8104-8107. 
[146]Y. Hamada, C. Adachi, T. Tsutsui, S. Saito, Optoelectronics-Dev. and technol. 1992, 7, 83-93.

[147]C. Wang, G.-Y. Jung, A. S. Batsanov, M. R. Bryce, M. C. Petty, J. Mater. Chem. 2002, 12, 173-180.

[148]J. Lee, N. Chopra, S.-H. Eom, Y. Zheng, J. Xue, F. So, J. Shi, App. Phys. Lett. 2008, 93, 123306-123306.

[149]D. O’Brien, A. Bleyer, D. G. Lidzey, D. D. C. Bradley, T. Tsutsui, J. Appl. Phys. 1997, 82, 2662-2670.

[150]F.-M. Hsu, C.-H. Chien, C. F. Shu, C. H. Lai, C. C. Hsieh, K. W. Wang, P.-T. Chou, Adv. Funct. Mater. 2009, 19, 2834-2843.

[151]Y. Yin, X. Wen, J. Yu, L. Zhang, W. Xie, IEEE Photon. Technol. Lett. 2013, 25, 2205-2208.

[152]Y. Yin, X. Piao, Y. Li, Y. Wang, J. Liu, K. Xu, W. Xie, Appl. Phys. Lett. 2012, 101, 063306.

[153]F.-M. Hsu, L.-J. Chien, K.-T. Chen, Y.-Z. Li, S.-W. Liu, Org. Electron. 2014, 15, 3327-3332.

[154]S. E. Jang, C. W. Joo, S. O. Jeon, K. S. Yook, J. Y. Lee, Org. Electron. 2010, 11, 1059-1065.

[155]H. Nakanotani, S. Akiyama, D. Ohnishi, M. Moriwake, M. Yahiro, T. Yoshihara, S. Tobita, C. Adachi, Adv. Funct. Mat. 2007, 17, 2328-2335.

[156]O. Usluer, S. Demic, D. A. Egbe, E. Birckner, C. Tozlu, A. Pivrikas, A. M. Ramil, N. S. Saricifci, Adv. Funct. Mat. 2010, 20, 4152-4161.

[157]Y. Zheng, S.-H. Eom, N. Chopra, J. Lee, F. So, J. Xue, App. Phys. Lett. 2008, 92, 223301.

[158]P. Strohriegl, J. V. Grazulevicius, Adv. Mater. 2002, 14, 1439-1452.

[159]H.-T. Cao, J. Wan, B. Li, H. Zhang, L.-H. Xie, C. Sun, Q.-Y. Feng, W.-J. Yu, W. Huang, Dyes Pigm. 2021, 185, 108894.

[160]J. Y. Shen, C. Y. Lee, T.-H. Huang, J. T. Lin, Y.-T. Tao, C.-H. Chen, C. Tsai, J. Mater. Chem. 2005, 15, 2455-2463.

[161]Z. Wang, P. Lu, S. Chen, Z. Gao, F. Shen, W. Zhang, Y. Xu, H. S. Kwok, Y. Ma, J. Mater. Chem. 2011, 21, 5451-5456.

[162]S. H. Rhee, K. b. Nam, C. S. Kim, M. Song, W. Cho, S. H. Jin, S. Y. Ryu, ECS Solid State Letters 2014, 3, R19-R22.

[163]Y. T. Tao, E. Balasubramaniam, A. Danel, P. Tomasik, App. Phys. Lett. 2000, 77, 933-935. 